\title{
SCALE MODEL SHAKE TABLE TESTING OF SEISMIC EARTH PRESSURES
} IN SOFT CLAY

\author{
A Thesis \\ Presented to the Faculty of \\ California Polytechnic State University \\ San Luis Obispo
}

In Partial Satisfaction
of the Requirements for the Degree of
Master of Science in Civil and Environmental Engineering

By

Ron Edward Noche

December 2013 
(C) 2013

Ron Edward Noche

ALL RIGHTS RESERVED 
TITLE:

AUTHOR:

DATE SUBMITTED:

COMMITTEE CHAIR:

COMMITTEE MEMBER:

COMMITTEE MEMBER:
Scale Model Shake Table Testing of Seismic Earth Pressures in Soft Clay

Ron Edward Noche

December 2013

Robb Moss, PhD, PE.

Associate Professor of Civil Engineering

Gregg Fiegel, PhD, PE, GE.

Professor of Civil Engineering

Bing Qu. PhD

Assistant Professor of Civil Engineering 


\section{ABSTRACT}

Scale Model Shake Table Testing of Seismic Earth Pressures in Soft Clay

By Ron Edward Noche

This research consists of scale model shake table tests to investigate the development of seismic earth pressures in soft clay. The soft clay was modeled after prototype San Francisco Bay Mud consisting of a mixture of kaolinite, bentonite, class $\mathrm{C}$ fly ash and water. A flexible walled testing container founded on a $1 \mathrm{~g}$ shake table was used to house the model soil and mimic 1D site response. An array of accelerometers embedded in the model soil measure during an input earthquake motion.

A scale model wall is equipped with pressure sensors to measure the seismic earth pressures over the duration of an input earthquake motion. A total of 14 time histories were run through this test set up. A single degree of freedom oscillator was added to the scale model wall and used to mimic the period of a structure. Test results show that for retaining walls with clay soils seismic earth pressures develop triangularly over the face of the wall with an amplitude of about 3.8 times the static pressures. For small building structures, the development of seismic earth pressures depends on height above the base of the wall. Although the pressure distribution is not well defined, localized peaks in pressure are observed at depths of $1 / 3 \mathrm{H}$ and $2 / 3 \mathrm{H}$ below the ground surface.

Arias intensity and cumulative absolute velocity correlate linearly with the measured dynamic pressures. Differences between arias intensity and 
cumulative absolute velocity for each scale model configuration are not pronounced.

The simplified Monnobe-Okabe method was also evaluated in this study. Although the Mononobe-Okabe method may be inappropriate for cohesive soils, a seismic coefficient of about $1 / 10$ the PGA was back-calculated from empirically measured earth pressures.

The results of this investigation provides an empirical basis to the behavior of walls in clay. 


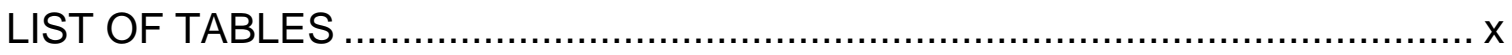

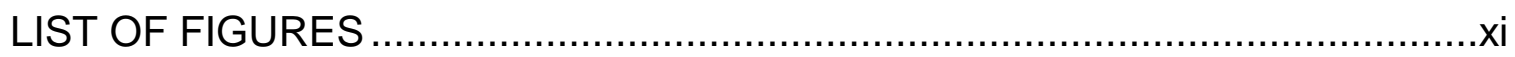

Chapter 1 - Statement of Research ......................................................... 1

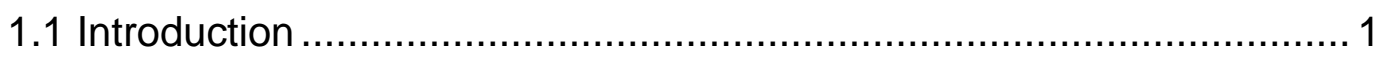

1.2 Seismic Earth Pressures.......................................................... 2

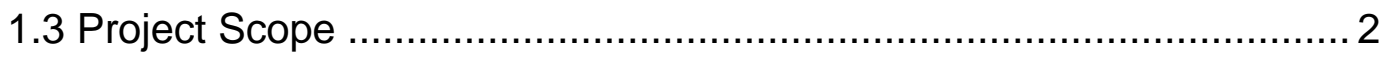

1.4 Organization of the Thesis ........................................................... 3

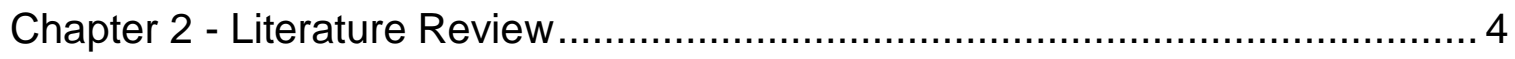

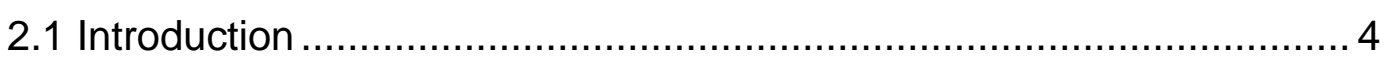

2.2 Wall Failure Case Histories in Past Earthquakes............................... 4

2.3 Building Code Provisions for Seismic Earth Pressures....................... 5

2.4 Analytical Methods for Evaluation of Seismic Earth Pressures ............ 6

2.4.1 Mononobe-Okabe Methods..................................................... 6

2.4.2 Displacement Methods....................................................... 11

2.4.3 Analytical Method for Non-yeilding Walls ............................... 14

2.5 Shake Table and Centrifuge Investigations .................................... 15

Chapter 3 - Development of Scale Model .................................................... 20

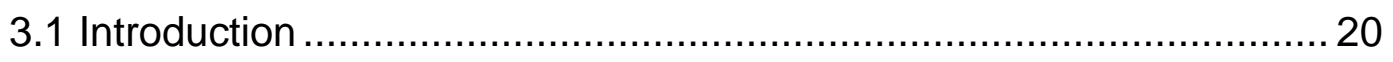

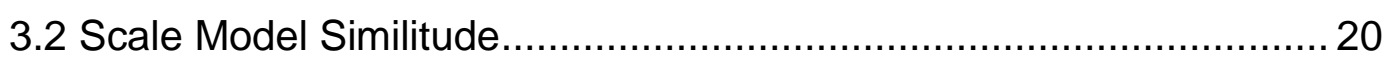

3.2.1 Similitude Criteria ............................................................ 24

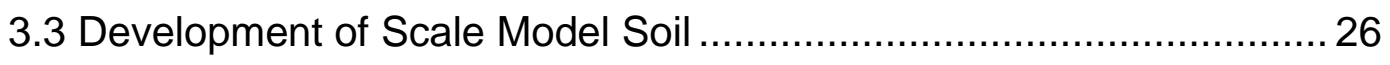

3.3.1 Design and Testing of Scale Model Soil................................. 29 
3.3.2 Final Scale Model Soil Recipe............................................... 31

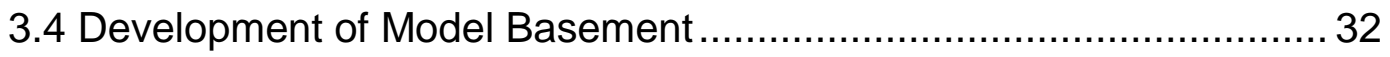

3.4.1 Materials and Configuration of Model Basement..................... 33

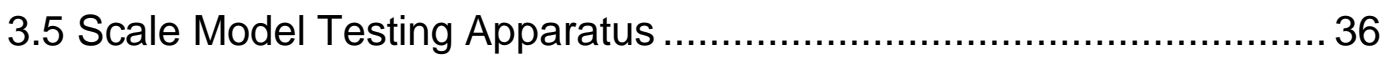

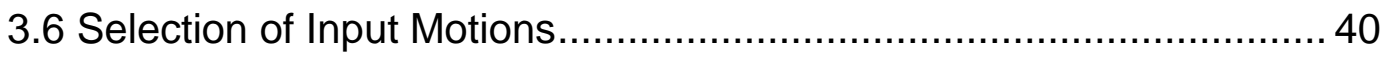

Chapter 4 - Pressure Sensor Testing and Investigation .................................. 45

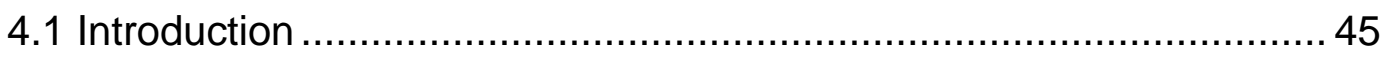

4.2 Sensor Products Inc. - Tactilus Free Form Pressure Sensors ........... 45

4.2.1 Development of Intermediary Circuit ..................................... 46

4.2.2 Development of Calibration Curve ....................................... 48

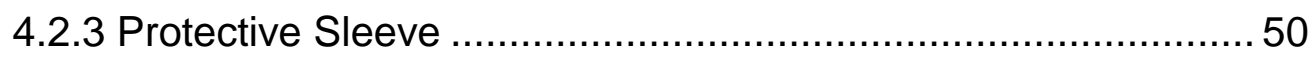

4.2.4 Pressure Verification ........................................................ 51

4.2.5 Testing Results - Tactilus Free Form ................................... 52

4.3 Pressure Profile Systems - ConTacts Discrete Tactile Sensors........ 52

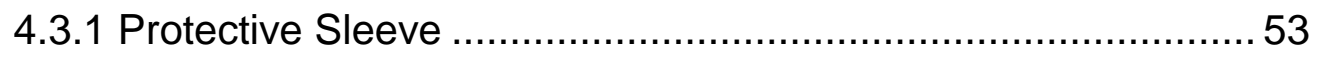

4.3.2 Development of Sensor Specific Calibration Curve .................. 54

4.3.3 Testing Results - ConTacts Tactile Pressure Sensors ............ 54

Chapter 5 - Experimental Setup and Instrumentation ................................... 56

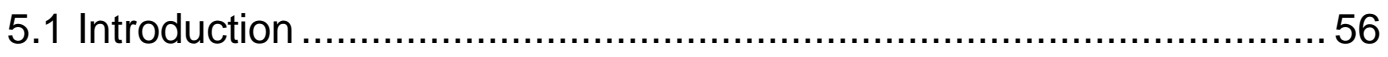

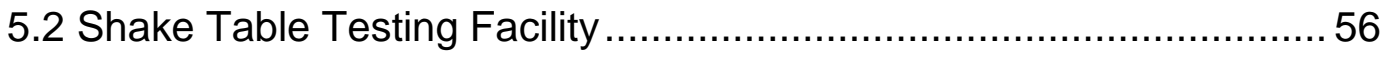

5.3 Shake Table Modifications for Current Research ...........................58

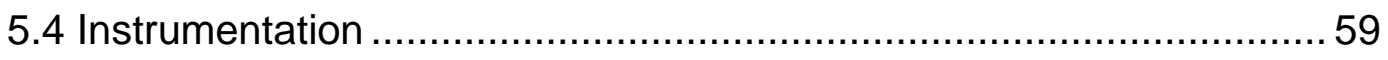

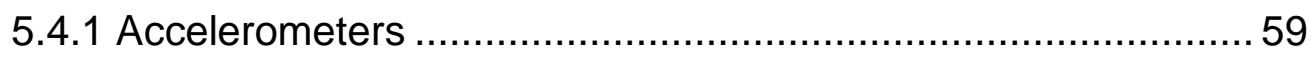

5.4.2 Tactile Pressure Sensors ................................................... 61

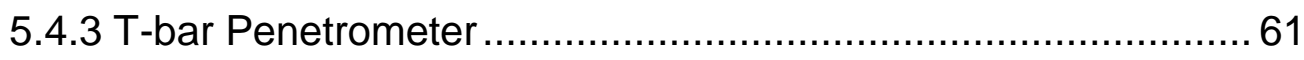


5.5 Model Soil Placement and Construction 63

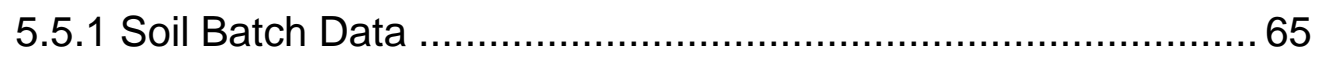

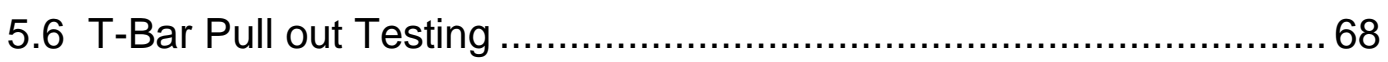

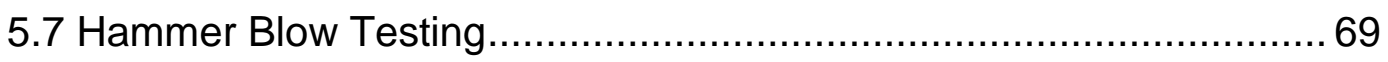

5.8 Model Basement Configuration and Placement ............................... 70

5.9 Model Basement Instrumentation ............................................... 70

5.9.1 Model Basement Embedment Procedures ............................. 72

5.10 Shake Table Instrumentation Configuration.................................. 73

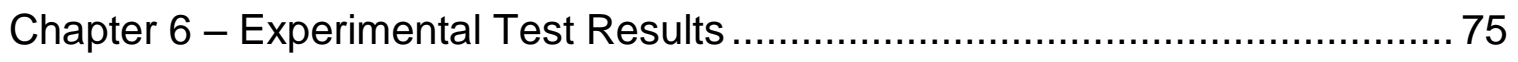

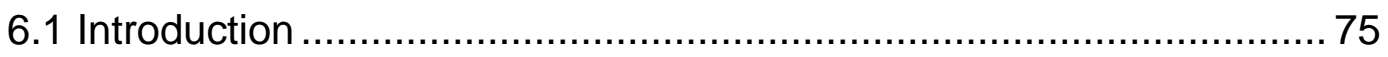

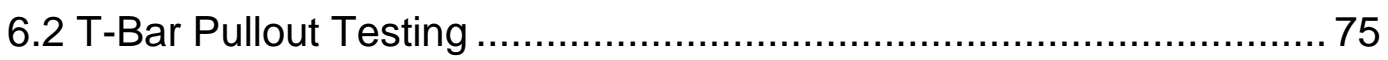

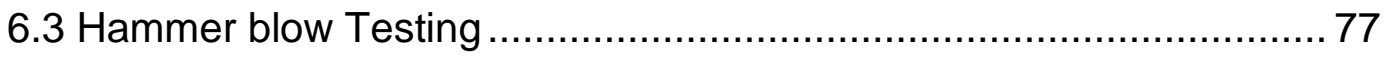

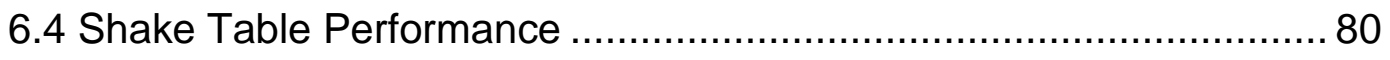

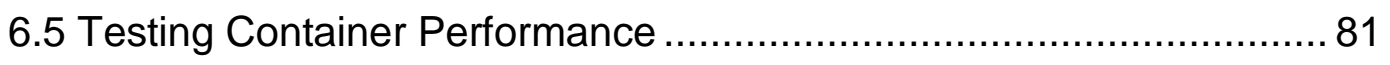

6.5.1 Testing Container Boundary Effects...................................... 81

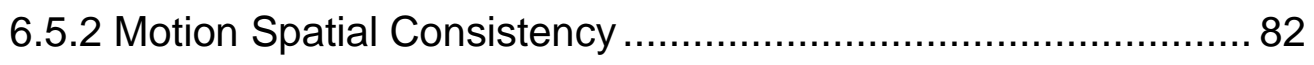

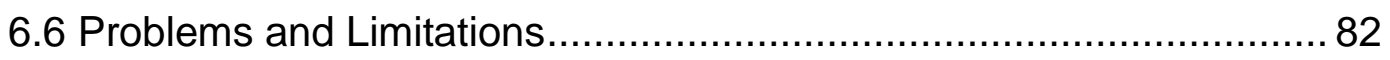

6.6.1 Experimental Drift in Earth Pressure Investigations ................. 83

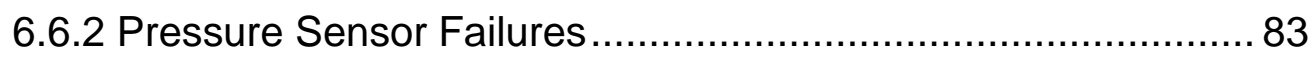

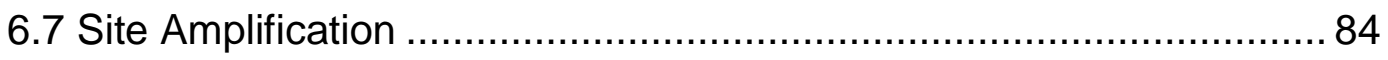

6.8 Ground Motion Parameters and Acceleration Response ................... 86

6.9 Acceleration Reduction/Dynamic Acceleration ................................. 88

6.10 Total Lateral Earth Pressures ….................................................. 91

6.10.1 Pressure Sensor Calibration and Reduction ........................ 91

6.10.2 Pressure Time History ...................................................... 93 


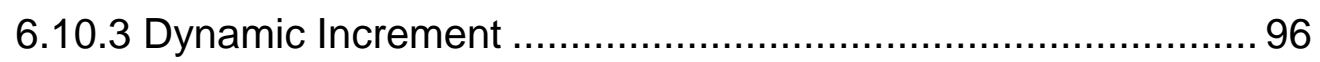

6.11 Evaluation of Seed and Whitman (1970) .................................. 101

6.11.1 Seismic Coefficient.......................................................... 103

6.11.2 Total Lateral Earth Pressures.......................................... 105

6.12 Discussion of Experimental Results........................................... 107

Chapter 7 - Summary and Conclusions ..................................................... 110

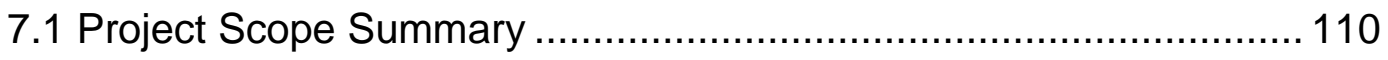

7.2 Findings from Experimental Research ....................................... 111

7.3 Opportunities for Future Investigations ....................................... 113

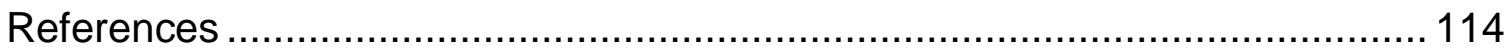

Appendices

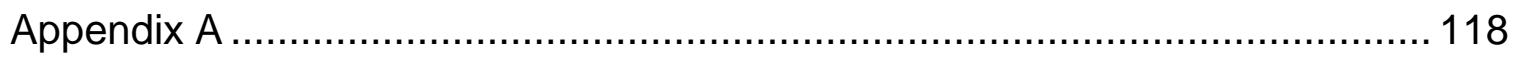

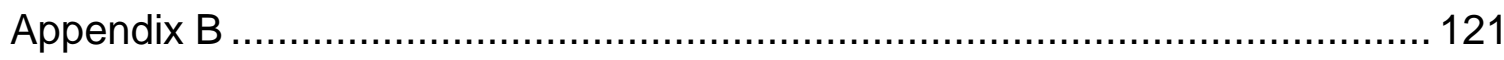

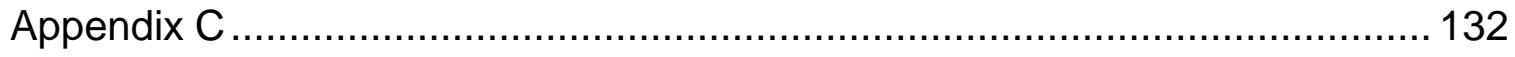




\section{LIST OF TABLES}

Table 3-1: Interaction modes and associated variables (adopted from

Meymand 1998; Crosariol, 2010; Kuo, 2012)

Table 3-2: Scale factors for selected engineering variables in terms of the geometric scaling factor $(\lambda)$ (adapted from lai, 1989;

Meymand,1998).....

Table 3-3: Comparison of soil properties of prototype Bay Mud and model soil in SSPSI investigation. (after Meymand 1998)

Table 3-4: List of seven input ground motions used in this study ...................... 40

Table 4-1: Tactilus Free Form Specifications .............................................. 46

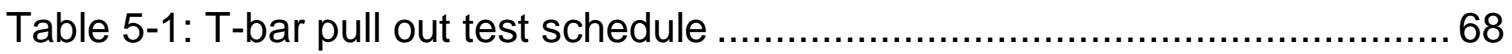

Table 5-2: List of instrumentation and nomenclature .................................... 73

Table 6-1: Summary of top down hammer blow tests .................................... 80

Table 6-2: Ground motion parameters for different shaking event during Phase 11

Table 6-3: Ground motion parameters for different shaking event during Phase 2

Table 6-4: Horizontal Ground Acceleration for Cohesionless Backfill or Retained Earth Materials (from Lew et al (2010)) 102

Table 6-5: Back calculated seismic coefficient and percent of soil surface acceleration for Phase 1 and Phase 2 


\section{LIST OF FIGURES}

Figure 2.1: Forces in Mononobe Okabe Analysis (after Whitman and Seed 1970)

Figure 2.2: Seismic Coefficient Charts for $c-\varphi$ soil for $\varphi=35^{\circ}$ (Anderson et al 2008) 10

Figure 2.3: Incremental Failure by Base Sliding (Richards and Elms 1979) 12

Figure 2.4: Mononobe and Matsuo (1929) experimental setup 15

Figure 3.1: Method of implied prototype flowchart, used to develop the model soil (from Meymand 1998) 28

Figure 3.2: Scale model basement and materials (from Kuo 2012) 34

Figure 3.3: Snapshot of scale model basement with attached SDOF damped mass (from Kuo 2012).... 36

Figure 3.4: Snapshot of fully assembled flexible wall testing container 37

Figure 3.5: Scaled horizontal azimuths of the Joshua Tree motion for the 1992 Lander earthquake with compressed time step by $\lambda^{0.5}$.

Figure 3.6: Scaled horizontal azimuths of the El Centro motion for the 1940 Imperial Valley earthquake with compressed time step by $\lambda^{0.5}$ 41

Figure 3.7: Scaled horizontal azimuths of the TCU075 motion for the 1999 Chi Chi earthquake with compressed time step by $\lambda^{0.5}$

Figure 3.8: Scaled horizontal azimuths of the Superstition Mountain motion for $b$ the 1979 Imperial Valley earthquake with compressed time step by $\lambda^{0.5}$

Figure 3.9: Scaled horizontal azimuths of the Los Gatos Presentation motion for the 1989 Loma Preita earthquake with compressed time step by $\lambda^{0.5}$.

Figure 3.10: Scaled horizontal azimuths of the Lake Hughes motion for the 1994 Northridge earthquake with compressed time step by $\lambda^{0.5}$....

Figure 3.11: Scaled horizontal azimuths of the Cape Mendocino motion for the 1992 Cape Mendocino earthquake with compressed time step by $\lambda^{0.5}$

Figure 4.1: Circuit Diagram as Proposed by Tekscan 
Figure 4.2: Intermediary Circuit Diagram and connection to Data

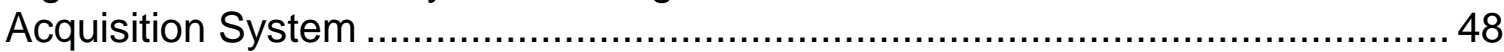

Figure 4.3: Derived Calibration Curve (Pressure V. Voltage) ............................ 49

Figure 4.4: Pressure Sensor within Protective Sleeve.................................... 50

Figure 4.5: ConTacts Pressure Sensor with C500 Signal Conditioning

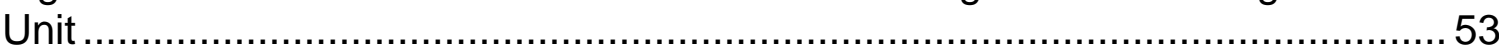

Figure 4.6: Recorded and Corrected Pressure Reading of Sensor 962 ............ 55

Figure 5.1: Parson's Earthquake and Geotechnical Engineering

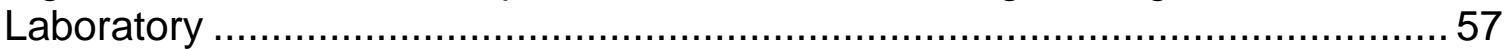

Figure 5.2: Accelerometers (a) used to measure acceleration in the soil and (b) used to measure horizontal accelerations in the scale model. (From Kuo 2012)

Figure 5.3: T-bar device with (a) $22 \mathrm{kN}$ load cell thread to the steel rod and eye bolt and (b) cylindrical cross bar (from Crosariol 2010)....................... 62

Figure 5.4: Reconstituted clay holding area and transport bucket..................... 63

Figure 5.5: Mixing equipment for new model soil bath.................................... 65

Figure 5.6: Water Content of Soil Throughout the Soil Column ......................... 66

Figure 5.7: Unit weight measurements at soil column heights........................ 67

Figure 5.8: Snapshot of timber beams holding T-bars in place ........................ 69

Figure 5.9: Snapshot of pressure sensor array as mounted on the scale

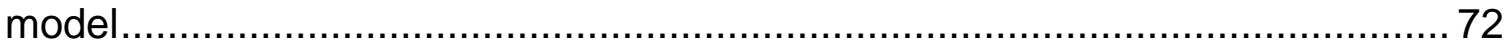

Figure 5.10: Plan view of soil column instrumentation configuration ................. 74

Figure 5.11: Profile view of soil column instrumentation configuration .............. 74

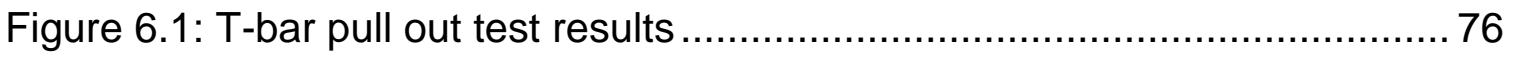

Figure 6.2: Average undrained shear strength of soil column using T-

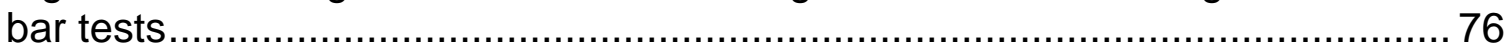

Figure 6.3: Hammer blow striking platform and rubber mallet ......................... 77

Figure 6.4: Typical wave form developed by top-down hammer blow tests. 
Figure 6.5: Arrival times of shear wave form for shear wave velocity

calculation

Figure 6.6: $5 \%$ damped spectra response acceleration for TCU $075 \mathrm{~W}$ (Phase 1') where 1S and 2S are the accelerometers directly below the model.

Figure 6.7: 5\% damped spectra response acceleration for TCU $075 \mathrm{~W}$ (Phase 2) where 1S and 2S are the accelerometers directly below the model.

Figure 6.8: Comparison of 5\% damped spectra response acceleration for TCU $075 \mathrm{~W}$ at the soil surface, $30 \mathrm{~cm}$ depth (3F), and table accelerometer locations from phases 1, 2 and $1^{\prime}$.

Figure 6.9: Out of phase relationship between raw acceleration data and corrected acceleration data for TCU $075 \mathrm{~W}$ motion (Phase 1').....

Figure 6.10: In phase relationship between raw acceleration data and corrected acceleration data after $0.15 \mathrm{sec}$ shift for TCU $075 \mathrm{~W}$ motion

Figure 6.11: Acceleration cycles recorded at soil surface, shake table, model foundation and a soil depth of $30 \mathrm{~cm}$ for the TCU075W input motion.

Figure 6.12: Pressure time history superimposed on acceleration time histories for the El Centro 180 motion (Phase 1') ....

Figure 6.13: Pressure time history superimposed on velocity time histories for the El Centro 180 motion (Phase 1') ....

Figure 6.14: Pressure time history for each pressure sensor superimposed on acceleration time history for the TCU075N motion (Phase 2)

Figure 6.15: Peak dynamic increment profile in terms of percent increase above static pressures for TCU $075 \mathrm{~N}$ motion

Figure 6.16: Dynamic increment profile in terms of percent increase above static pressures for TCU $075 \mathrm{~W}$ motion

Figure 6.17: Average dynamic increment profile in terms of percent increase above static pressures....

Figure 6.18: Average peak dynamic increment as a function of Arias Intensity (Phase 1'). 
Figure 6.19: Average peak dynamic increment as a function of Cumulative Absolute Velocity (Phase 1').

Figure 6.20: Average peak dynamic increment as a function of Arias Intensity (Phase 2)

Figure 6.21: Average peak dynamic increment as a function of Cumulative Absolute Velocity (Phase 2)

Figure 6.22: Recorded earth pressures in comparison to M-O analysis using a seismic coefficient of $2 \%$ and $8 \%$ of peak accelerations at the soil surface (Phase 1')

Figure 6.23: Recorded earth pressures in comparison to $\mathrm{M}-\mathrm{O}$ analysis using a seismic coefficient of $2 \%$ and $8 \%$ of peak accelerations at the soil surface (Phase 2) 
Chapter 1 - Statement of Research

\subsection{Introduction}

Earth retaining structures are vital components in the development of transportation systems, lifelines and other civil constructions. These structures often found supporting soils in excavations, slopes, and bridges. If such a structure were to fail, transportation systems, lifelines and people's lives could be in jeopardy. As a result, it is important that the design and construction such earth retaining structures not be compromised, even in catastrophic events such as earthquakes.

Although the principal of retaining soils is among of some of the most fundamental concepts in geotechnical engineering, the design of retaining walls for seismic loading has been a subject of much research and debate. Recent code changes require that retaining walls be designed for seismic earth pressures, however, field evidence of recent major earthquakes show little signs of damage due to such pressures. The apparent discrepancy between code and field observations has lead researches to evaluate existing design criteria to better understand the response of retaining structures during earthquakes. Due to the risks involved with strong ground motion, a thorough understanding of the behavior of such structures in earthquakes is needed in order to mitigate damage and loss of life during a seismic event. 


\subsection{Seismic Earth Pressures}

During an earthquake, total earth pressures applied to an earth retaining structure can be broken down into static and dynamic components. The static earth pressure component is developed by of soils pushing up against vertical earth retaining structures. However, the development of seismically induced earth pressures on retaining structures is not as well understood and has been the recipient of much attention.

Predominant methods for evaluating seismic earth pressures stem from the pioneering work by Okabe (1926) and Mononobe and Matsuo (1929) following the Great Kanto Earthquake of 1923. The analytical method proposed by these authors is known as the Mononobe-Okabe (M-O) method. Although originally developed for gravity retaining walls with cohesionless backfill materials, this method and its derivatives are the most commonly used method for evaluating seismic earth pressures. As such, the $\mathrm{M}-\mathrm{O}$ method is a common target for critique and evaluation. The method is discussed in more detail in Chapter 2.

\subsection{Project Scope}

Although there are a number of studies to evaluate seismic earth pressures in cohesionless backfill, few studies have been performed to evaluate retaining systems with cohesion. Cohesion is understood to reduce static lateral earth pressures and by extension reduce seismic lateral earth pressures as compared to cohesionless material. Due to the limited number of empirical tests 
for evaluation of seismic earth pressures with cohesive backfill, there is a need for empirical tests such as this to bridge this knowledge gap.

The purpose of this research investigation is to use physical shake table tests to evaluate the development of seismic earth pressures due to soft clay on an scale model retaining structure amidst strong ground motion and explore the effects of soil structure interaction of a model basement on the development of such earth pressures. A testing platform developed my Meymand (1998) and modified by Crosariol (2010) is used in for this investigation. A scale model basement, originally developed for by Kuo (2012) is also adapted for this study. Earth pressure data is measured by an array of pressure sensors mounted to the face of a scale model. Accelerometers are placed throughout the soil column to measures accelerations within the soil.

\subsection{Organization of the Thesis}

Chapter 2 outlines building code provisions, analytical methods and research highlights. Chapter 3 presents an overview of the development of scaling relations, the model soil, the model retaining structure, and the testing container. Chapter 4 discusses the identification and testing of pressure sensors for the current investigation. Chapter 5 outlines procedures for material placement and material testing, instrumentation detail, and test platform configuration. Chapter 6 presents testing results and discussion of experimental results. Finally, Chapter 7 provides a discussion empirical observations and recommendations for future research. 


\section{Chapter 2 - Literature Review}

\subsection{Introduction}

In the field of geotechnical engineering, designing retaining walls for seismic earth pressures has been a subject of much research and debate. Predominant methods for evaluating seismic earth pressures have been found to yield overly conservative designs; having a great impact on cost. Field performance of engineered basement walls has shown little to no evidence of failure in past earthquakes, yet recent changes in the U.S. building codes have required provisions to consider seismic earth pressures on earth retaining walls, significantly impacting the design. The following literature review presents analytical methods, and highlights research geared towards the advancement of current design methodologies pertinent to the investigations conducted in this thesis.

\subsection{Wall Failure Case Histories in Past Earthquakes}

Although damage and failure have been reported for retaining walls during earthquakes, the damage can often be associated with soil or foundations failures or poorly constructed non-engineered walls. Lew et al (2010) reports that investigations of subterranean walls show little to no signs of damage

due to seismic earth pressures during major earthquakes such as San Fernando Earthquake 1971, Whitter Narrows 1987, Loma Prieta 1989, and Northridge 1994. 


\subsection{Building Code Provisions for Seismic Earth Pressures}

Building codes are a set of minimum standards and provisions used for the design and construction of buildings to provide adequate safety to the public. Seismic provisions are often introduced to the building code as a result of observation and poor building performances during past earthquakes. Although damage to retaining walls due to seismic earth pressures have not been observed, recent changes to the buildings codes have made provisions to consider such pressures on earth retaining walls.

The International Building Code (IBC) is model building code used throughout the United States. Prior to 2003, no specific requirements for seismic earth pressures were addressed by US building codes. The 2006 edition of the IBC included provisions for the consideration of seismic earth pressures on earth retaining walls.

1803.5.12 Seismic Design Categories D through F. For structures assigned to Seismic Design Category D, E or $F$ in accordance with Section 1613, the geotechnical investigation required by Section 1803.5.11, shall also include:

1. The determination of lateral pressures on foundation walls and retaining walls due to earthquake motions.

Furthermore, the California Building Code (2007) states that:

\section{A.1 General.}

Retaining walls higher than 12 feet $(3658 \mathrm{~mm}$ ), as measured from the top of the foundation, shall be designed to resist the additional earth pressure caused by seismic ground shaking. 


\subsection{Analytical Methods for Evaluation of Seismic Earth Pressures}

The lack of reported wall failures due to seismic earth pressures suggests that the behavior of retaining walls in major earthquakes is poorly understood. This has led researchers to revaluate current analytical methods for seismic earth pressures. In light of the current understanding of retaining wall design, Whitman (1991) recommends that "engineers must rely primarily on sound understanding of fundamental principles and general patterns of behavior."

The seismic design analysis of retaining walls can be broken down into two major categories: "yielding" and "nonyielding" walls. "Yielding" walls are designed to allow sufficient movement for minimum active earth pressures to develop, while "nonyielding" walls are restrained preventing such movement.

\subsubsection{Mononobe-Okabe Methods}

Following the Great Kwanto Earthquake in 1923 in Japan, Mononobe and Matsuo (1929) and Okabe (1924) developed experiments that explored the effect of ground motions on retaining walls. They proposed an analytical method based on Coulomb's theory of static earth pressure to predict seismic earth pressures

on a retaining wall. Mononobe Okabe $(\mathrm{M}-\mathrm{O})$ method has become the most widely used method for determining seismic forces developing on a retaining wall.

The method was developed for dry cohesionless material with the following assumptions:

1. The retaining wall yields sufficiently for minimum active earth pressures to develop 
2. Once active earth pressures have developed, the soil wedge is at the point of incipient failure and the maximum shear strength is mobilized along the potential sliding surface.

3. The soil behind the retaining wall behaves like a rigid body and the acceleration is uniform in the soil wedge.

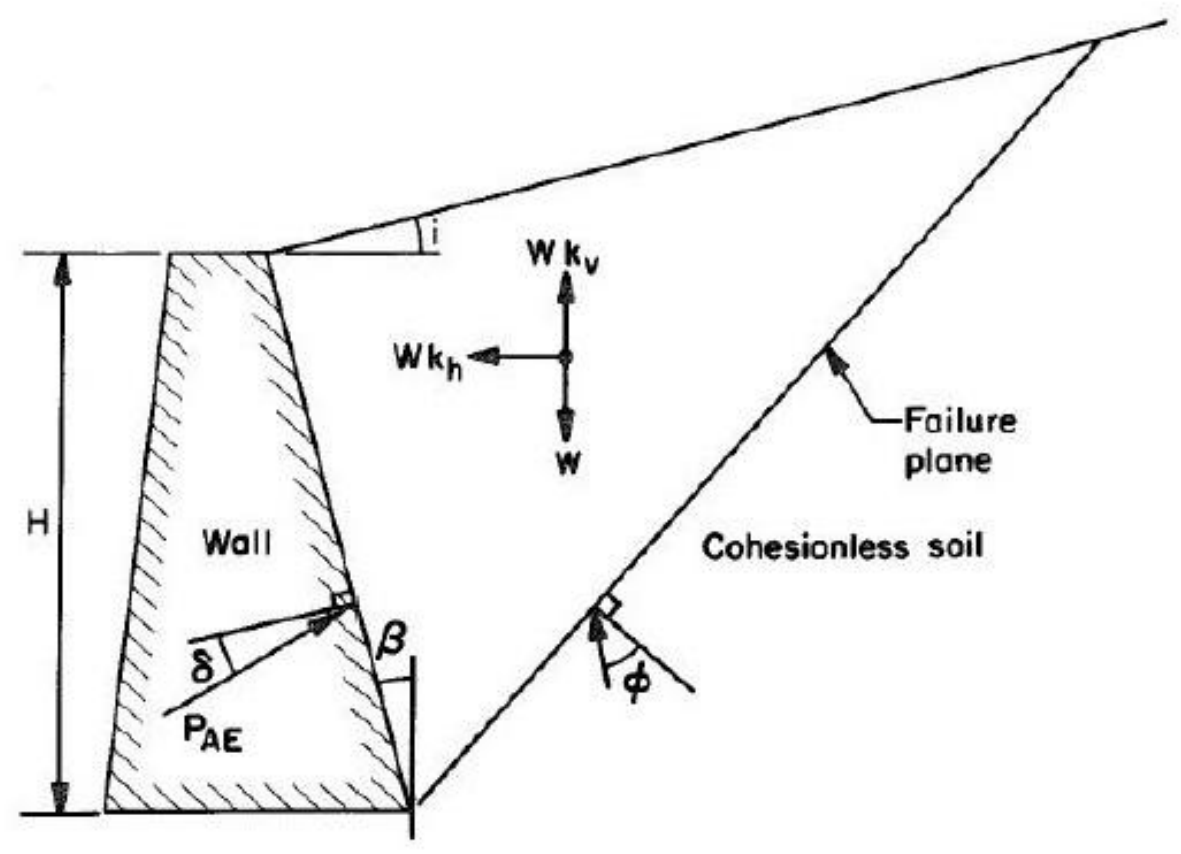

Figure 2.1: Forces in Mononobe Okabe Analysis (after Whitman and Seed 1970)

The $\mathrm{M}-\mathrm{O}$ method suggests that the active lateral thrust can be calculated from the static equilibrium of the soil wedge presented in Figure 2.1. The maximum thrust, $\mathrm{P}_{\mathrm{AE}}$, is presented as follows:

$$
P_{A E}=\frac{1}{2} \gamma H^{2}\left(1-k_{v}\right) K_{A E}
$$

where, 


$$
\begin{aligned}
& K_{A E}=\frac{\cos ^{2}(\varphi-\theta-\beta)}{\cos (\theta) \cos ^{2}(\delta+\beta+\theta)\left[1+\sqrt{\frac{\sin (\varphi+\delta) \sin (\varphi-\theta-i)}{\cos (\delta+\beta+\theta) \cos (i-\beta)}}\right]^{2}} \\
& P_{A E}=\text { Maximum dynamic active force } \\
& K_{A E}=\text { Coefficient of total lateral earth pressure } \\
& V=\text { unit weight of the soil } \\
& H=\text { height of the wall } \\
& \varphi=\text { angle internal friction of the soil } \\
& \delta=\text { angle of wall friction } \\
& i=\text { slope of the ground surface behind the wall } \\
& \beta=\text { slope of the wall relative to the vertical } \\
& \theta=\text { tan }{ }^{-1} \frac{k_{h}}{1-k_{v}} \\
& k_{h}=\text { horizontal wedge acceleration (in g) } \\
& k_{v}=\text { vertical wedge acceleration (in g) }
\end{aligned}
$$




$$
\begin{gathered}
P_{A E}=P_{A}+\Delta P_{A E} \\
\Delta P_{A E}=\frac{1}{2} \gamma H^{2} \Delta K_{A E}
\end{gathered}
$$

where $\Delta \mathrm{K}_{\mathrm{AE}}$ can be approximated as

$$
\Delta K_{A E} \approx \frac{3}{4} k_{h}
$$

Seed and Whitman (1970) suggested that the dynamic thrust on the wall should be applied somewhere between $1 / 2$ and $2 / 3$ the wall height above the base of the wall. For the design of retaining walls, they note that the "factor of safety provided in the design of the wall for static pressures may be adequate to prevent damage or detrimental movement during earthquakes." Furthermore, since the peak ground acceleration of an earthquake occurs for only an instant, the duration is therefore not sufficient to cause significant wall displacements, the use of $85 \%$ peak ground acceleration is suggested as a reasonable estimate for the horizontal ground acceleration.

Although the M-O method is specially developed for retaining walls with a dry cohesionless backfill, studies have been made to analyze retaining walls backfill with cohesion. In the NCHRP Report 611, Anderson et al (2008) present charts that correlate seismic coefficient $\left(k_{h}\right)$ and the coefficient of total lateral earth pressure $\left(\mathrm{K}_{\mathrm{AE}}\right)$ to the cohesion, wall height and unit weight parameters of the soil for a specific friction angle. 


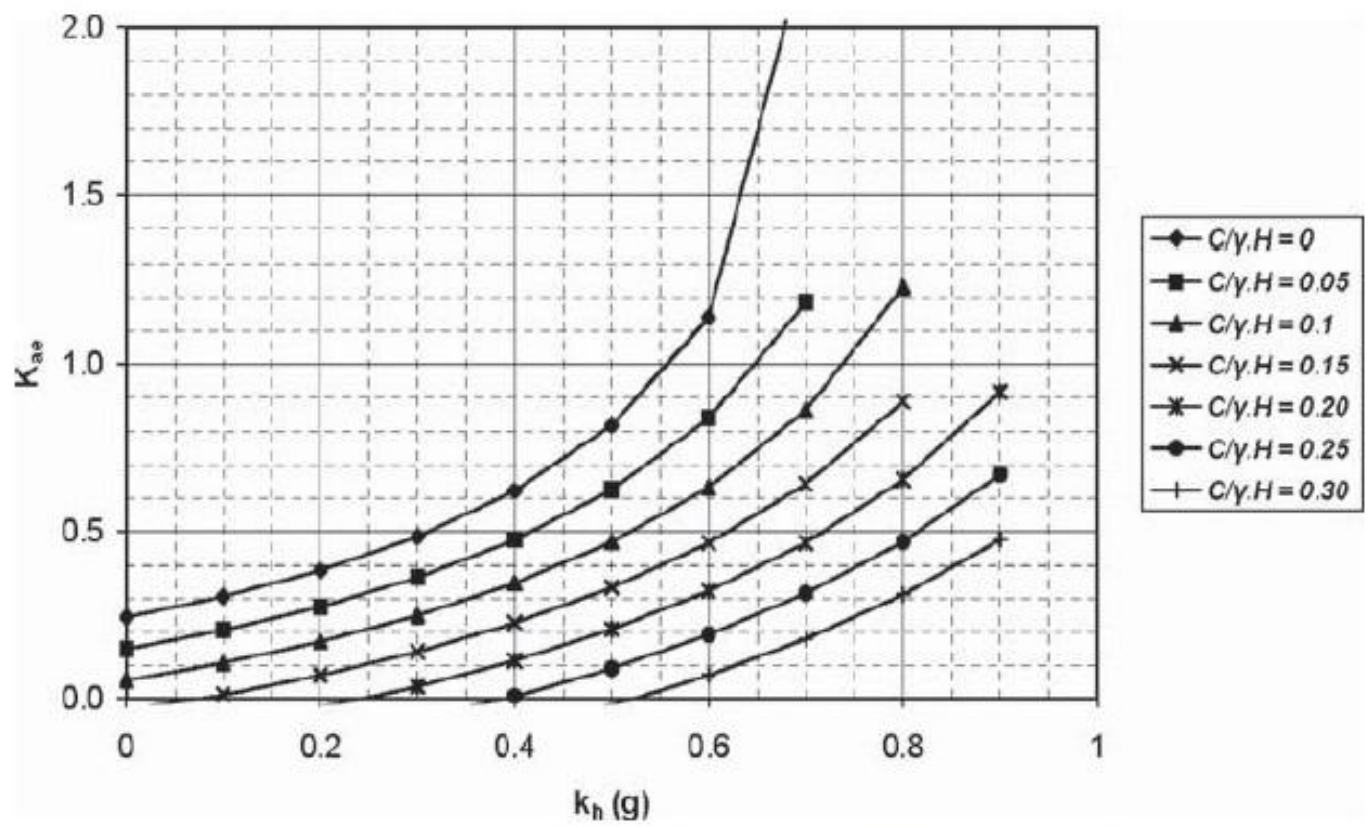

Figure 2.2: Seismic Coefficient Charts for $c-\varphi$ soil for $\varphi=35^{\circ}$ (Anderson et al 2008)

These charts indicate that even small amounts of cohesion in the soil can significantly reduce the dynamic pressures in the wall for design. Anderson et al (2008) suggest that cohesion in the soil provides some inherent shear strength that resists inertial soil loading, thus reducing the design magnitude of seismic earth pressures applied to a retaining wall during an earthquake. Although the inclusion of cohesion in design would reduce the dynamic active pressures acting on a wall, uncertainties in the amount of cohesion and apparent cohesion (from capillarity) makes it difficult to incorporate soil cohesion in the design of retaining walls.

The Mononobe-Okabe method was originally developed for gravity retaining walls with cohesionless backfill materials. Although the scope and assumptions are clearly described in the method, the $\mathrm{M}-\mathrm{O}$ method is often used 
for the evaluation of dynamic pressures on for situations of which it was not originally intended, such as basement walls. The apparent misuse of the method has prompted Ostadan and White (1998) to report that "the M-O method is one of the most abused methods in geotechnical practice."

\subsubsection{Displacement Methods}

Richards and Elms (1979) have suggested a displacement based method for the design of gravity retaining walls. Displacement methods are based on allowable wall displacement than a force equilibrium criterion. Based on the sliding block model in Newmark (1965), originally developed for calculating displacements for earth dams and embankments, Richards and Elms (1979) developed a method for calculating seismic wall displacements based on a design peak ground acceleration and peak ground velocity. A relationship between relative wall displacements with the acceleration and velocity time histories of the backfill soil and retaining wall is presented in Figure 1.3. 


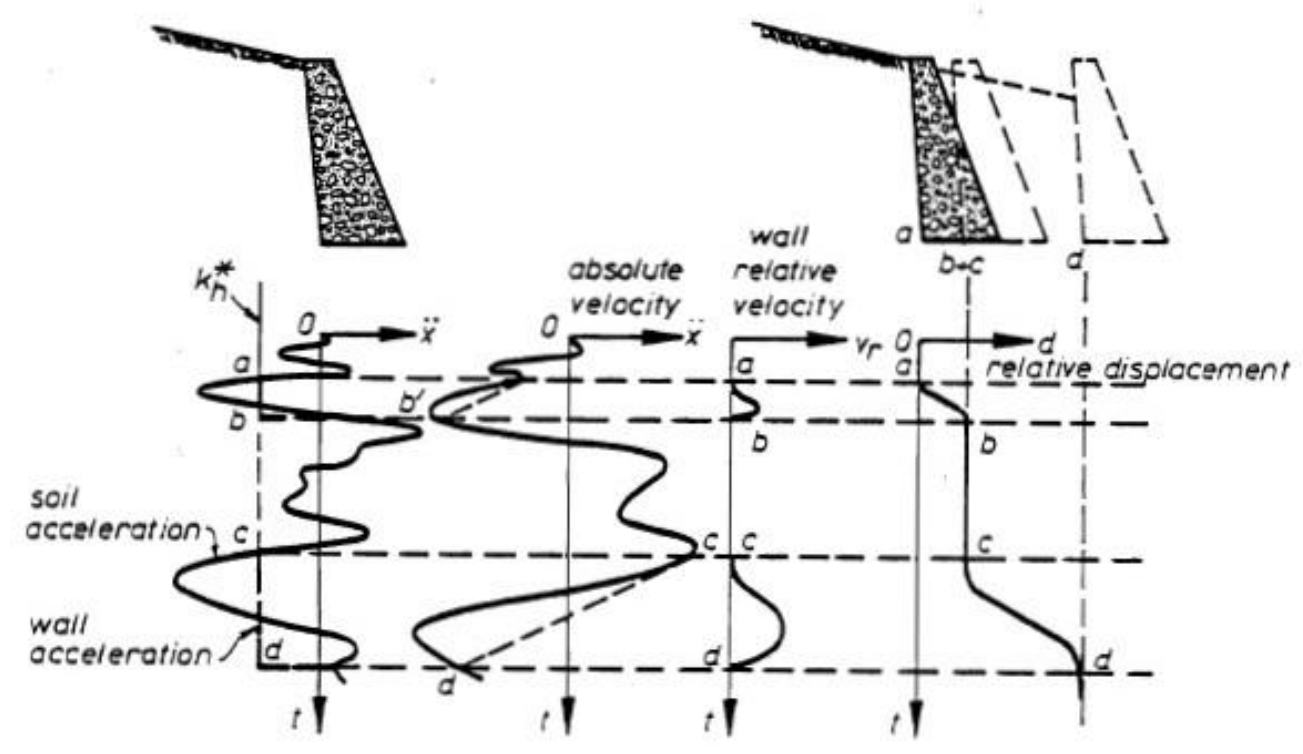

Figure 2.3: Incremental Failure by Base Sliding (Richards and Elms 1979)

Richards and Elms (1979) note that the total displacement of a gravity retaining wall consists of a series of smaller displacements. The authors have observed the following for the development of a progressive wall failure.

1. For an unsaturated backfill, outward lurches sum to a finite wall displacement

2. An earthquake with few sharp peaks in acceleration is not as destructive a one with high velocity peaks where the critical acceleration is exceeded more often for longer periods of time.

3. Residual lateral pressures must at least equal those calculated in Mononobe-Okabe analysis for acceleration factor $k_{h}$.

Richards and Elms (1979) presents their design procedure using charts developed by Franklin and Chang (1977) to determine an acceleration factor 
based on a permissible relative displacement. The proposed design procedure is as follows.

1. Determine a permissible maximum displacement.

2. Use the following equation to obtain the acceleration factor $k_{h}$.

$$
k_{h}=A_{a}\left(\frac{0.2 A_{v}^{2}}{A_{a} d}\right)^{\frac{1}{4}}
$$

where $A_{a}$ and $A_{v}$ are acceleration coefficients from the Applied Technology Council (ATC) Building Code, and d is relative wall displacement in inches.

3. Use $k_{h}$ in the following equation to obtain the required wall weight $\mathrm{W}_{\mathrm{w}}$

$$
W_{w}=\frac{\frac{1}{2} \gamma H^{2}\left[\cos (\delta+\beta)-\sin (\delta+\beta) \tan \varphi_{b}\right]}{\tan \varphi_{b}-\tan \theta} K_{A E}
$$

where $\mathrm{K}_{\mathrm{AE}}$ and $\mathrm{W}_{\mathrm{w}}$ parameters are described in Seed and Whitman (1970).

4. Apply suitable factor of safety to the wall weight Richards and Elms (1979) conclude that Mononobe-Okabe analysis produces satisfactory results if the wall inertia is included in the design, as is proposed in the above method.

Wong (1982) describes apparent short comings of the method proposed by Richards and Elms (1979), and modifies the Richards and Elms method to 
allow time variation of dynamic earth pressures, wall orientation, and the incorporation of the vertical acceleration. Although Wong (1982) indicates that the modified method offers improvement of the Richards and Elms design procedure, Wong suggests that the method "should be used with caution and good judgment" due to the lack of field and experimental validation.

Richards and Shi (1994) further expand on the Richards and Elms (1979) method to incorporate soils with cohesion. In the proposed method, chart solutions are used to calculate dynamic thrust for either the cracked or uncracked states. The design procedure is given to determine the critical horizontal acceleration for a particular wall which could then be applied to the Richards and Elms (1979) method to calculate seismic displacements. Richards and Shi (1994) found that in comparison to cohesionless soil, cohesive soils exhibit a reduced active thrust on the wall, whereas it exhibits an increased thrust in the passive case.

\subsubsection{Analytical Method for Non-yeilding Walls}

For the case of a non-yielding wall, the most widely used method is depicted in Wood (1973). The method is based on a finite element analysis of the soil-wall system. Chart solutions are provided in the method to calculate the horizontal forcing with respect to poisson's ratio of the soil. Wood (1973) predicts

the total dynamic trust to be $\gamma H^{2} \frac{a}{g}$ (where $\mathrm{Y}$ is the unit weight of the soil, $\mathrm{H}$ is the wall height, and $a$ is the base acceleration) acting at approximately the midheight of the wall. The Wood (1973) suggests that the forces involved in a non- 
yielding wall on a ridgid foundation can be greater than twice the force calculated using the Mononobe-Okabe Method.

\subsection{Shake Table and Centrifuge Investigations}

Mononobe and Matsuo (1929) began the first regime of experimental testing of retaining walls in response to the Great Kwanto Earthquake in Japan to verify the analytical methods for seismic earth pressures developed by Okabe (1926). The experiments were performed in a sand box of dry sandy soils on a $1 \mathrm{~g}$ shake table, with wall heights of $4 \mathrm{ft}$ and $6 \mathrm{ft}$. The sand box was set on rollers connected to a winch driven by electric motor imparting a simple harmonic motion to the experiment as shown in Figure 2.

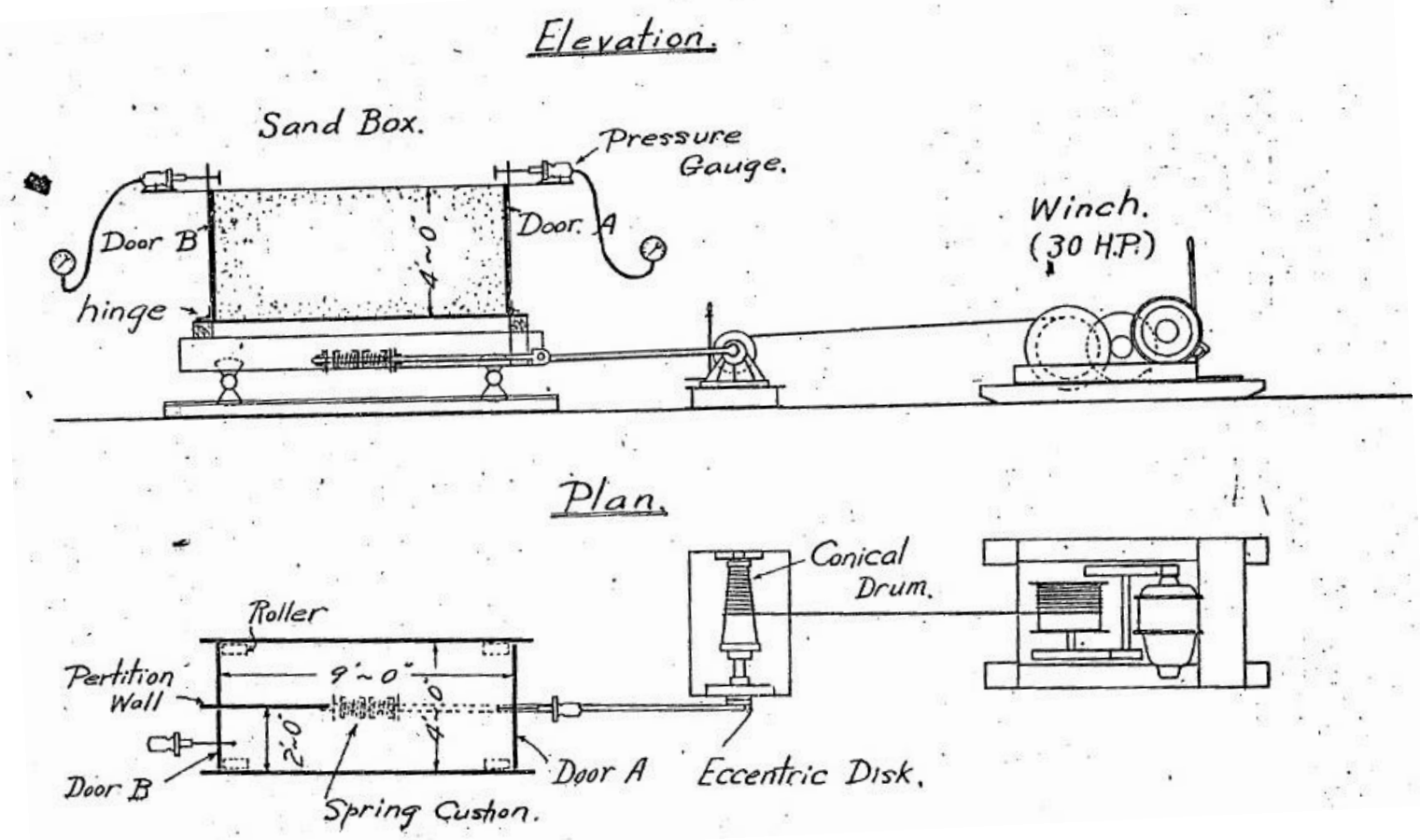

Figure 2.4: Mononobe and Matsuo (1929) experimental setup 
Mononobe and Matsuo's experiment, though pioneering in their scope cannot be accurately scaled to taller wall heights. Although Mononobe and Matsuo's experiment provided accurate results for the geometry and material of the experiment, such results are also limited to the geometry and material of the experiment.

Many subsequent $1 \mathrm{~g}$ shake table tests has been performed by researchers exploring the nature of seismic earth pressures on retaining walls. These investigations are limited due to the inherent inability $1 \mathrm{~g}$ shake table tests to accurately model soil stresses for granular backfills. Results from some of these shake table investigations are published by Sherif et al. (1982), Bolton and Steedman (1982), Sherif and Fang (1984), Steedman (1984), Bolton and Steedman (1985), and Ishibashi and Fang (1987). These experiments have generally shown agreement with Mononobe-Okabe analysis, and apply the total seismic resultant force at a position greater than $1 / 3$ of the wall height above the base.

Centrifuge testing provides a method to accurately simulate prototype conditions with the proper strength and stiffness in granular soils. Ortiz Scott and Lee (1983), who were one of the first to apply centrifuge testing to model the seismic behavior of a retaining wall, stated that "it is difficult or impossible to achieve in a shaking table a pressure distribution which can be related quantitatively to that of the full scale situation." In their experiment, Ortiz et al (1983) found that the point of application of the static and dynamic earth 
pressures was at about one-third the height of the wall above the base, showing agreement with Mononobe-Okabe.

Nakamura (2006) used centrifuge testing to reevaluate the accuracy of Mononobe-Okabe theory using centrifuge testing. Nakamura (2006) reports that for retaining wall design, Mononobe-Okabe theory is an inappropriate method for calculating seismic earth pressures because the seismic behavior of the retaining wall and the backfill soil based in M-O theory conditions does not match actual seismic behavior. A summary of the results found as listed as follows below.

1. Contrary to the rigid wedge assumption in the $\mathrm{M}-\mathrm{O}$ theory, the part of the backfill that follows the displacement of the wall plastically deforms while sliding down

2. M-O theory assumes no phase difference between the soil and the wall, however in the active direction, acceleration is transmitted through the retaining wall then into the backfill.

3. M-O theory assumes a triangular distribution of earth pressures on the back face of the retaining wall. Results have shown the that the distribution is not triangular and changes over time. Results also show that the earth pressures increment is nearly zero when loaded in the active direction, so that when the inertia force is maximum, earth pressures are nearly equal to initial value prior to shaking.

Al Atik and Sitar (2010) also performed centrifuge tests to further investigate Mononobe-Okabe theory for granular soils. In their investigation, they 
report that seismic earth pressures on cantilever retaining walls can be neglected at accelerations below $0.4 \mathrm{~g}$. They also report that the maximum dynamic earth pressures exhibited a triangular distribution with depth, and that the observed triangular distribution appeared analogous to that of static earth pressures. As a result, Al Atik and Sitar (2010) conclude that " there seems to be no basis for the currently accepted position of the point of application of the dynamic earth pressure force in dynamic limit equilibrium analyses at 0.6 to $0.67 \mathrm{H}$ and, instead, the point of application should be at $1 / 3 \mathrm{H}$, as originally suggested by Mononobe and Matsuo (1932)"

More recently, Sitar et al (2012) conducted centrifuge investigations to evaluate seismic earth pressures on three retaining wall configurations of structures and backfill as follows:

1. Two U-shaped structures with cross bracing and medium dense sand backfill

2. Cantilever U-shaped and a free standing cantilever wall with medium sand backfill

3. Cross braced U-shaped structure and a free standing cantilever with low plasticity silty clay backfill

The experimental investigations suggest that the simplified M-O method proposed by Seed and Whitman (1970) is a suitable upper bound approximation of seismic earth pressures for retaining structures between $6-7 \mathrm{~m}$ high with the dynamic earth pressure force applied at $1 / 3 \mathrm{H}$ above the base of the wall. The 
experimental data suggests the same for braced excavations or basement walls and for systems with a silty clay backfill. 
Chapter 3 - Development of Scale Model

\subsection{Introduction}

Physical scale model shake table testing is used in this research for the evaluation of seismic earth pressures on retaining walls. Scale model testing is a means of analyzing large scale complex systems in a controlled environment. For the present research, natural large scale phenomena, such as earthquakes, cannot be readily predicted or produced in field. Scale model shake table testing provides researchers with the opportunity to take a glimpse as to how full scale (prototype) structures might respond in the event of an earthquake. This 1-g shake table study consists of a designed model soil mix housed in a flexible wall testing container. A scale model retaining structure, equipped with pressure sensors, was embedded into a column of soil to measure seismic earth pressure as they develop on the model basement wall. This chapter discusses scale modeling theory and how it is used in the current investigation.

\subsection{Scale Model Similitude}

For scale model testing, scaling relations must be understood to ensure that a scale model adequately resembles behavior at a prototype level. Scale model similitude is the basis for determining scaling relations and describes the relationship between model and prototype behavior. Kline (1965) describes dimensional analysis, similitude theory, and method of governing equations as three methods for scale modeling applications. Dimensional analysis converts dimensional equations into equivalent equations based on Mass-Length-Time, 
also referred to as fundamental "measures of nature". Similitude theory creates a scaling factor through dimensional analysis to relate model to prototype behavior by identifying forces in a system. The method of governing equations incorporates the transformation of differential equations into non-dimensional form and creates similarity variables to relate model to prototype.

Langhaar (1951) describes scale models having geometric, kinematic, or dynamic similarity to the prototype. Geometric similarity refers to a scale model having corresponding physical dimensions. Kinematic similarity discusses models having corresponding materials and corresponding behavior with the prototype. Dynamic similarity refers to corresponding parts between model and prototype experiencing corresponding forces. Moncarz and Krawinkler (1981) discuss nomenclature for referring to the degree by which scale models meet similitude requirements with the prototype. Scale models are describes as being "true", "adequate" or "distorted" representations of prototype behavior. True models satisfy all similitude requirements. Adequate models properly scale primary model features, but allow deviations for secondary features. Distorted models deviate from similitude requirements resulting in poor prediction of prototype behavior unless compensating distortions are introduced.

Dimensional analysis reduces specific engineering parameters to fundamental Mass-Length-Time $(M-L-T)$ units while deriving scaling factors for each of the three quantities. Mass $(\mu)$, length $(\lambda)$ and time $(\tau)$ scale factors are evaluated in the geometric scaling factor $(\lambda)$. Through this method, scaling factors can be derived for all pertinent variables in terms of the geometric scaling 
factor $(\lambda)$, where scale factors are the ratio of prototype to model. A number of examples of deriving scaling factors are depicted in Meymand (1998) and Crosariol (2010).

Meymand (1998) explores dimensional analysis in terms of the Buckingham $\mathrm{Pi}$ Theorem. The theorem states that "any dimensionally homogeneous equation involving certain physical quantities can be reduced to an equivalent equation involving a complete set of dimensionless products." According to the theorem, any physical quantity can be expressed in terms of $\mathrm{Pi}$, a dimensionless product of physical quantities. For scale modeling, specific variables are chosen to appropriately form model and prototype Pi terms. Scaling relations are then formed by setting model $\mathrm{Pi}$ terms as equal to the corresponding prototype Pi terms.

Moncarz and Krawinkler (1981) used the formation of Pi terms to discuss two conditions to satisfy requirements for a "true" scale model: the Froude number and Cauchy conditions. For 1-g scale modeling, the Froude number, dimensionless product of acceleration over gravitational acceleration, must equal unity. The Cauchy condition is satisfied when the ratio of model to prototype shear wave velocities is equal to square root of the geometric scaling factor $\sqrt{\lambda}$. Meymand (1998) describes the Cauchy condition as "a necessary requirement for simultaneous replication of restoring forces, inertial forces, and gravitational forces in a dynamic system." However, in order to satisfy the Cauchy condition and design a "true" scale model, the selection of model materials is limited to having a small modulus and a high density. Although acquiring such materials 
may be difficult, scale models can be adjusted to meet the "adequate" scale model conditions.

Rocha (1957) derived similitude relations for total and effective stress soil conditions. He asserted that the constitutive behavior of soil may be scaled in a 1-g environment if stress and strain are assumed to be linear between the model and prototype. Due to the complexity of non-linear soil response, Rocha limited his derived relations to elastic deformations.

Iai (1989) expands on similitude relations for dynamic tests in saturated soil structure fluid system. He makes use of basic equations which govern saturated soil-structure-fluid system behavior to extend "similitude into a more general form". lai adopts a set of approximations, deriving the similitude, regarding the idealization of the soil skeleton and deformations. lai points out that the deformations are regarded as small, such that equilibrium equation is considered the same before and after the deformation. Strains are also regarded as small and may be approximated linearly. Based on these idealizations, the derived similitude is not valid if large deformation or strains are expected. Iai derives a comprehensive set of scaling relations presented later in this chapter.

The objective of scale modeling is to achieve "dynamic similarity" between the model and prototype. With dimensional analysis as the basis of scale model similitude, Meymand (1998) proposed three test conditions to establish scaling parameters for shake table testing in saturated clay.

- Testing is conducted in a 1-g environment, therefore model and prototype accelerations must be equal. 
- Model soil must have a similar density with the desired prototype soil.

- Tests are conducted in saturated clay, where the undrained stress-strain response is independent of confining pressure.

\subsubsection{Similitude Criteria}

Relevant interactions modes can be indentified for scale model shake table testing in this present investigation. These modes of interaction include free-field site response, kinematic interaction, inertial interaction, physical interaction and damping. Table 3-1 lists the associated variables with each interaction mode.

Table 3-1: Interaction modes and associated variables (adopted from Meymand 1998; Crosariol, 2010; Kuo, 2012)

\begin{tabular}{|c|c|}
\hline Interaction Mode & Variables \\
\hline \multirow{4}{*}{ 1. Free-field Site Response } & Shear wave velocity $\left(V_{s}\right)$ \\
\hline & Soil density $\left(\rho_{s}\right)$ \\
\hline & Modulus degradation $\left(G / G_{\max }\right)$ \\
\hline & Damping $(\beta)$ \\
\hline \multirow{3}{*}{ 2. Kinematic Interaction } & Free-field site response \\
\hline & Flexural rigidity $(E I)$ \\
\hline & Structural geometry $(L)$ \\
\hline \multirow{4}{*}{ 3. Inertial Interaction } & Stiffness $(K)$ \\
\hline & Structural mass $(M)$ \\
\hline & Flexural rigidity $(E I)$ \\
\hline & Structural geometry $(L)$ \\
\hline \multirow{2}{*}{ 4. Physical Interaction } & Construction \\
\hline & Dynamic Loading $(F)$ \\
\hline \multirow{4}{*}{ 5. Damping } & Free-field site response \\
\hline & Material modulus $(E)$ \\
\hline & Structural mass $(M)$ \\
\hline & Structural geometry $(L)$ \\
\hline
\end{tabular}


For proper scale modeling, material mass $(\mathrm{M})$ can be problematic for radiation damping. Meymand (1998) suggests that for high shaking levels, as expected for this testing program, the effects of radiation damping can be considered insignificant. Additionally, interactions that deal directly with construction in a prototype situation cannot be easily incorporated in scale model and are disregarded in this investigation.

A list of pertinent scaling relations has been selected based on the aforementioned similitude scaling criteria for 1-g scale model shake table testing presented in Table 3-2. Scaling factors are applicable to various engineering properties as long as they have the same dimensions. Crosairol (2010) selected a geometric scaling factor $(\lambda)$ of 10 based on the limitations of the testing equipment and this has been adopted in the current investigation.

Table 3-2: Scale factors for selected engineering variables in terms of the geometric scaling factor $(\lambda)$ (adapted from lai, 1989; Meymand,1998)

\begin{tabular}{|l|c|c|}
\hline Variable & Scale Factor & For $\boldsymbol{\lambda}=\mathbf{1 0}$ \\
\hline Soil Density & 1 & 1 \\
\hline Force & $\lambda^{3}$ & 1000 \\
\hline Stiffness & $\lambda^{2}$ & 100 \\
\hline Modulus & $\lambda$ & 10 \\
\hline Acceleration & 1 & 1 \\
\hline Shear wave Velocity & $\lambda^{1 / 2}$ & 3.16 \\
\hline Soil Damping & 1 & 1 \\
\hline Poisson's ratio & 1 & 1 \\
\hline Time & $\lambda^{1 / 2}$ & 3.16 \\
\hline Frequency & $\lambda^{-1 / 2}$ & 0.316 \\
\hline Length & $\lambda$ & 10 \\
\hline Stress & $\lambda$ & 10 \\
\hline Strain & 1 & 1 \\
\hline Flexural Rigidity & $\lambda^{5}$ & 1000000 \\
\hline Dimensionless Quantities & 1 & 1 \\
\hline
\end{tabular}




\subsection{Development of Scale Model Soil}

The use of reconstituted soil as model soil is commonly used in centrifuge testing. Natural soil is mined an reconstituted to fit within a testing container. The soil is then consolidated to achieve the desired strength. However, due to the large testing container and the required time for consolidation in a 1-g environment, this technique is impractical for shake table investigations.

The use of a synthetic model soil can be used as an alternative for shake table investigations. Meymand (1998) describes that "a synthetic soil was recognized to sacrifice actual in-situ soil properties such as heterogeneity, anisotropy, fabric, and stress history, but without serious detriment to the performance of a well-designed model soil..

The model soil used in the current research is nearly identical to model soil used in Kuo (2012) and Crosariol (2010) shake table studies, adapted from Meymand's (1998) mixture for scale model seismic soil pile structure interaction (SSPSI) shake table research. Extensive research went into assuring that that model soil would satisfy the complex scale modeling criteria. Meymand, in his research, broke down the scale model soil properties into two general categories, free-field response and soil-pile interaction. Small strain soil properties would primarily affect free-field site response, while large strains are a primary consideration for soil pile interaction.

Meymand (1998) designates five discrete and non-linear soil parameters affecting soil response: shear wave velocity, density, modulus degradation and damping, stress strain response, and undrained shear strength. The soil density 
of both model and prototype soils have a 1 to 1 scaling ratio. The nonlinear stress-strain and modulus degradation and damping parameters cannot be directly modeled from the prototype soil, but rather the method of implied prototypes, an iterative procedure best described in the flowchart in Figure 3-1, was used in order to determine whether the scale model properties of these parameters are reasonable within the target range. The remaining parameters, undrained shear strength and shear wave velocity are considered the primary criteria for scale model soil. Depending on the type of desired soil response, small strain elastic or large strain inelastic, either the soil shear wave velocity or undrained shear strength should be emphasized in the scale model. If the full nonlinear system response is to be modeled, then simultaneous satisfaction of both criteria is necessary. Scale modeling of the full nonlinear system response can be difficult due to that fact that undrained shear strength and shear wave velocity, $\lambda$ and $\sqrt{\lambda}$ respectively, have different scaling factors. For this investigation, San Francisco Bay Mud was determined as the target prototype soil for the development of the scale model soil. 


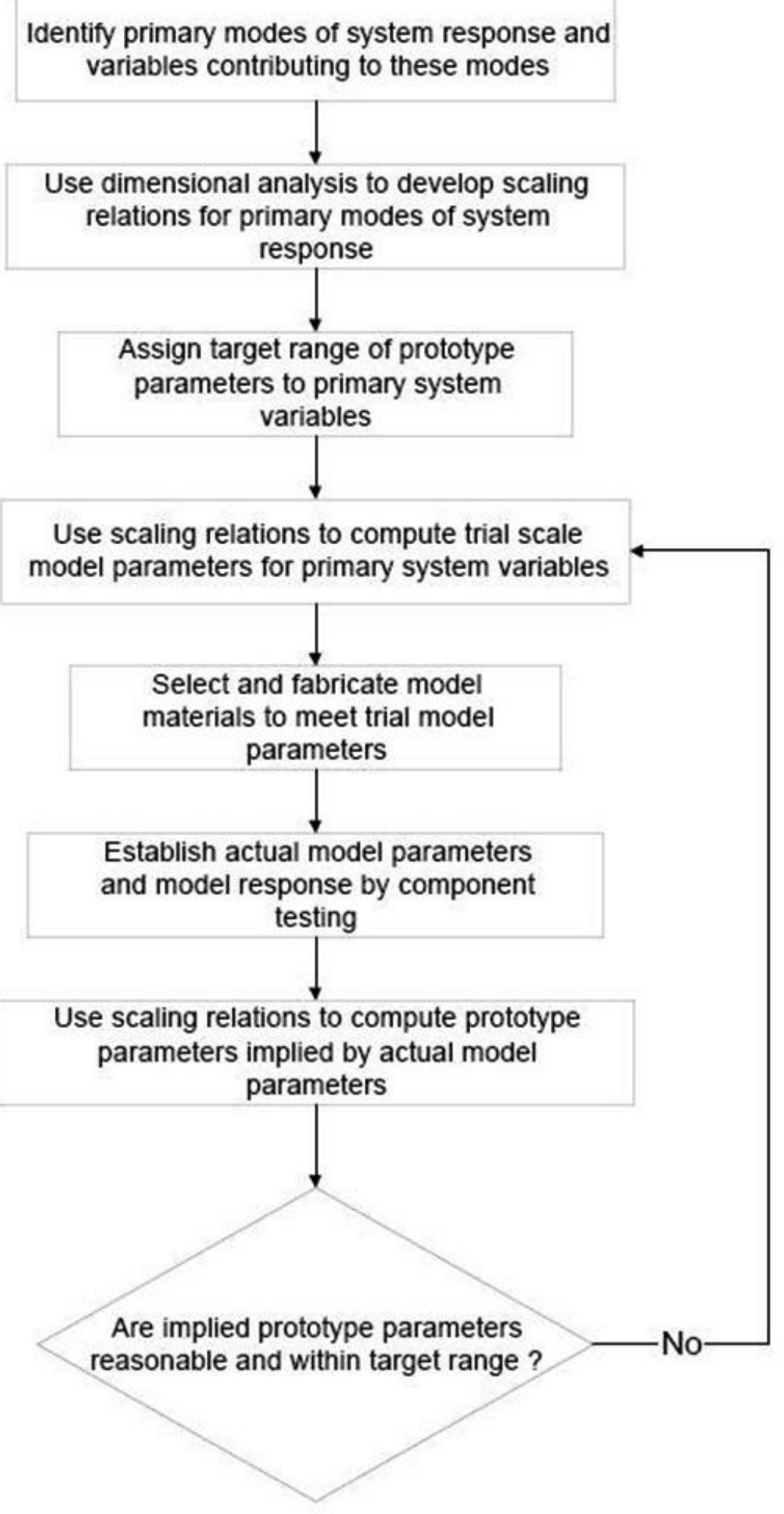

Figure 3.1: Method of implied prototype flowchart, used to develop the model soil (from Meymand 1998) 


\subsubsection{Design and Testing of Scale Model Soil}

The scale model soil used Meymand's (1998) investigation is adapted from the Berkeley recipe originally developed my Seed and Clough (1963) for shake table modeling seismic response of earth embankments. This original recipe consists of a 3 to 1 mix of kaolinite to bentonite with a water content of approximately $200 \%$. Different degrees of dynamic strength gain were observed in reference to the static strength of model and prototype soils. A 0.65 scaling factor applied to the prototype soil static shear strength to account for dynamic increase between the model and prototype soils. Similar mixes were used for investigating dynamic slope stability and fault rupture propagation.

Using the Berkeley recipe, small batches of the initial mix design were prepared for unconsolidated undrained triaxial (UUTX) and bender element shear wave velocity tests. The results of the initial soils testing indicated that for a given undrained shear strength, the corresponding shear wave velocity was too low to meet the scaled prototype criteria. Meymand (1998) included the addition of admixtures to the original recipe in order to increase the small strain dynamic stiffness (i.e., shear wave velocity) without significantly altering the soil's undrained shear strength. A number of admixtures, including fine sand, silt, and fly ash, were considered in varying proportions with varying water contents to be added to the soil mixture recipe. A byproduct of coal power generation, fly ash was the only admixture that yielded the desired results.

A number of tests went into evaluating the performance of fly ash in the soil mixture. A summary of these tests and results are presented below. 
- Meymand (1998) conducted UUTX compression test to evaluate the performance of fly ash on the mixture's undrain shear strength. Meymand observed a dependence of undrain shear strength on the mixture's water content in soils with reference $20 \%$ fly ash content by weight. Further tests, with fly ash contents ranging from $0-60 \%$, indicate that fly ash has a relatively insignificant effect on the shear strength of the model soil.

- Gruber (1996) conducted 66 UUTX tests on model soils and Bay Mud samples to determine whether the model soil response reasonably compared to prototype behavior. Both model and prototype specimens were tested under "normal" and "fast" loading rates. Gruber observed higher failure strains under fast loading for Bay Mud specimens, while the model soil failure strains remain relatively consistent under both loading rates. Under confined pressure tests, model soil behaved as a strain hardening material at both loading rates. For unconfined loading at a normal loading rate, the model soil failure stain closely resembled the failure strain of Bay Mud. Gruber concluded that although the model soil did not exactly mimic the stress-strain behavior of the prototype soil, for scale modeling of high plasticity soft clay, such as San Francisco Bay Mud, the model soil did exhibit a reasonable response.

- Wartman (1996) conducted a study to evaluate the effect of fly ash on geotechnical properties of model clay soil. Wartman noted that although 
class $\mathrm{C}$ fly ash exhibits a cementitious pozzolanic reaction with the soil mixture, no significant increases in undrained shear strength observed. The cure age and mix age of the fly ash soil mixture had little to no effect on the undrained strength. Bender elements tests were also conducted to evaluate the effect of fly ash on the shear wave velocity of the soil mixtures. Although tests show that fly ash has a strong influence on shear wave velocity and cure time, and observed slow consolidation rate indicates a relative stability of soil properties during the testing window.

Table 3-3: Comparison of soil properties of prototype Bay Mud and model soil in SSPSI investigation. (after Meymand 1998)

\begin{tabular}{|l|r|r|}
\hline Property & \multicolumn{1}{|c|}{ Bay Mud } & \multicolumn{1}{l|}{ Model } \\
\hline Saturated Unit Weight $\left(\mathrm{kN} / \mathrm{m}^{3}\right)$ & 14.80 & 14.80 \\
\hline Water Content (\%) & 99.00 & 100.00 \\
\hline Liquid Limit (\%) & 88.00 & 115.00 \\
\hline Plastic Limit (\%) & 48.00 & 40.00 \\
\hline Plasticity Index (\%) & 40.00 & 75.00 \\
\hline Coefficient of Consolidation Cv (m²/year) & 0.75 to 0.92 & $6.5 \times 10^{-3}$ \\
\hline Undrained Shear Strength (kPa) & 29 to 57 & 4.10 \\
\hline Shear Wave Velocity (m/s) & 114 to 160 & 40.00 \\
\hline
\end{tabular}

\subsubsection{Final Scale Model Soil Recipe}

For the evaluation of seismic earth pressures in this study, the prototype San Francisco Bay Mud is modeled by mixing 67.5\% kaolinite, $22.5 \%$ bentonite, and $10 \%$ class C fly ash with a water content of $125 \%$; nearly identical to the recipe used by Crosariol (2010) and Kuo (2012), after Meymand (1998). The water content in this investigation, after Crosariol and Kuo, was increased to 
$125 \%$ to accommodate the demands of pumping equipment in the lab. The specific ingredients are as follows:

- Bentonite, an American Standard 200 mesh, distributed by Scott Sales Company in Huntington Park, CA

- Kaolinite, Kamin 25, distributed by PT Hutchins 68 Company in City of Industry, CA.

- Class C fly ash, obtained from Mineral Resources Technologies.

\subsection{Development of Model Basement}

The model basement used in the current research was developed by Kuo (2012) for soil-foundation-structure-interaction (SFSI) research with the present investigation in mind. The model was initially designed to investigate the increases in damping due to dynamic soil-basement-wall interaction at varying embedment depths. However, the present research uses the model basement to investigate the development of seismic earth pressures on the model basement wall.

The primary factor in adapting the model for the present investigation is the consideration of the model basement wall to be either yielding or nonyielding. A retaining wall is considered to be yielding when the wall yields sufficiently to produce minimum active earth pressures. The basement walls used in this investigation are made of flexible acrylic sheets and also include a free edge, not pinned fixed or pinned as in some prototype basements, allowing for walls to yield. Additionally, an excessive amount of time may be required for active earth pressures to develop on the model basement wall particularly in soft 
clay. For this investigation, provisions have been made to force the soils into an active condition to accommodate the shake table testing schedule. These provisions are further discussed in Chapter 5.

\subsubsection{Materials and Configuration of Model Basement}

The scale model is based on a damped single degree-of-freedom (SDOF) system structure where the embedment depth and fundamental period of the model may be adjusted to meet the demands of the investigation. According to Kuo (2012), geometric constraints of the testing container imposed limitations of the foundation size. Boundary effects of the testing container, such as a $10 \%$ increase in maximum spectral acceleration towards the side walls as compared to that at the center, significantly influenced the placement and design of the model basement. Furthermore, Kuo sought to capture the response of both the free-field and model array simultaneously and designed the foundation dimensions appropriately.

The model basement structure consists of aluminum skeleton bolted onto a steel square mat foundation. The square $45.7 \mathrm{~cm}$ wide steel plate with $1.8 \mathrm{~cm}$ thickness was used as a heavy foundation to prevent overturning as a result of relatively large horizontal accelerations during shake table testing. The steel plate was coated with a several layers of a corrosive resistant paint to prevent rusting due the inclusion of fly ash in the soil composition. The aluminum structural frame is composed of $2.54 \mathrm{~cm}$ wide L-shaped beams riveted together to form four columns interconnected my horizontal bracings at the top, mid-height and bottom of each column. 


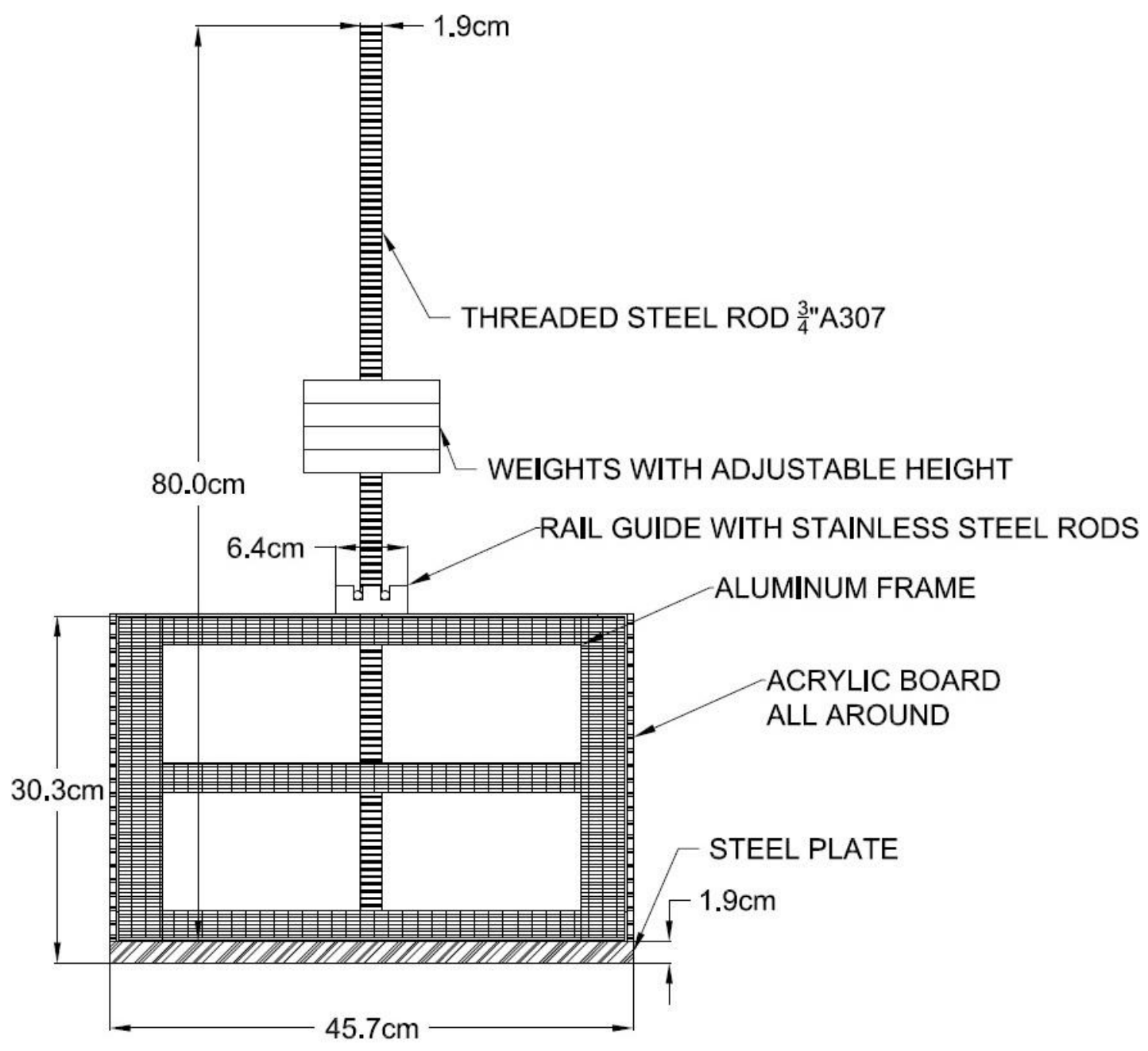

Figure 3.2: Scale model basement and materials (from Kuo 2012)

Four $30 \mathrm{~cm}$ tall acrylic boards are selected to make up the rust resistant basement walls of the model. Screws were used to fasten the acrylic boards to the horizontal aluminum bracings. Small gaps present between adjacent acrylic boards and the steel foundation were filled with silicone caulking to prevent unwanted soil material from entering the model. Silicone caulking was also used to cover exposed screws to prevent rusting. 
For the SSI component of the investigation the model also consists of a removable $1.9 \mathrm{~cm}$ diameter threaded carbon steel (A307) rod which carries a 9.1 kg SDOF lumped mass. Kuo (2012) conducted an extensive fixed base shake table study to determine the fundamental period of the structure with the lumped mass was placed at varying heights about the foundation. The lumped mass is fastened to the threaded rod with washer and hex nuts and can be adjusted to accommodate the fundamental period of the prototype structure. The threaded rod is securely fastened into a tapped hole in the center of the steel foundation.

A guide rail system was used ensure that the lumped mass was constrained to move in one direction. The guide rail system minimized errors caused by energy dissipation from any movement deviating from that of the shaking direction. Two fabricated $6.4 \mathrm{~cm}$ wide acrylic blocks with slots are attached to the top center of opposing walls of the basement model. Two stainless steel rods are placed into the slots and run parallel with the shaking direction. The stainless steel rods lay flush with a preinstalled coupling nut on the threaded rod to constrain the movement of the lumped mass. The coupling nut is lubricated to reduce contact friction and zip-ties hold the guide rails in place. 


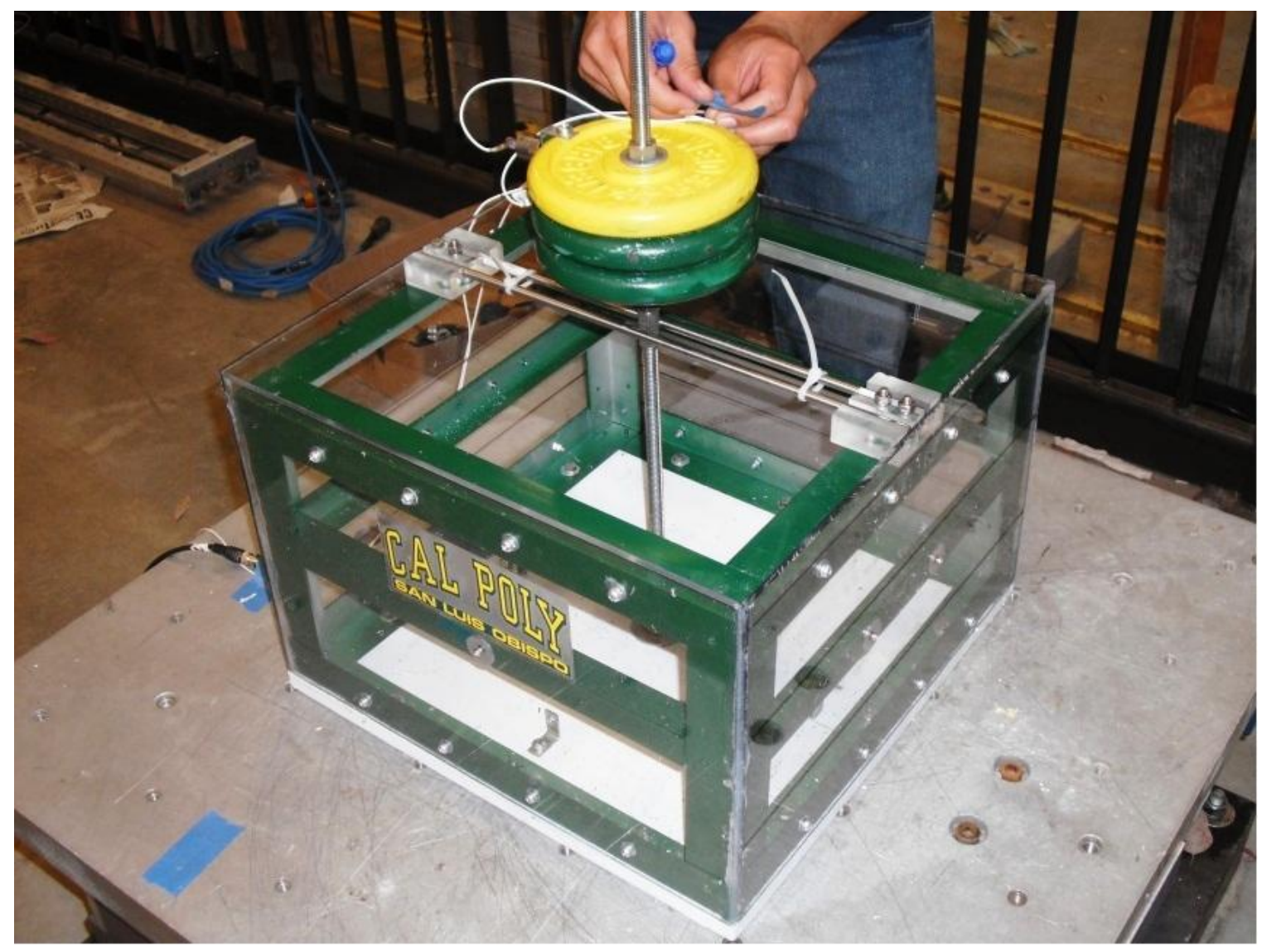

Figure 3.3: Snapshot of scale model basement with attached SDOF damped mass (from Kuo 2012)

\subsection{Scale Model Testing Apparatus}

The same testing container developed by Meymand (1998), and modified by Crosariol (2010) and Kuo (2012) is used in the current research. The flexible wall testing container is used to confine a Cylindrical column of soil while allowing for translations in horizontal directions. The flexible wall significantly decreases the influence of rigid boundary effect, allowing for the soil in the container to model free field conditions. 


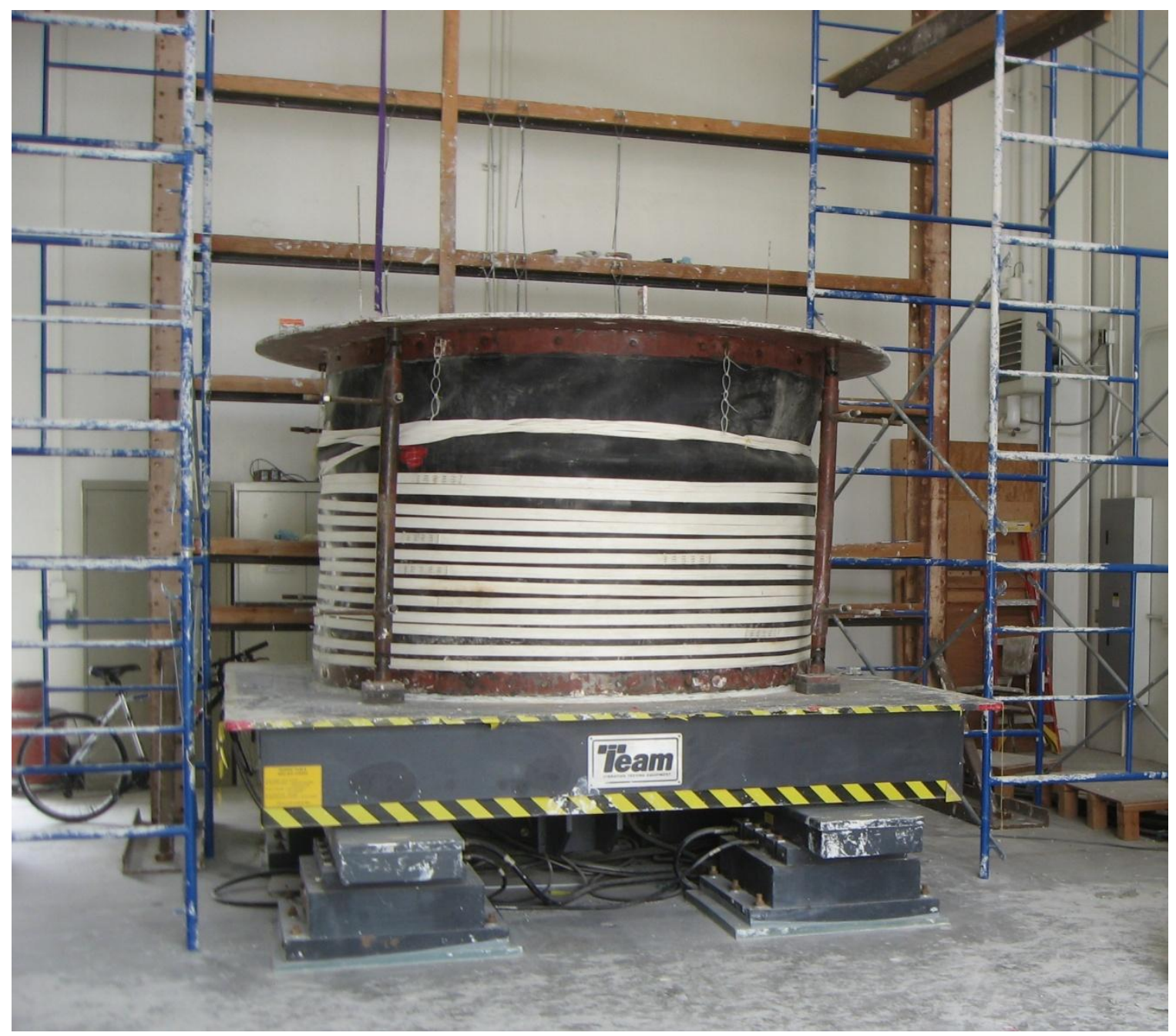

Figure 3.4: Snapshot of fully assembled flexible wall testing container

The testing apparatus makes use of an outer steel structure

interconnected with the flexible wall to maintain the cylindrical shape of the housed soil column. Four steel columns provide support for a circular steel ring at the top of testing container and a steel base plate makes up the floor of the system. The heavy steel columns are fabricated from steel tubes with an outer diameter of $73 \mathrm{~mm}$ containing universal joins on each end. The top ring and the base plate, fabricated from $16 \mathrm{~mm}$ thick steel, are the two locations where the flexible wall connects to the steel structure. 
The freedom of motion that the universal joints provide the testing container requires the use of steel cross braces to prevent movement during the assembly of the testing container. The cross braces are then removed during testing, returning the freedom of motion to the system. The steel cross braces are mounted diagonally connecting adjacent columns using threaded rods extending outward from each column. The steel columns are securely fastened to "base adapters" which are then directly connected to the shake table. Crosariol (2010) fabricated these "base adapters" from $51 \mathrm{~mm}$ thick by $150 \mathrm{~mm}$ by $150 \mathrm{~mm}$ steel blocks for compatibility with the shake table. Additional modifications were made to the steel columns, from the original design, in order to meet the lower weight restrictions of the Cal Poly shake table. Remnants of an epoxy and gravel mix used in Crosariol (2010) and Kuo (2012) exists on the top surface of the base plate for an increase in friction between the model soil and the base plate during testing.

The flexible wall, composed of a $6.4 \mathrm{~mm}$ rubber membrane, provides the primary soil confinement of the system. The membrane was bolted between the top ring and base plate using two piece compression rings. The rubber membrane was fabricated from a single neoprene sheet where the ends were fastened together with a single vertical seam to form an open ended cylinder. The neoprene membrane also serves as a watertight testing container, suitable for saturated soils. During the assembly of the testing container, cracks and crevices that interfaced with the rubber membrane were thoroughly caulked with silicone caulking to prevent the leaking of water. Further confinement for the 
model soil is provided by a set of sixteen $45 \mathrm{~mm}$ wide woven fiber bands placed around the circumference of the rubber membrane. These fiber bands, tested at a minimum breaking strength of $11,000 \mathrm{lbs}$, are designed to carry hoop stresses and limit bulging of the rubbers membrane.

The exterior compression rings, consisting of $55 \mathrm{~mm}$ thick and $105 \mathrm{~mm}$ wide steel bands, are welded to the inner circumference of the top ring and the outer edge of the base plate. Semicircle bands, two for the top ring and two for the base plate, form the internal components of the compression rings system. Additionally, twelve $150 \mathrm{~mm}$ wide textured geomembrane strips (40 mil GSE HyperFriction Flex) are hung from the top ring down to the base plate. Meymand (1998) explains that these strips "provide provide a path for complementary shear stresses developed in the soil to be carried in the container. "

Extensive testing and research went into the development of the testing container at UC Berkeley. A suit of tests and analyses were performed to evaluate the material requirements for the design and the distribution of stresses on the container. Analysis and testing details for the container are found in Meymand (1998)'s study. For the current testing system, the replacement neoprene membrane and the woven fiber bands were selected such that they closely match the original material specifications and therefore suitable for the research. This was done in order to retain the confidence in the testing container used at Cal Poly. 


\subsection{Selection of Input Motions}

The ground motion selected for this research are selected after work done by Crosariol (2010) and Kuo (2012) in order to incorporate a variety of large seismic loads to this shake table testing program.

Table 3-4: List of seven input ground motions used in this study

\begin{tabular}{|l|l|l|l|r|}
\hline Earthquake & Station Name & Prefix & Date & Magnitude \\
\hline Landers & 22170 Joshua Tree & JOS & $6 / 28 / 1992$ & 7.3 \\
\hline Imperial Valley & 117 el Centro Array \#9 & ELC & $5 / 19 / 1940$ & 6.9 \\
\hline Chi Chi & TCU75 & TCU & $9 / 20 / 1999$ & 7.6 \\
\hline Imperial Valley & Superstition Mtn. Camera & IPV & $10 / 15 / 1979$ & 6.5 \\
\hline Loma Prieta & Los Gatos Presentation C. & LGP & $10 / 18 / 1989$ & 6.9 \\
\hline $\begin{array}{l}\text { Cape } \\
\text { Mendocino }\end{array}$ & Cape Mendocino & CPM & $4 / 25 / 1992$ & 7.1 \\
\hline Northridge & Lake Hughes \#9 & LO9 & $1 / 17 / 1994$ & 6.7 \\
\hline
\end{tabular}

A total of seven ground motions were selected for this testing program.

The first three ground motions are selected after Crosariol's USSSI investigations and the remaining four ground motions are selected after Kuo's SFSI research to provide comparable testing data and performance validation of the flexible wall testing container. For each motion, both the horizontal azimuths are included in this study for a total of 14 input ground motions.

To meet the requirements of the similitude scaling relation, the recorded ground motions must also be scaled to provide the appropriate dynamic response. According to similitude scaling criteria, time is scaled at $\lambda^{0.5}$. Therefore, the time step for each of the ground motions care compressed to $\Delta t / \lambda^{0.5}$. With a $\lambda=10$, the time step of the ground motions are compressed by a factor of 3.16 . The motions used in this testing program were recorded at the ground surface 
but are intended to serve as a base motion for shake table testing. In order to account for this differentiation the motions are corrected for full ground reflection by subtracting out the full reflection of an "outcrop" motion to create a "within" motion through deconvolution. The scaled input motions are presented below.
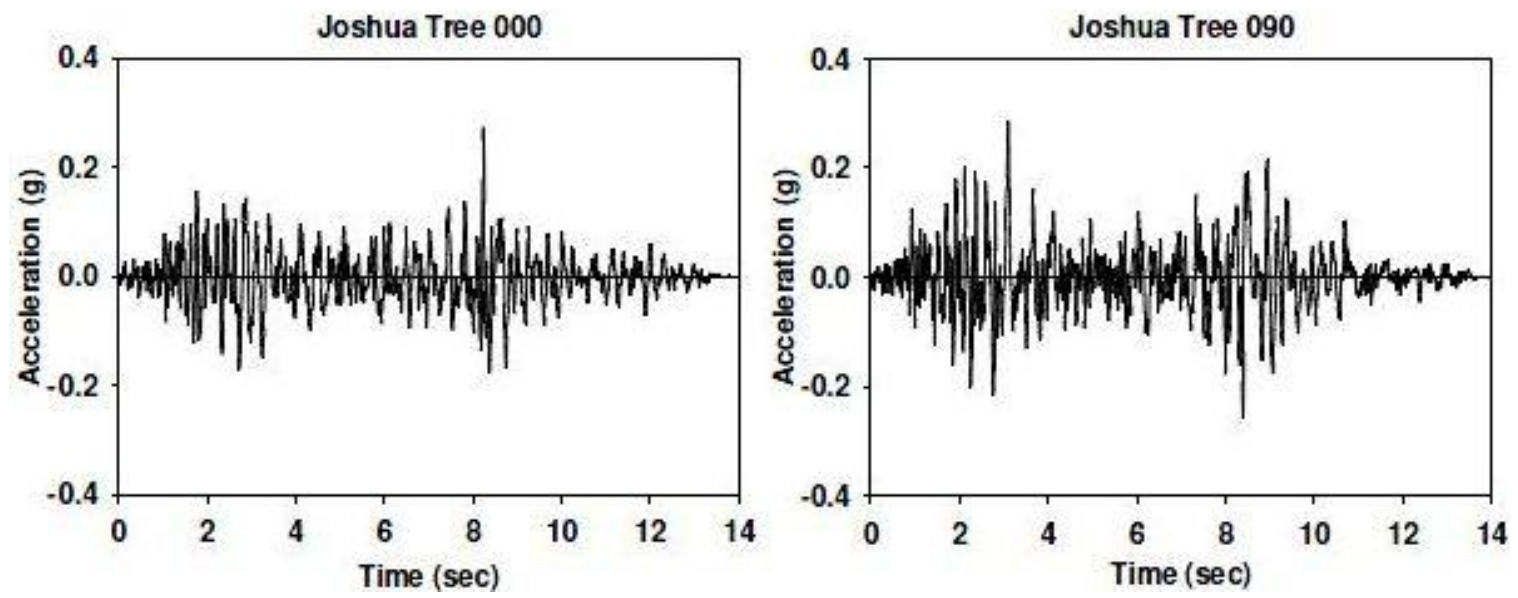

Figure 3.5: Scaled horizontal azimuths of the Joshua Tree motion for the 1992 Lander earthquake with compressed time step by $\lambda^{0.5}$
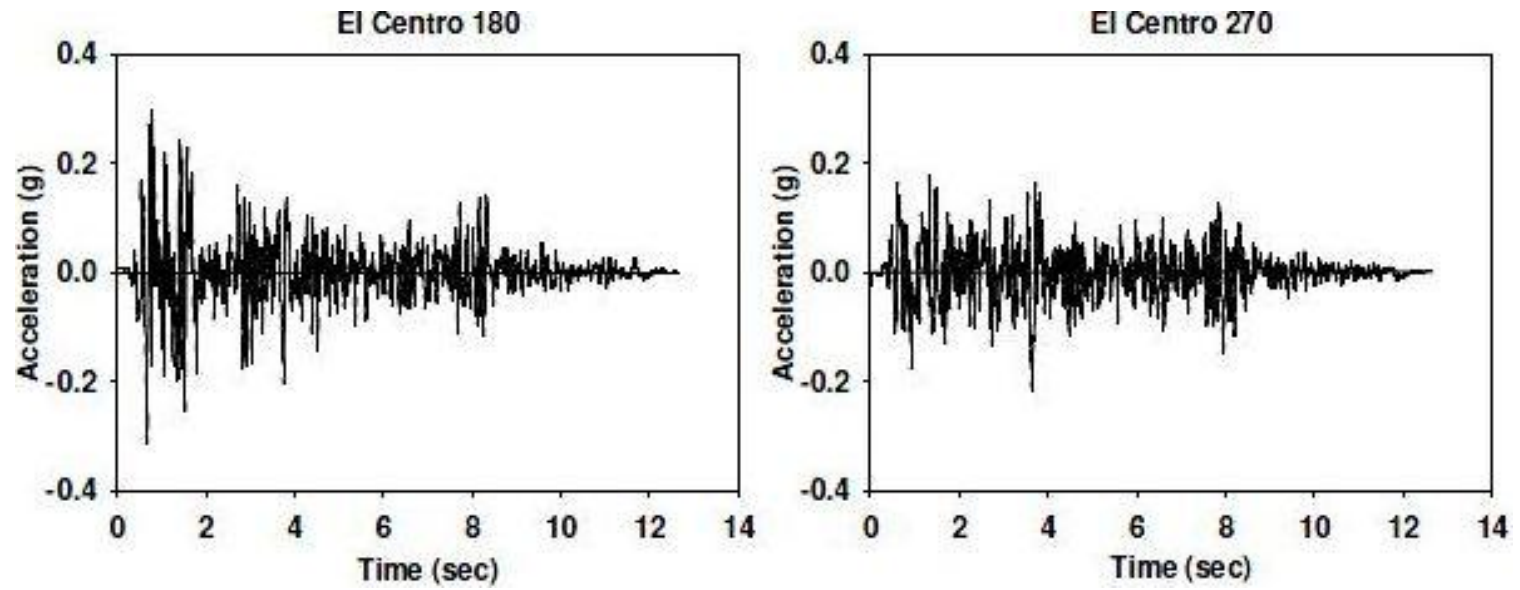

Figure 3.6: Scaled horizontal azimuths of the El Centro motion for the 1940 Imperial Valley earthquake with compressed time step by $\lambda^{0.5}$ 

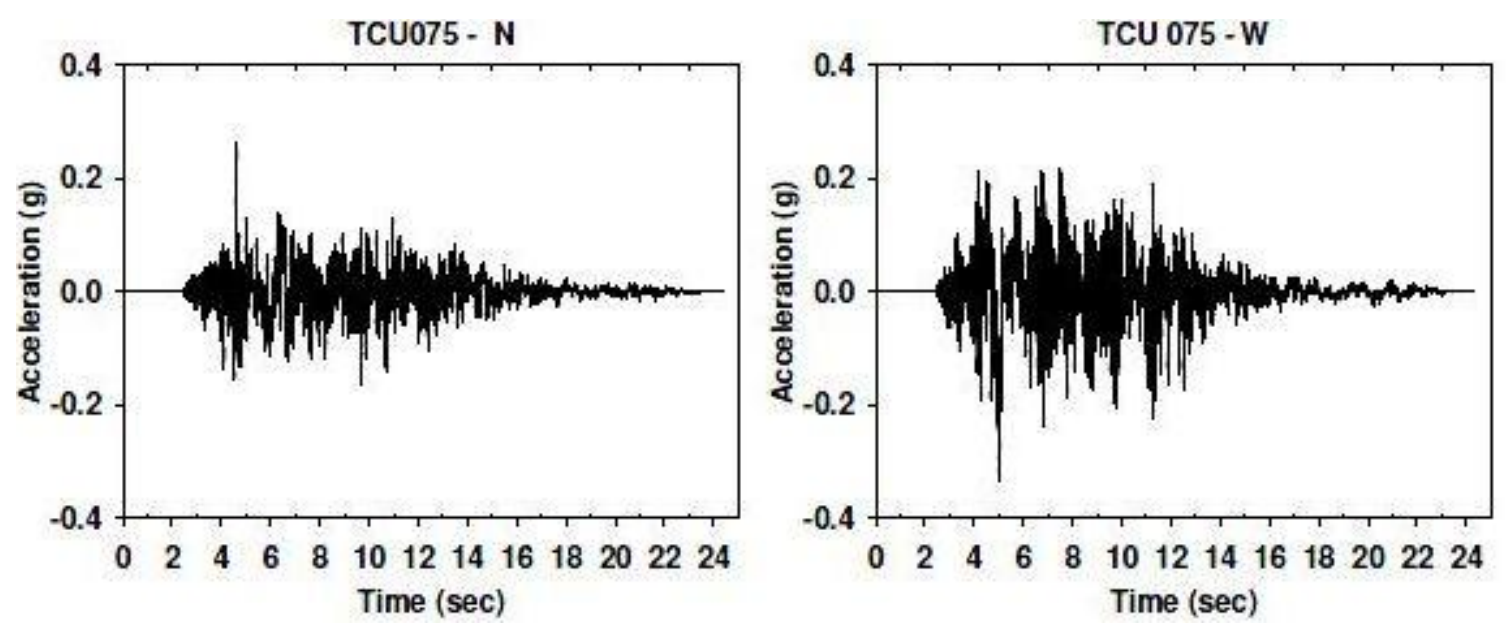

Figure 3.7: Scaled horizontal azimuths of the TCU075 motion for the 1999 Chi Chi earthquake with compressed time step by $\lambda^{0.5}$
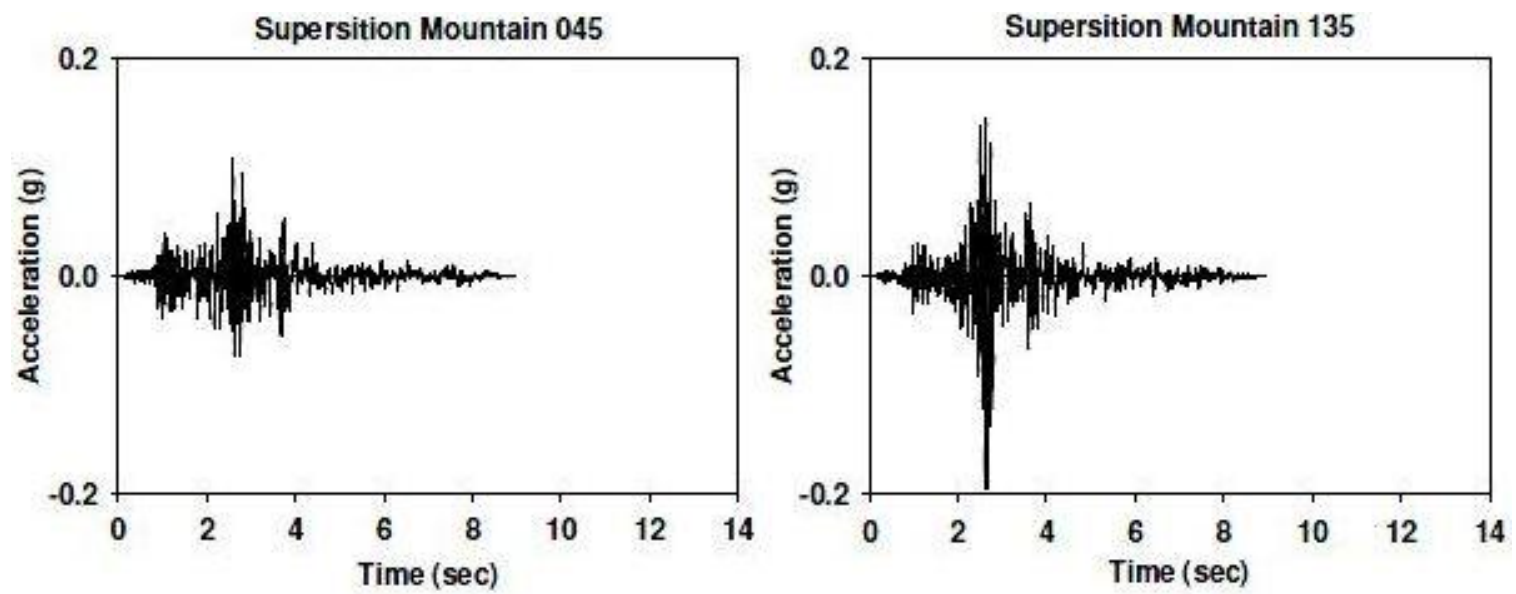

Figure 3.8: Scaled horizontal azimuths of the Superstition Mountain motion for $b$ the 1979 Imperial Valley earthquake with compressed time step by $\lambda^{0.5}$ 

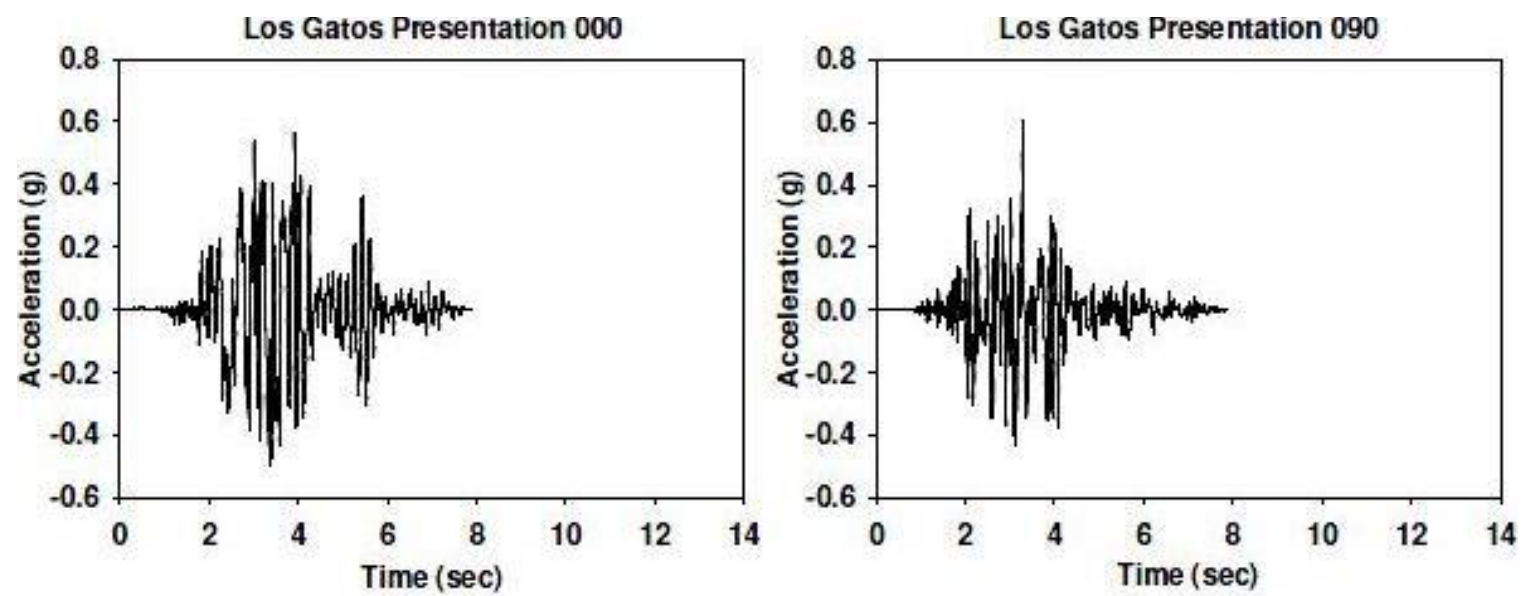

Figure 3.9: Scaled horizontal azimuths of the Los Gatos Presentation motion for the 1989 Loma Preita earthquake with compressed time step by $\lambda^{0.5}$
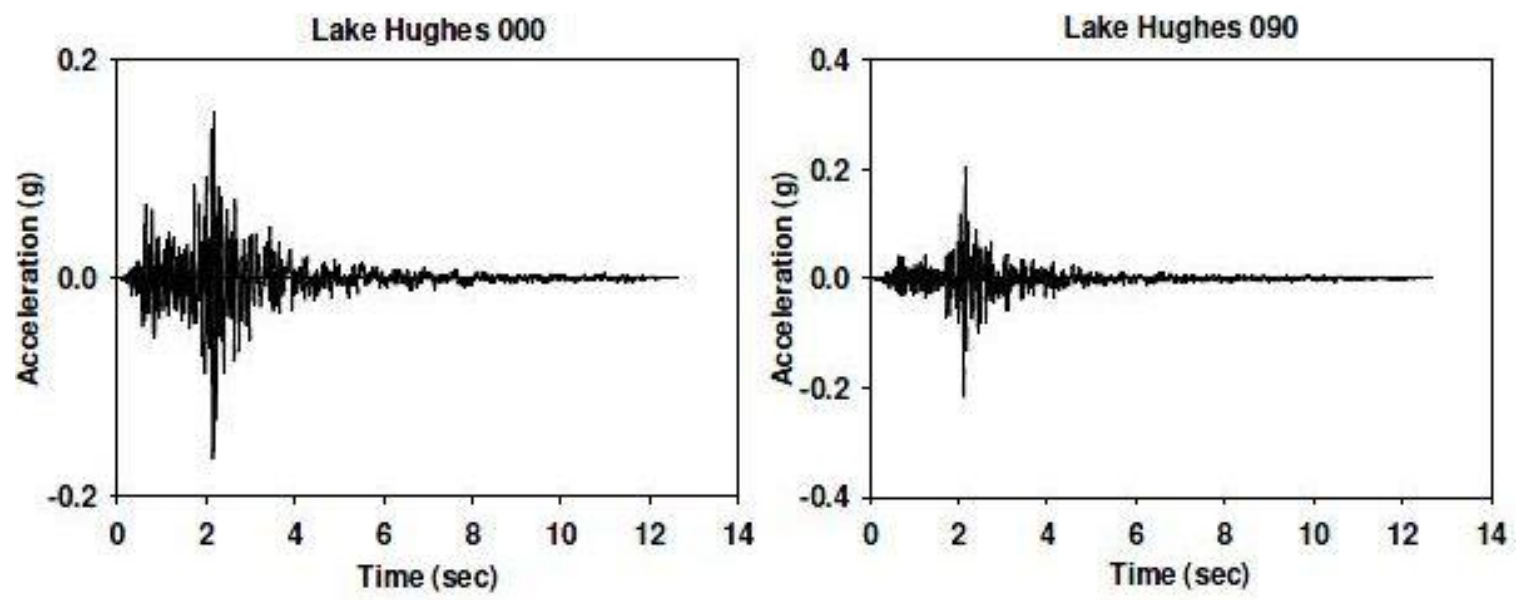

Figure 3.10: Scaled horizontal azimuths of the Lake Hughes motion for the 1994 Northridge earthquake with compressed time step by $\lambda^{0.5}$ 

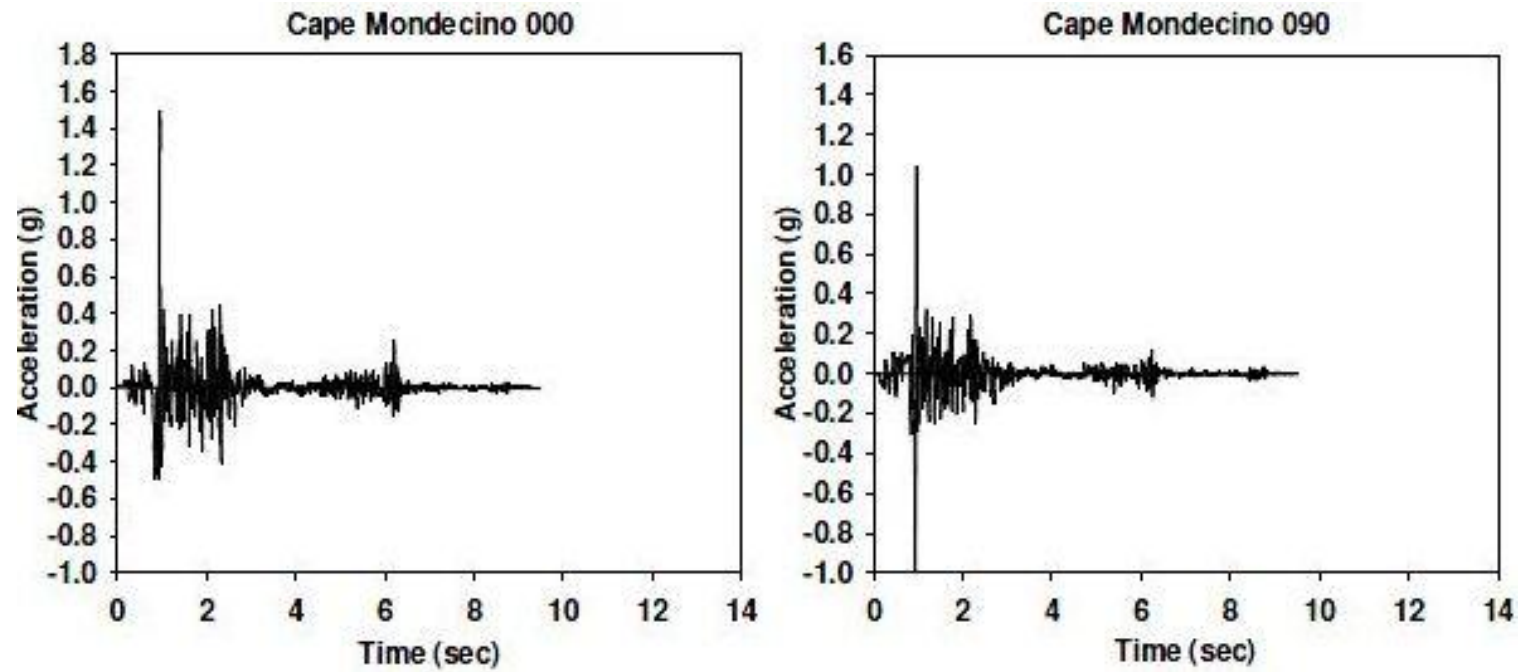

Figure 3.11: Scaled horizontal azimuths of the Cape Mendocino motion for the 1992 Cape Mendocino earthquake with compressed time step by $\lambda^{0.5}$ 
Chapter 4 - Pressure Sensor Testing and Investigation

\subsection{Introduction}

In order to perform the necessary investigations to collect and observe empirical data on the subject of seismic earth pressures on basement and retaining structures in soft clay, appropriate pressure sensors first needed to be identified and evaluated to determine their suitability for the testing regimen. The use of tactile pressure sensors have been used similar research experiments (Al Atik and Sitar 2007, Palmer et al 2009) and have been also been selected for the current research. Certain requirements were considered in the selection of the pressure sensors listed below.

- The sensors needed to be able to report pressure readings at a frequency of $400 \mathrm{~Hz}$, the predetermined time step for acceleration measurements.

- The pressure sensors needed to be compatible with the current data acquisition.

- Due to the corrosive nature of the model soil, corrosive resistive/ water protective provisions were also considered to protect the pressure sensor. This chapter explores the investigation and testing of two such pressure sensors to measure both static and dynamic earth pressures

\subsection{Sensor Products Inc. - Tactilus Free Form Pressure Sensors}

Tactilus Free Form sensors were selected to for investigation in order to determine the sensors compatibility and performance with available equipment. 
Tactilus Free Form sensors are flexible tactile surface pressure sensors that allow for the measurement of pressures at precise locations without the constraint of a pressure sensing matrix such as that in pressure sensor skins.

Table 4-1: Tactilus Free Form Specifications

\begin{tabular}{|l|l|}
\hline \multicolumn{2}{|c|}{ Sensor Specifications } \\
\hline Technology & Resistive \\
\hline Pressure Range & $0-200$ PSI $\left(0-14.1 \mathrm{~kg} / \mathrm{cm}^{2}\right)$ \\
\hline Dimensions & $4 \mathrm{~mm}$ to $44 \mathrm{~mm}$ \\
\hline Thickness & From 14 mils \\
\hline Durability & Up to 1000 uses \\
\hline Recommend Current & $5 \mathrm{~mA}$ \\
\hline Supply Voltage & $3-6 \mathrm{VDC}$ \\
\hline Temperature Range & $0^{\circ}$ to $113^{\circ} \mathrm{F}\left(0^{\circ}\right.$ to $\left.45^{\prime} \mathrm{C}\right)$ \\
\hline Spatial Resolution & Custom \\
\hline Scan Speed & 100 hertz \\
\hline
\end{tabular}

\subsubsection{Development of Intermediary Circuit}

Tactilus Free Form pressure sensors can be simplified as a variable resistor for circuit analysis. Initially these sensors exhibit incredibly high resistances when no load is applied. As pressure is applied to the sensing surface, the internal resistance of the sensor begins to changes from high to low, where lower resistances indicate higher pressures. A calibration curve that correlates the change in resistance with the applied pressure is supplied by the manufacturer.

Despite the simplicity of measuring the changes in resistance as they correlate to pressure, the data acquisition system used for this research is constrained to acquiring data in terms of a voltage change. This constraint 
prompted the development of an intermediary circuit to ultimately convert the change in resistance, due to an applied pressure to the sensor, to a change in voltage.

After further investigation, a circuit diagram, as proposed by Tekscan (Tekscan 2010 for driving their FlexiForce piezoresistive sensing device, was selected to facilitate the creation of the intermediary circuit. This circuit is driven by a $-5 \mathrm{~V} D C$ excitation voltage and uses an inverting operational amplifier to produce an output based on the sensor's resistance.

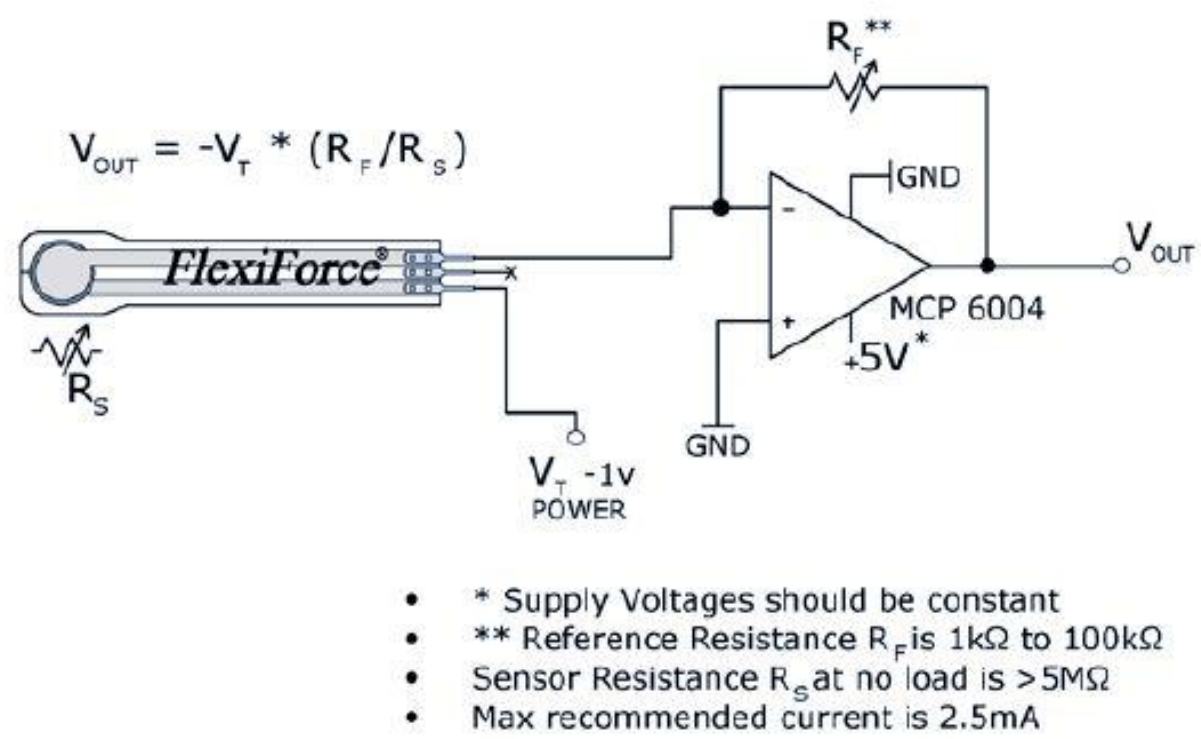

Figure 4.1: Circuit Diagram as Proposed by Tekscan

A solderless breadboard was selected as a platform to create the intermediary circuit prototype. An integrated circuit created my Mirochip (Microchip 2009), model MCP6004, contains four embedded operational amplifiers to be used as needed to facilitate multiple pressure sensors. A 9V 
battery was used in conjunction with a voltage regulator to supply the required $5 \mathrm{~V}$ to power the integrated circuit. Capacitors were also included to maximize the stability of the regulated $5 \mathrm{~V}$ output. A dedicated voltage source was used to supply the $-0.5 \mathrm{~V}$ input voltage and a constant reference resistance $\left(R_{F}\right)$ of 100 $\mathrm{k} \Omega$ was used, as recommended, for greater sensitivity.

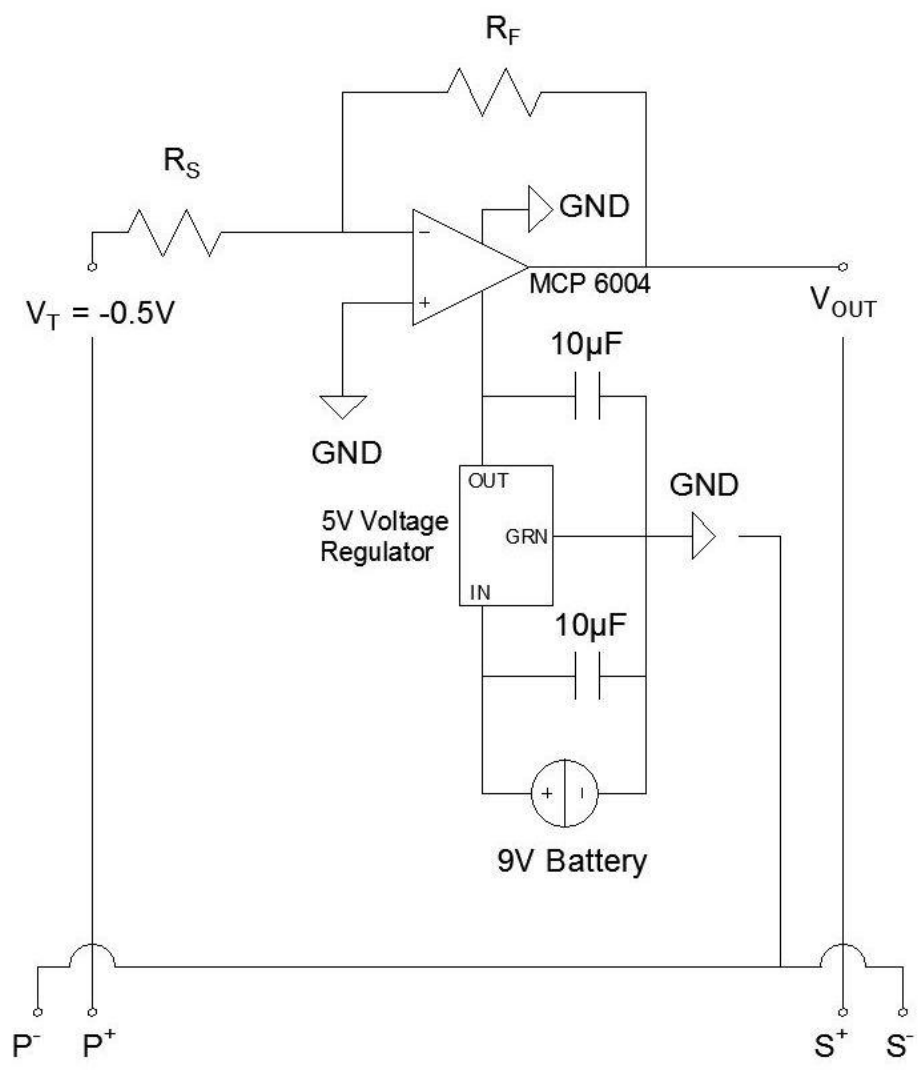

Figure 4.2: Intermediary Circuit Diagram and connection to Data Acquisition System

\subsubsection{Development of Calibration Curve}

The Tactilus Free Form sensors are supplied with a manufacturer produced table that correlates the applied pressure to output resistance. However, the data acquisition system used for this experiment requires a 
calibration curve that correlates applied pressure to output voltage. As previously mentioned, the Tactilus Free Form sensor can be simplified as variable resistor, where change in resistance corresponds to a change in applied pressure. Using a multimeter to measure the output voltage of the circuit, known resistances were used in place of the pressure sensor to plot a curve that graphs the relationship between the input change in resistance and the output voltage of the circuit. A suite of 16 known resistances, ranging from around $12 \mathrm{k} \Omega$ to about $215 \mathrm{k} \Omega$, were used to develop correlation between input resistances and output voltage.

Equations developed to characterize both the Pressure to Resistance curve and the Resistance to Voltage curve were combined and derive a curve that correlates input pressure with output voltage.

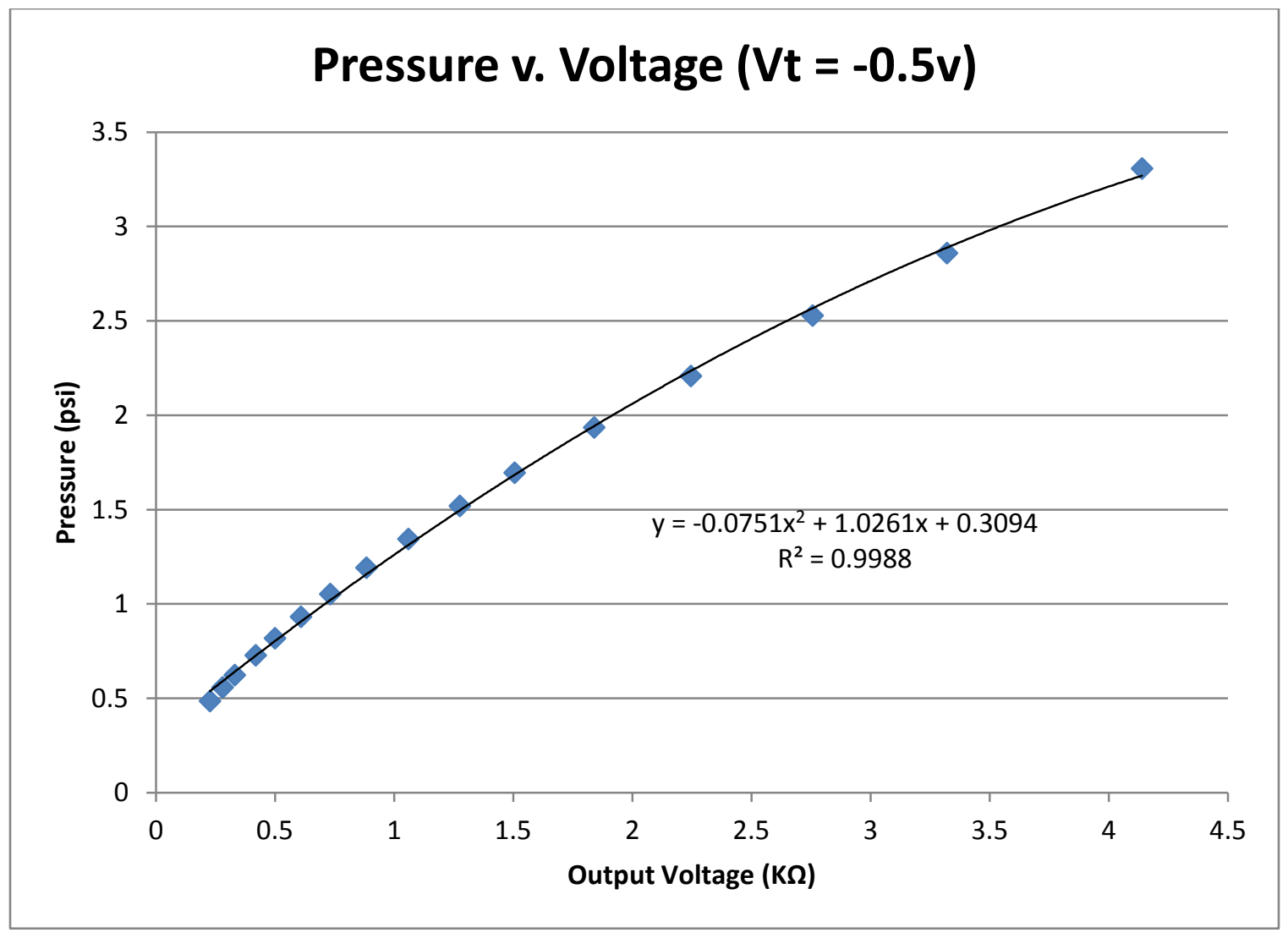

Figure 4.3: Derived Calibration Curve (Pressure V. Voltage) 


\subsubsection{Protective Sleeve}

As previously mentioned, the clay soil used in the experiment is a mixture of kaoline and bentonite with the addition of fly ash for soil strength. Furthermore, the addition fly ash to the soil mixture turns the clay soil into a caustic clay soil, adding the potential to seriously damage unprotected equipment. While running the shake table, the pressure sensors would be exposed to not only caustic material, but also moisture and the effects of dynamic motion, which could damage or compromise the sensor's readings if not properly protected. Therefore, the development of a protective sleeve was a necessary component for the investigation and testing of these pressure sensors.

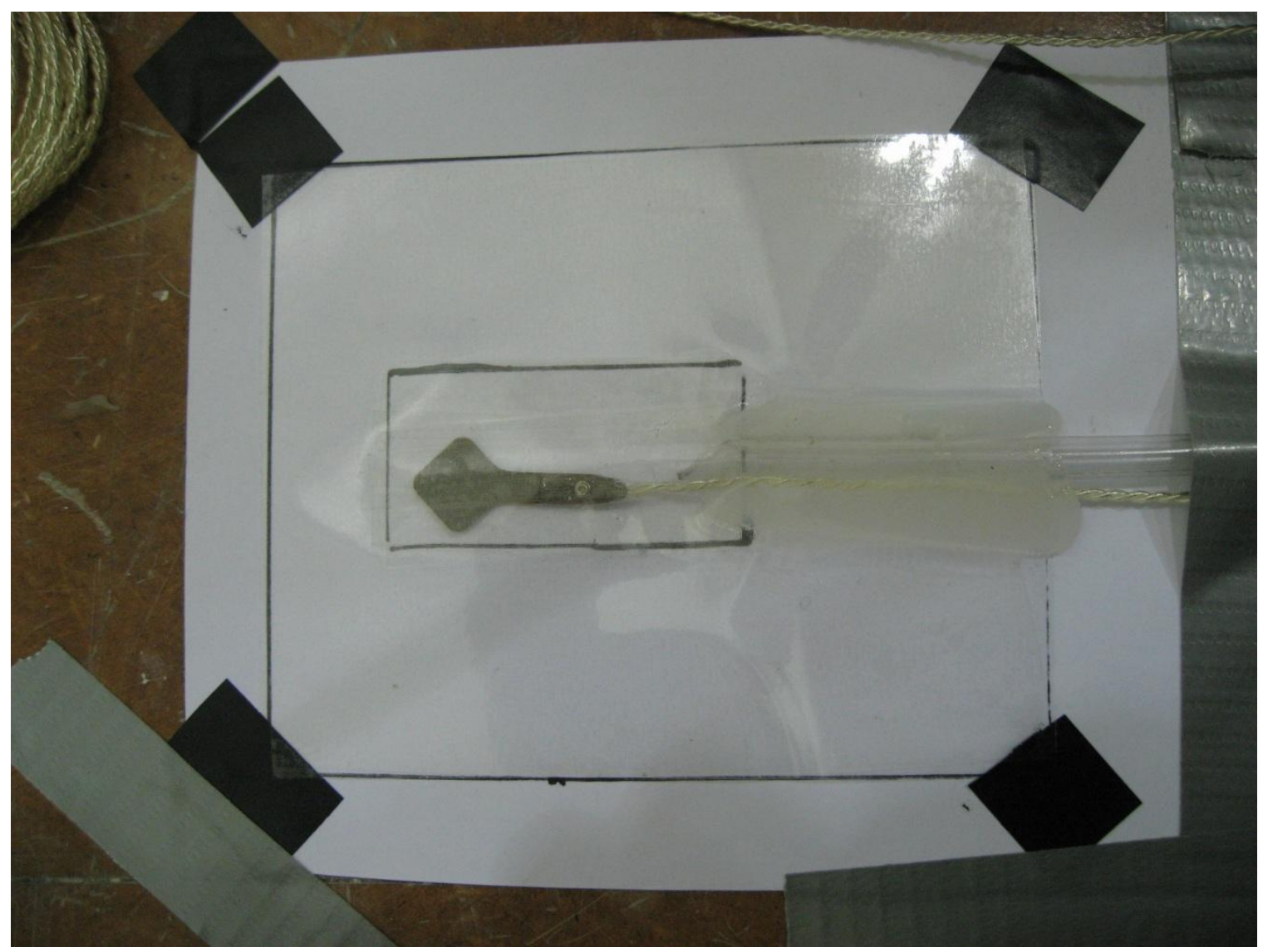

Figure 4.4: Pressure Sensor within Protective Sleeve 
The protective sleeves were created by overlaying a self-adhesive laminating sheet upon another, the adhesive end of one to the adhesive end of another, with a small pocket in the center to house the pressure sensor. The pocket was created using a single sided adhesive tape to adhere to the laminating sheet to create non-stick region within the laminating sheet matrix. A relatively small diameter plastic tube accompanies the pressure sensor within the small pocket to allow air to flow out of the pocket and to prevent the formation of an air bubble which could affect pressure readings. Silicone caulking was used to ensure a tight seal around the wire and tubing to prevent unwanted material from getting inside. Finally, the newly 'wrapped' sensor was allowed three days for the caulking to dry before being used for testing.

\subsubsection{Pressure Verification}

Although these tactile pressure sensors are supplied with a calibration curve provided by their manufacturer, a secondary source of verification was required to ensure that the pressure readings presented by the data acquisition system are actual pressures being applied to the sensor. The difficulty with verifying the pressures readings of the sensor has been the issue of applying a known pressure over the sensing area to a high level of accuracy. Using the protective sleeve discussed in the previous section, the pressure sensors were submerged into a known depth of water. Since water pressure increases linearly with depth, submerging the protected pressure sensor into known depth of water would apply a known pressure to the pressure sensor. The discrepancy between 
the data acquisition system's output and the applied pressure was corrected to for the experiment.

\subsubsection{Testing Results - Tactilus Free Form}

The Tactilus Free Form sensor yielded fluctuating and nonrepeatable pressure readings. When touched, the Tactilus Free Form generates a spike on the display of the data acquisition system. Relatively gentle pressures result in smaller spikes and relatively firm pressures generate larger spikes. At first glance, the Tactilus Free Form sensor behaves just as expected, however when submerged to a known depth of water to verify the pressure readings, the sensor was observed to record wild fluctuation without converging on a single pressure. The intermediary circuit was thought to be the issue, but directly connecting the pressure sensor to a multimeter showed similar fluctuations in resistance. Based on these results, an alternative pressure sensor was decided upon for current research.

\subsection{Pressure Profile Systems - ConTacts Discrete Tactile Sensors}

In light of the poor performance observed through experimentation with the Tactilus Free Form sensors, ConTacts tactile pressure sensors were selected for testing and investigation. Pressure Profile Systems (PP) offers conformable testing squares that can be used for a wide variety of applications. PPS asserts that their tactile pressure sensors can accommodate moderate flexing without compromising the sensors performance. Unlike the Tactilus Free Form sensors, which required an intermediary circuit to connect to the data acquisition system, 
ConTact's by PPS is supplied with their C500 signal conditioning system to drive each sensor. The C500 has three terminals designated POWER, OUT, and GROUND which can easily connect to the data acquisition system used in this experiment.

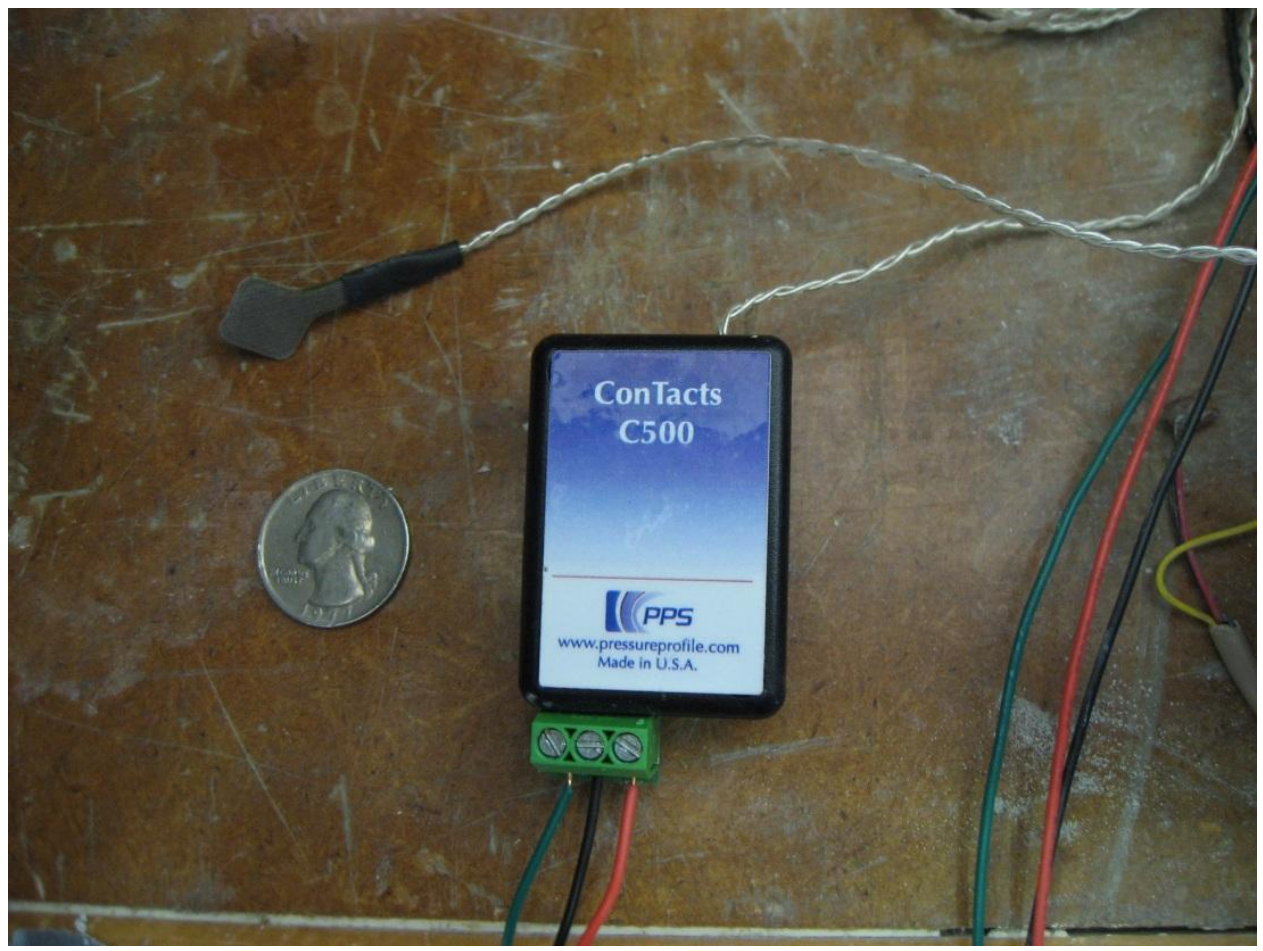

Figure 4.5: ConTacts Pressure Sensor with C500 Signal Conditioning Unit

\subsubsection{Protective Sleeve}

As described earlier in this chapter, a water protective sleeve is necessary to prevent corrosion and moisture from adversely affecting the sensing devise. To that end, similar provisions have been made to ensure that ConTact pressure sensor is adequately protected. 


\subsubsection{Development of Sensor Specific Calibration Curve}

Although each ConTact pressure sensor is supplied with a manufacturer produced calibration curve, the calibration curve does not take into account the possible interference of the protective sleeve on the pressure reading. A test to verify the pressure reading was needed in order to confirm that the sensors behave as expected.

These pressure sensors were submerged into water in order to develop a sensor specific calibration curves. The pressure sensor was first mounted onto a meter stick to provide better control and ease of measurement during the dipping process. Four dips were recorded for each pressure sensor, where pressure readings were recorded every five centimeters up to a total depth of $80 \mathrm{~cm}$. The recorded pressure readings from each depth were averaged together to generalize variation at each location. Comparisons were made between the pressures applied to the sensor and the pressures reported by the data acquisition system. Correction factors were then computed to recalibrate each sensor for the current application.

\subsubsection{Testing Results - ConTacts Tactile Pressure Sensors}

Upon first dipping into a known depth of water for pressure verification, an immediate difference was observed in comparison to the Tactilus Free Form sensors. Instead of random fluctuations, ConTacts pressure sensor a reported pressure readings with more stability. Multiple tests showed consistent and repeatable pressure readings. Although the pressure readings initially show a larger recorded pressure than expected, once corrected, the pressure sensors 
report a linear pressure increase with depth of water, as expected (Figure 4.6). Corrected pressure reading plots are provided in Appendix A. The results of this pressure sensor investigation have prompted the purchase and use of PPS's ConTact tactile pressure sensors for the current research.

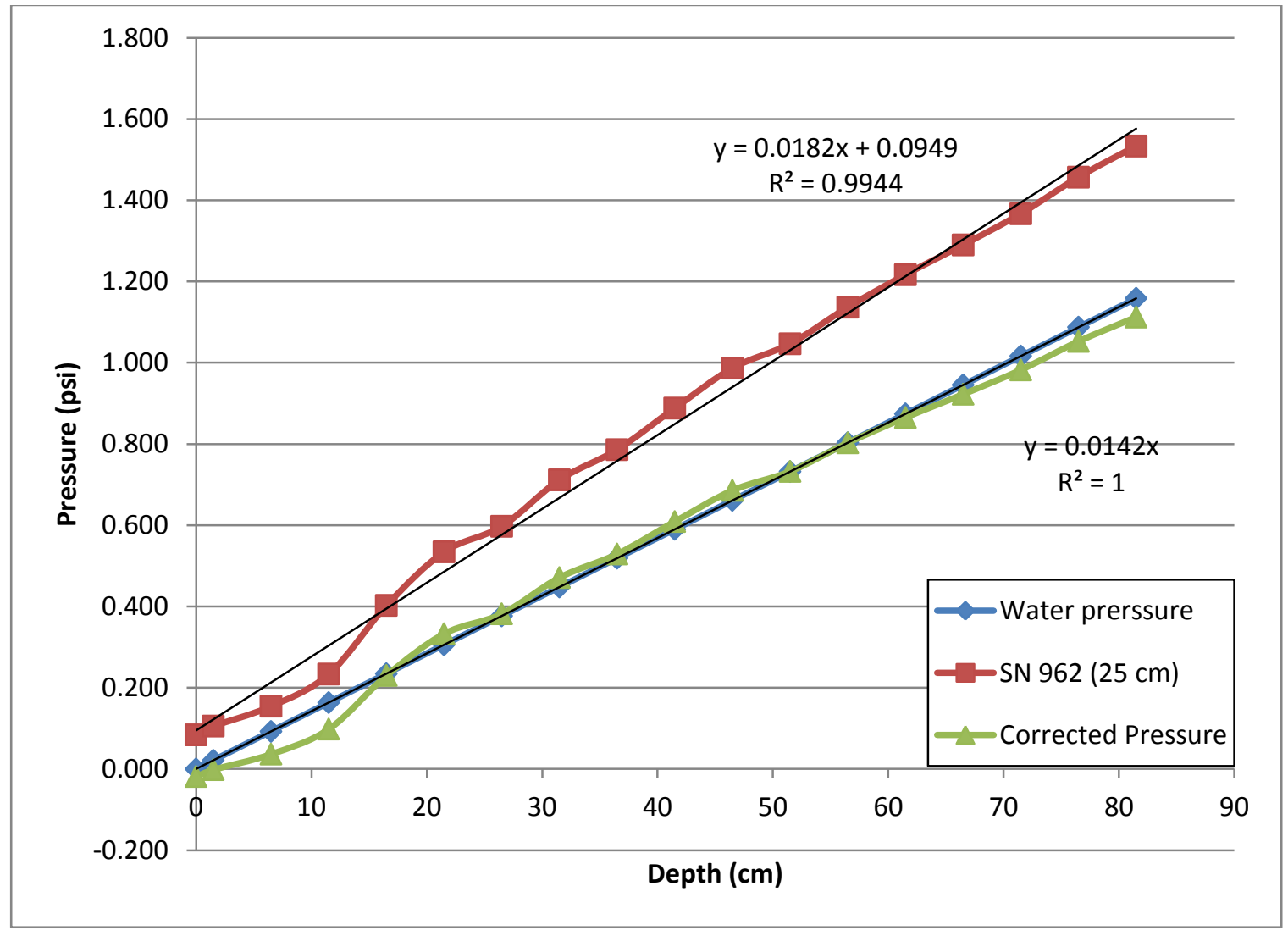

Figure 4.6: Recorded and Corrected Pressure Reading of Sensor 962 
Chapter 5 - Experimental Setup and Instrumentation

\subsection{Introduction}

This chapter describes the experimental preparation for the shake table investigations conducted in this study. Much of the initial testing container setup is adapted after shake table investigations by Crosariol (2010), who first adapted the experimental equipment and setup procedures for use at the Cal Poly facility.

\subsection{Shake Table Testing Facility}

The Parson's Earthquake and Geotechnical Engineering Laboratory is the primary facility where much of the testing and investigation for this study was conducted. This laboratory houses most of the equipment used in this investigation including the shake table, hydraulic controls, shake table controls, data acquisition system, and the overhead crane. The shake table is manufactured by the Team Corporation. It consists of a 3 by 3 meter testing surface and can carry a maximum payload of $9000 \mathrm{~kg}$. The shake table's total dynamic stroke is $26.7 \mathrm{~cm}$ and operates between the frequency range of 0.1 to $50 \mathrm{~Hz}$. 


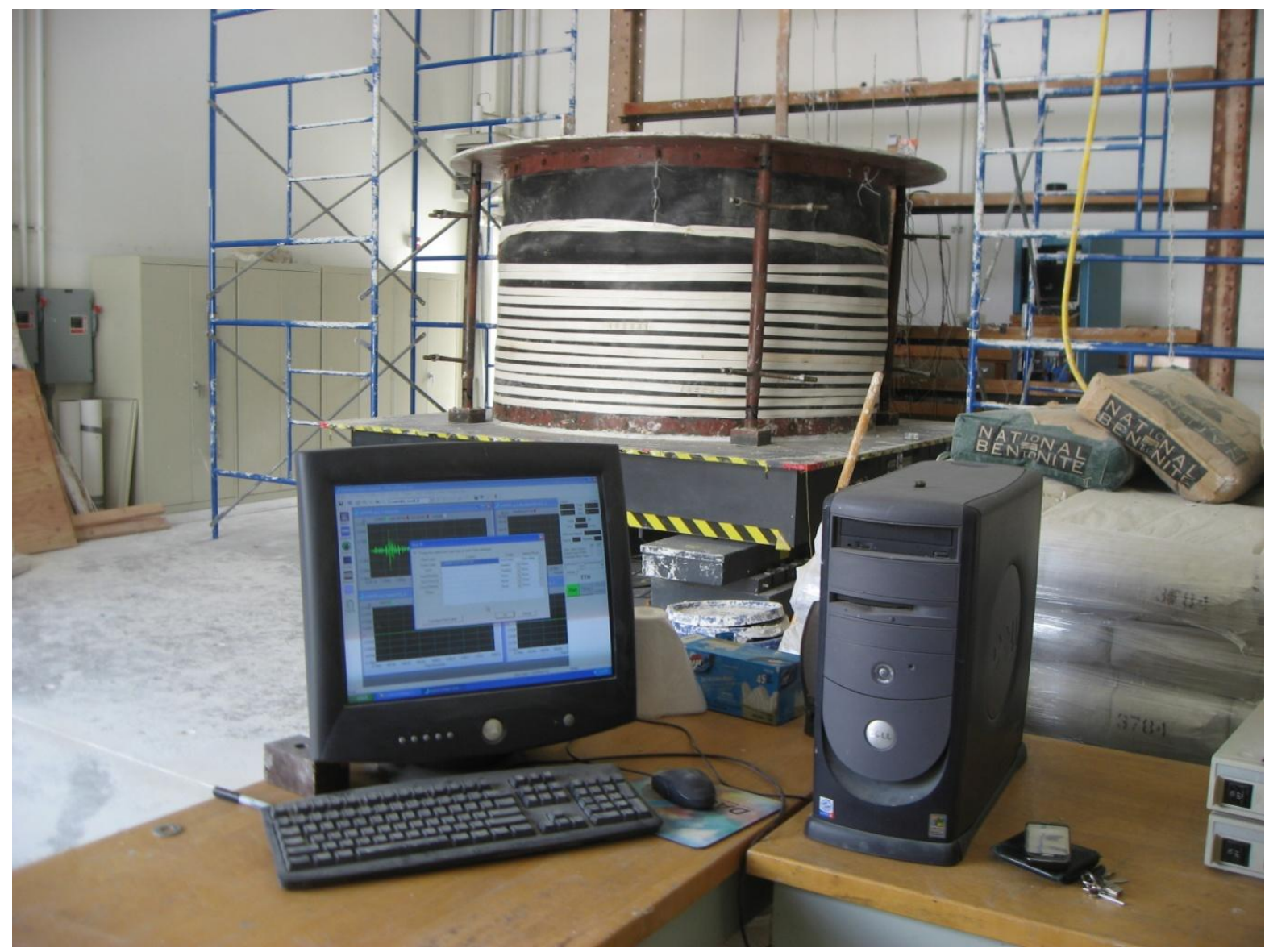

Figure 5.1: Parson's Earthquake and Geotechnical Engineering Laboratory

The shake table actuators that can produce a dynamic force of $169 \mathrm{kN}$ under the maximum payload capacity of the table. These actuators are powered by a 60 hp hydraulic power supply (HPS) unit. The Team HPS 2200 valve driver, which controls the positioning of the actuator, works together with the Dactron shaker control unit to drive the shake table during testing. The PCB Piezotronics model 482A22 signal conditioner handles table accelerations detected by a single PCB model 353B52 ICP accelerometer mounted on the shake table. Furthermore, shake table operations are controlled on a PC installed with 
Dactron Shaker Control Laser software which can permit the input of any motion, so long as the motion fits within the dynamic limitations of the shake table. The data acquisition system used in this investigation is a PC equipped with National Instruments SCXI 1001 chassis that houses SCXI signal conditioning units. National Instruments NI-DAQ data acquisition software and Lab View are installed on the PC and provide a method of real time data monitoring and collection.

\subsection{Shake Table Modifications for Current Research}

Previous shake table investigations located the flexible wall testing container at pre-existing bolt holes on the testing surface of the shake table. The use of the pre-existing bolt holes positioned the testing container off the center of the table. Once filled with clay, the testing container in this configuration could provide an unnecessary stress to the shake table system. Although this orientation had little to no effect on experimental results, the unbalanced load from the testing container may eventually compromise the performance of the shake table for future investigations. In order apply a balanced load to the testing surface, four new bolt holes were drilled and tapped into the shake table. These new bolt holes allow for installation of the testing container over the center of shake table. This study makes use of the new bolt holes, centering the testing container on the shake table. 


\subsection{Instrumentation}

A number of data collection instruments are used for this shake table investigation including accelerometers, pressure sensors and T-bar penetrometers. Accelerometers are placed within the soil column, on the model structure and mounted on the shake table. These accelerometers are used to record accelerations during shake table testing and to develop shear wave velocity profiles. Tactile pressure sensors are used to characterize the development of earth pressures behind the model retaining wall. Furthermore, Tbar penetrometers attached to a load cell are used to estimate soil strength. This section discusses the use and placement of these instruments within the testing container.

\subsubsection{Accelerometers}

The accelerometers used in this study are Integrated Circuit Piezoelectric (ICP), manufactured by PCB Piezotronics. The piezoelectric sensing element responds to an applied acceleration by producing a proportional electrical output. These accelerometers contain signal conditioning within ICP unit to minimize signal degradation through the coaxial cable. The voltage signal is transmitted to the data acquisition system where the signal converted to acceleration measurements reported in gravitational units $(\mathrm{g})$. Calibration developed by the manufacturer is applied to each accelerometer prior to use in this investigation.

Two models of accelerometers PCB models were used within the testing container. Model 393B04 seismic ICP accelerometers were selected to measure acceleration within the soil column and need to be fully protected from caustic 
soil material and moisture. The coaxial connection was sealed with $100 \%$ silicone to prevent the penetration of unwanted moisture. Additional silicone was used to encase the entire accelerometer to further protect the accelerometers from moisture and corrosive nature of the model clay. The accelerometers were mounted to individual acrylic plastic foundations to minimize movement and ease accelerometer placement during installation. Two Model J353B51 accelerometers were used within the model basement. One was attached directly to the lumped mass during phase II of testing and the other was placed on the base plate of the model to measure horizontal accelerations.

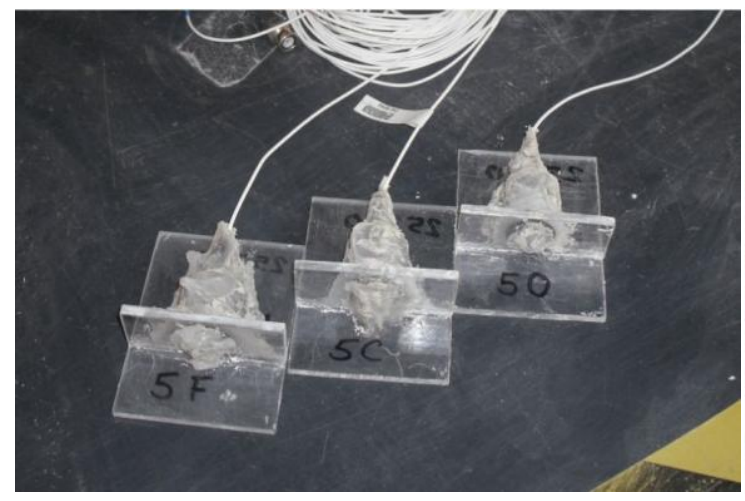

(a)

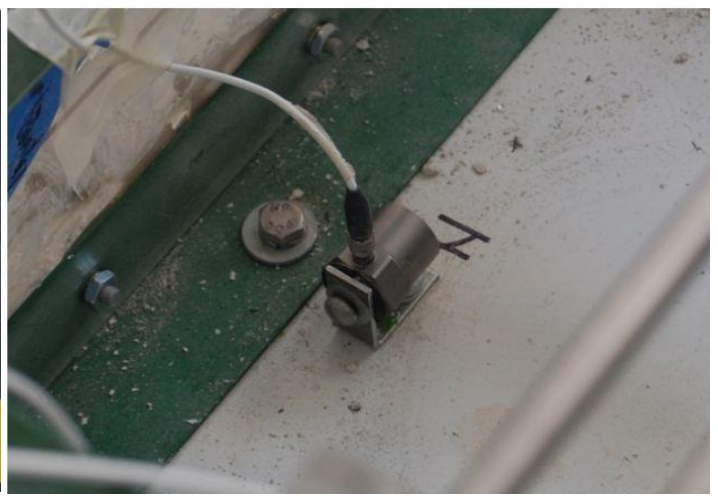

(b)

Figure 5.2: Accelerometers (a) used to measure acceleration in the soil and (b) used to measure horizontal accelerations in the scale model. (From Kuo 2012)

The placement and positioning of accelerometers into soft model clay requires extreme care. Timber beams, small levels, and plumb bobs were used to ensure the placement and alignment of these accelerometers within the soil column. Once buried, it is not possible to subsequently verify the placement and orientation of the accelerometer. Great caution was also taken during soil 
placement into the testing container in order minimize disturbance to buried instruments.

\subsubsection{Tactile Pressure Sensors}

The pressure sensors used in this study are ConTacts Discrete Tactile Sensors manufactured by Pressure Profile Systems (PPS). These sensors are used to measure seismic pressures as they develop along the wall during testing. A protective sleeve was developed to protect the sensors from moisture and corrosion. The selection and testing of these sensors are described in detail in Chapter 4, and the placement and orientation of these sensors on the scale model is discussed later in this chapter.

\subsubsection{T-bar Penetrometer}

The T-bar penetrometer was developed by Stewart and Randolf (1991) for estimating soil strength with depth. The T-bar is consists of a long narrow rod oriented perpendicularly to horizontal roughened cylindrical cross bar, forming a "T" shape. A load cell measures soil resistance by using the attached rod to either pull or push the cross bar through soil. The resulting load resistance profile is used to estimate undrained shear strength based on research described in Randolf and Houlsby (1984). They derived a closed-form solutions for limiting pressure acting on a circular pile which was adapted for T-bar pull out testing. The derived closed-form solution assumes that soil flows around the cylindrical cross bar and fully closes behind it. Due to the relatively small cross section, the 
effect of the narrow rod is neglected in the analysis. The undrained shear strength equation as follows,

$$
S_{u}=\frac{P}{N_{b} D}
$$

where $S_{u}$ is the undrained shear strength of the soil, $P=$ force per unit length acting on the cylinder, $\mathrm{N}_{\mathrm{b}}=$ bar factor, and $\mathrm{D}=$ diameter of the cylinder.

The T-bar used in this study consists of a $95 \mathrm{~mm}$ long, $19 \mathrm{~mm}$ diameter steel cross bar orthogonally welded to a 2.1 meter long, $6.3 \mathrm{~mm}$ diameter steel pulling rod. A $2.2 \mathrm{kN}$ load cell is threaded to the end of the narrow rod to measure soil resistance. The bar factor is a function of bar roughness/adhesion and varies from 9 to 12. A bar factor of 10.5 was adopted for the analysis of t-bar test results as recommended by Randolph and Houlsby (1984) for general applications.
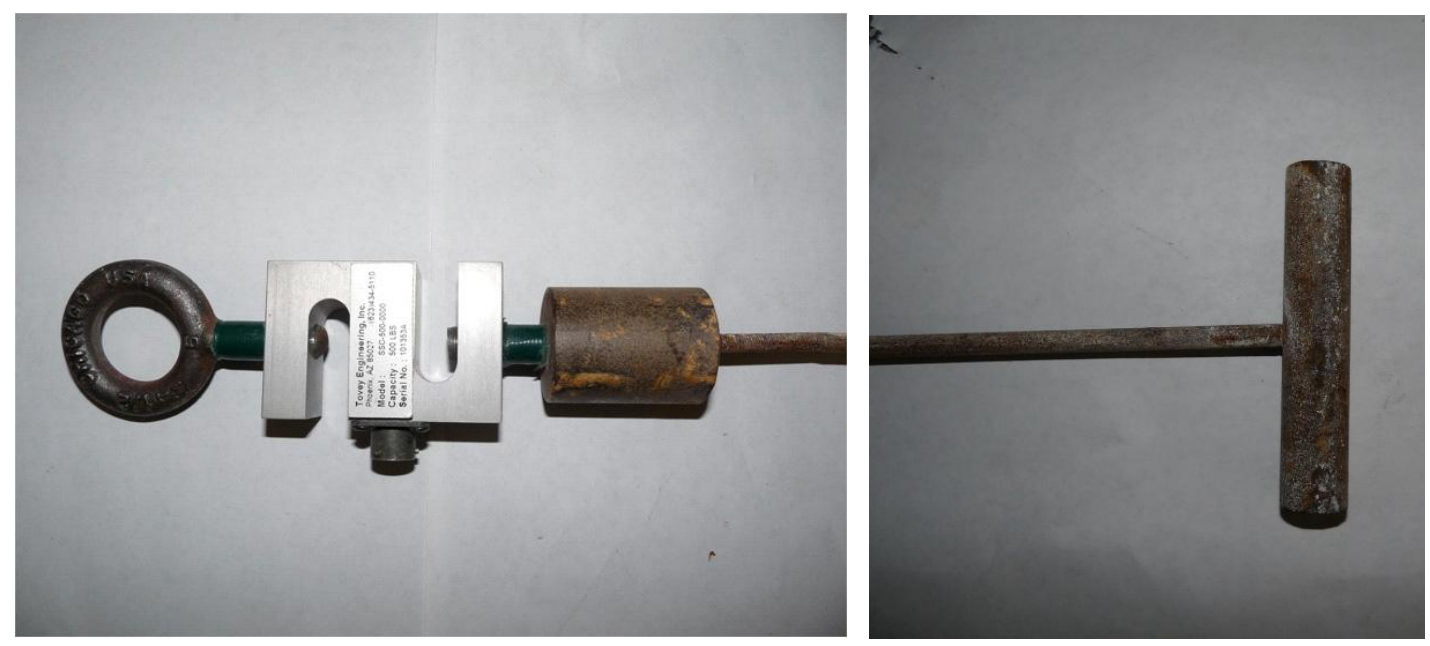

(a)

(b)

Figure 5.3: T-bar device with (a) $22 \mathrm{kN}$ load cell thread to the steel rod and eye bolt and (b) cylindrical cross bar (from Crosariol 2010) 


\subsection{Model Soil Placement and Construction}

As described in Chapter 3 , the model soil recipe is composed of $67.5 \%$ kaolinite, $22.5 \%$ bentonite, and $10 \%$ class $\mathrm{C}$ fly ash. The water content selected for the model soil design is $120 \%$ to accommodate the demands of the mixing equipment. The soil mixture used in the current study is nearly identical to the soil mixture used by Crosariol (2010) and Kuo (2012).

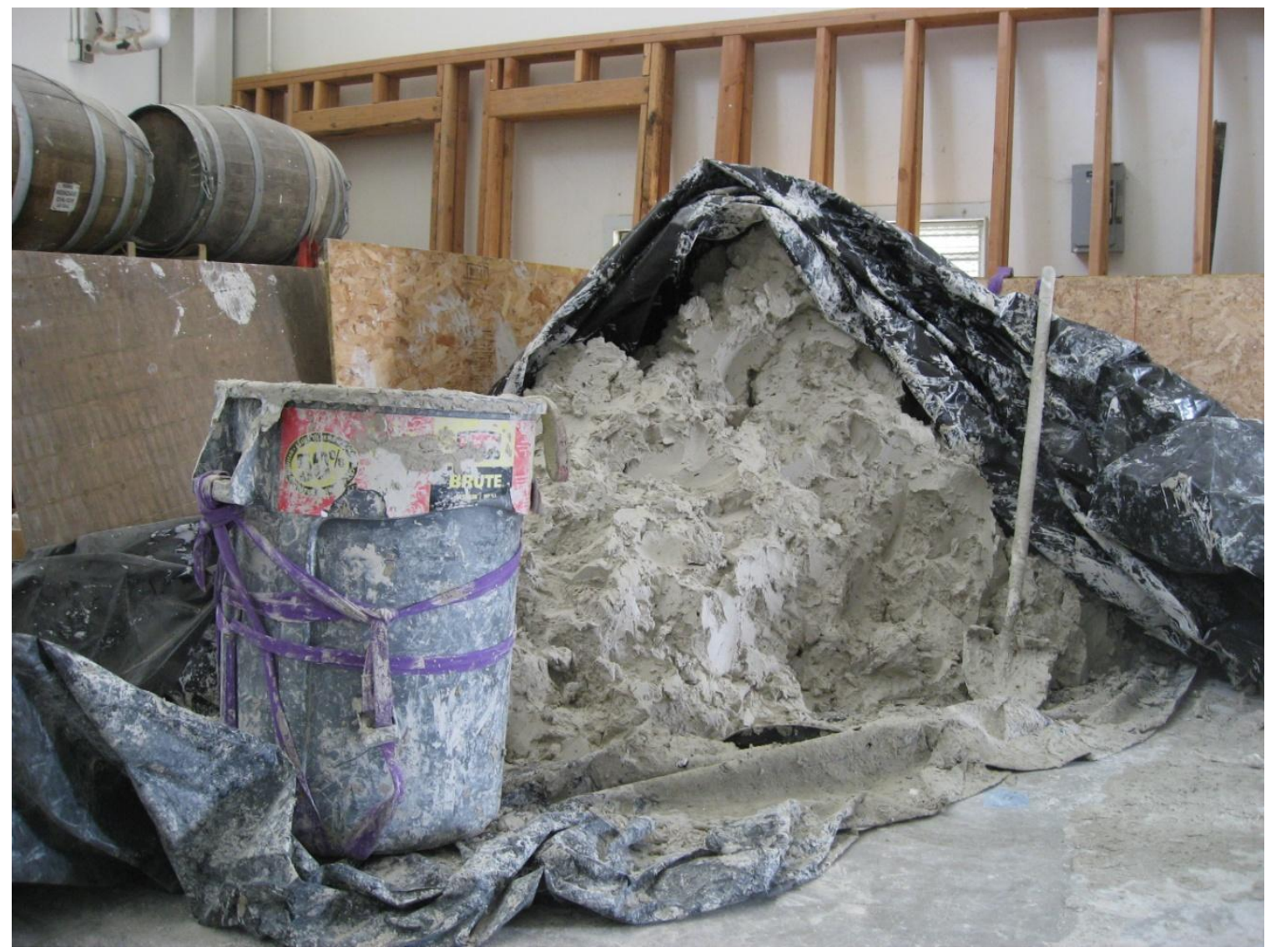

Figure 5.4: Reconstituted clay holding area and transport bucket 
Reconstituted model clay, preserved from Kuo (2012) shake table investigations, was held in a holding area near the shake table (Figure 5.4). Chunks of clay were loaded into a transport bucket to be craned into the testing container. In order to minimize voids and achieve a homogeneous consistency, the reconstituted soil was hand packed into the testing container. Great care was taken not to disturb the placement or orientation of instrumentation during packing of the reconstituted soil. During soil placement, the rubber membrane was monitored to prevent any unwanted bulging. Additionally, the exposed clay was covered in between laboratory sessions to help prevent unnecessary drying.

The target soil column height of $100 \mathrm{~cm}$ was only partially satisfied with the left over reconstituted clay soil therefore a new model soil batch was required to achieve the desired height. Mixing equipment, custom built by ChemGrout Inc., was used to combine the components of the model soil. A detailed description of the mixer and mixing process is presented in Crosariol (2010). To accommodate the space limitations within the testing container, the newly mixed soil was pumped directly into the soil holding area and then crane lifted in a transport bucket into the testing container. The newly mixed soil was then hand packed following the process described for the reconstituted model clay. 


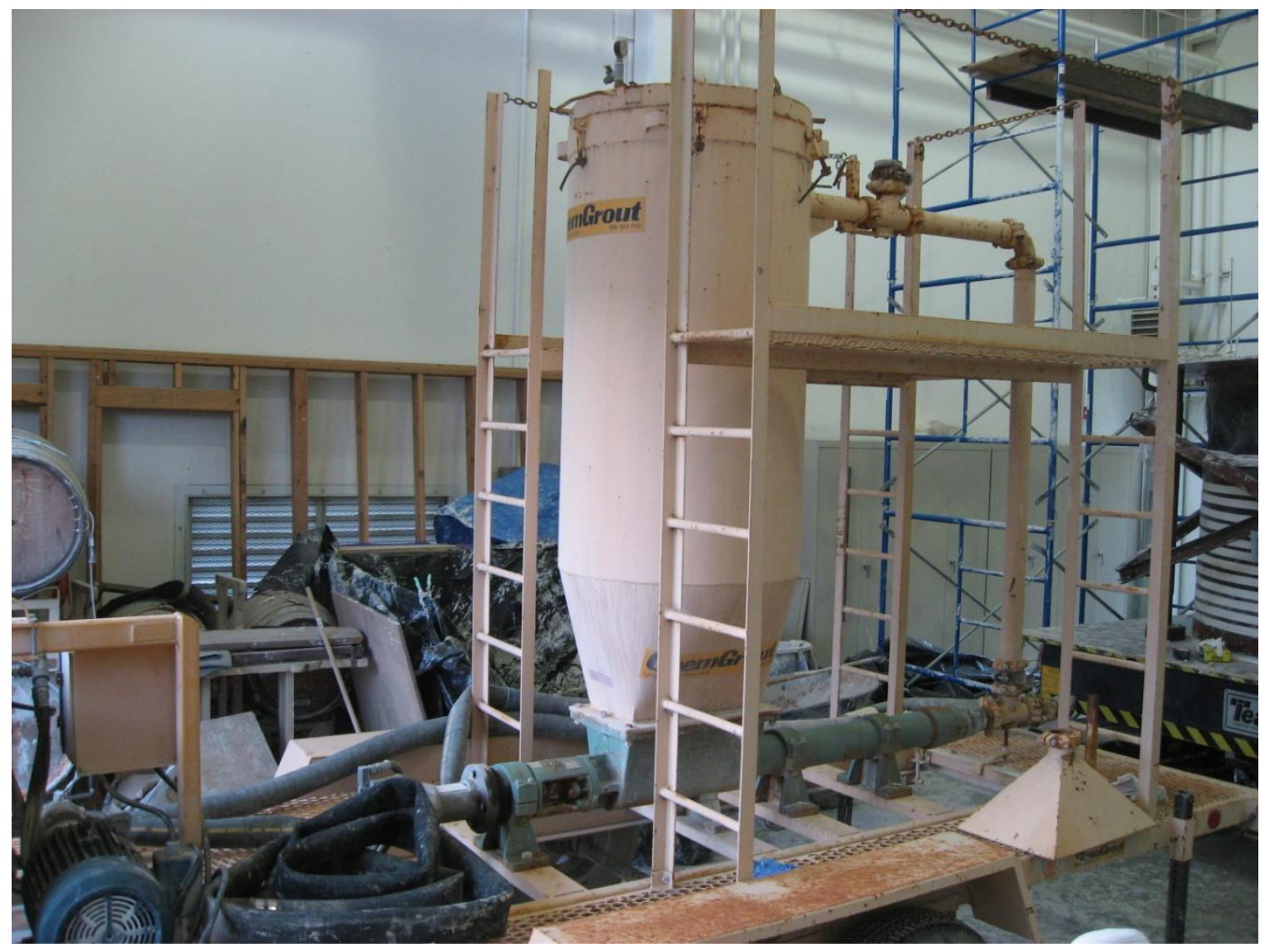

Figure 5.5: Mixing equipment for new model soil bath

\subsubsection{Soil Batch Data}

The soil column is placed layer by layer using mostly reconstituted clay preserved from a previous shake table investigation. Of the total testing container height, about $0.45 \mathrm{~m}$ were left unfilled to isolate the soil column from experiencing inertial effects from the top ring. Although measures the reconstituted clay was covered to help prevent drying, the reconstituted clay found on the outer portions of the clay mound was naturally stiffer than clay found in the center. This stiffer clay was placed first into the testing container to create a stiff base layer to provide good contact for continuity of table motions. 
At soil column height increments of $10 \mathrm{~cm}$, soil sample were gathered to measure the average water content and unit weight of the soil at each layer of the soil column. As displayed in Figure 5.6, the water content levels hover right around $100 \%$, which is the desired water content level for the prototype soil as specified in Meymand (1998). Figure 5.6, shows the water content around soil height of $50 \mathrm{~cm}$ having dropped to around $92 \%$. Due to disturbances, such as the deconstruction of the previous investigation and filling of the testing container in the current study, the model clay may have experienced nonhomogeneous drying.

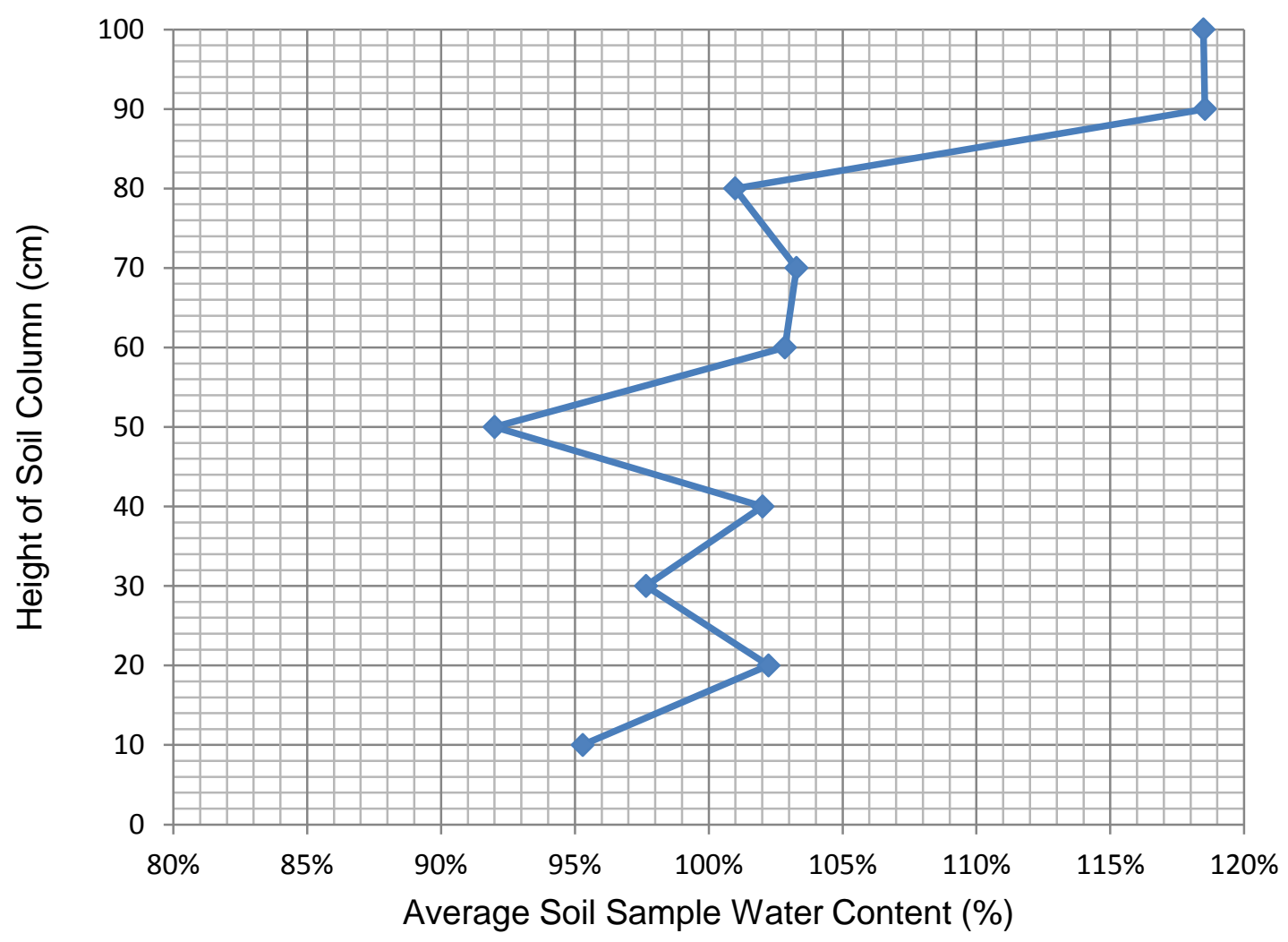

Figure 5.6: Water Content of Soil Throughout the Soil Column 


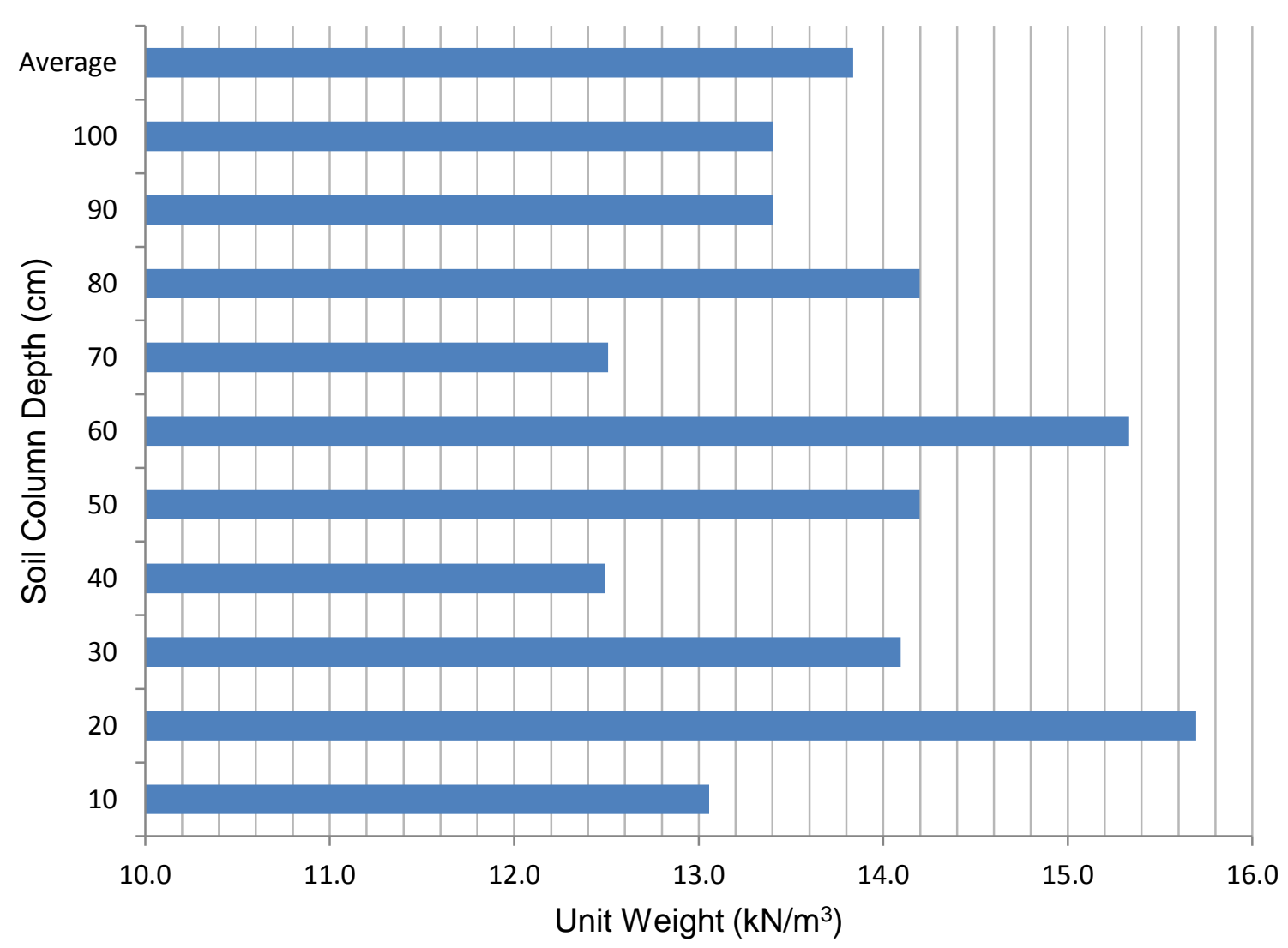

Figure 5.7: Unit weight measurements at soil column heights

The average unit weight of the entire soil column is found to be 13.8 $\mathrm{kN} / \mathrm{m}^{3}$ (Figure 5.7). Although this is lower than the target unit weight of 14.8 $\mathrm{kN} / \mathrm{m}^{3}$ required to satisfy the $1: 1$ prototype to model soil density scaling relation, the 1.07 scaling factor resulting from the average unit weight is reasonably close to unity and does not significantly distort the model. The lower average unit weight is attributed to the original increase in water content to satisfy the demands of the mixer. Although there is some variation when considering unit weight as a function of water content, the average unit weight of $13.8 \mathrm{kN} / \mathrm{m}^{3}$ is adopted as representative of the soil column. 


\subsection{T-Bar Pull out Testing}

Four T-bars are vertically placed at the corners of the testing container prior to soil placement. The T-bars are held in place by timber cross beams with drilled holes for the T-bars to fit through (Figure 5.8). A variety of clamps are used to securely fasten the timber beams to the top ring of the testing container and to the T-bars themselves to maintain stability and upright orientation during soil placement. The pull-out tests were conducted to encompass strength gain over the entire testing period and is listed in Table 5.1

The pull-out tests are conducted using an overhead crane. The T-bars were pulled out at a constant rate of $1.29 \mathrm{~cm} / \mathrm{s}$, the lowest constant operational speed setting for the crane. A load cell was hooked onto the craned a fastened to the threaded end of the T-bar and load data was collected at a sampling rate of $25 \mathrm{~Hz}$. Results of the T-bar pull-out tests are discussed in Chapter 6.

Table 5-1: T-bar pull out test schedule

\begin{tabular}{|l|l|l|l|}
\hline$\#$ & Date & Test_ID & Test Description \\
\hline 1 & $1 / 31 / 2012$ & TSW & T-bar pull out test for South West corner \\
\hline 2 & $3 / 23 / 2012$ & TNE & T-bar pull out test for North East corner \\
\hline 3 & $4 / 10 / 2012$ & TNW & T-bar pull out test for North West corner \\
\hline 4 & $5 / 31 / 2012$ & TSW & T-bar pull out test for South East corner \\
\hline
\end{tabular}




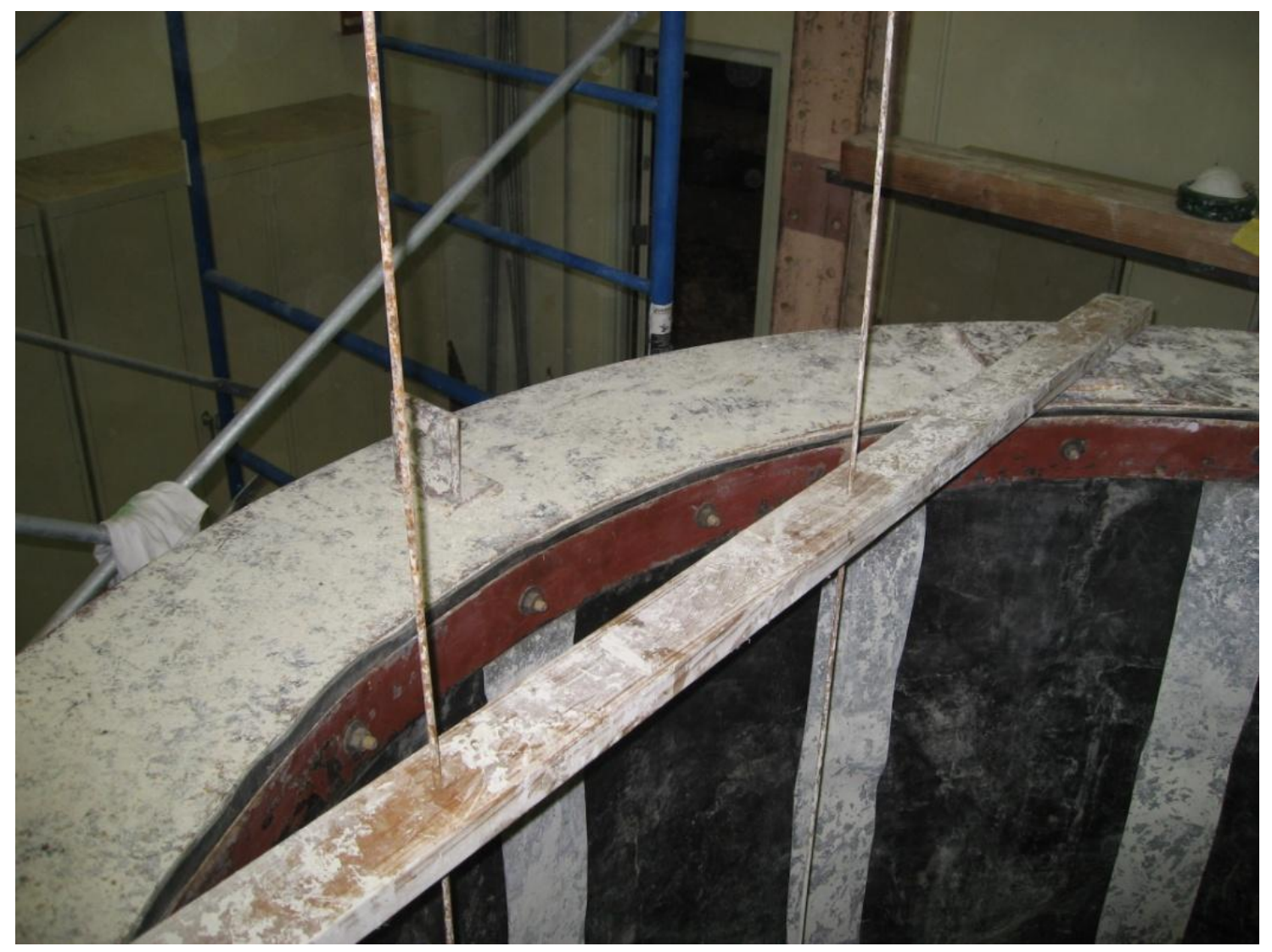

Figure 5.8: Snapshot of timber beams holding T-bars in place

\subsection{Hammer Blow Testing}

Hammer blow tests were conducted to measure the in-situ shear wave velocity within the soil column. Shear wave velocity testing was performed by delivering hammer blows to a steel bar coupled to the soil surface. These hammer blows propagate of a vertical wave through three accelerometers in the center of the soil column. The resulting shear wave velocity was calculated by knowing the distance between each accelerometer and measuring the arrival time of individual shear waves detected accelerometers in an array. A sampling rate of $10000 \mathrm{~Hz}$ was used to precisely identify the arrival time of the wave form at each accelerometer. 
Although previous investigations have conducted both top-down and bottom-up hammer blow testing in order to clearly present the shear wave velocity within the soil column, bottom-up hammer blow tests performed by Crosariol (2010) are shown to have "very inconsistent and difficult to identify" wave forms due to container-soil interaction effects. Due to this inconsistency, bottom-up hammer blow tests were not performed for the current investigation. Results of the hammer blow tests are discussed in Chapter 6.

\subsection{Model Basement Configuration and Placement}

The testing of seismic earth pressures on a scale model basement can be broken down into two distinct phases. Phase I of testing incorporates the fully embedded model structure in the center of the soil column. Phase II of testing consists of a similar setup, but with the incorporation of a SDOF attachment to measure the effects of SSI on the development of seismic earth pressures on the basement wall. The instrumentation requirements and embedment procedures for both phases of testing are discussed later in this chapter.

\subsection{Model Basement Instrumentation}

The interior of the model basement has one accelerometer mounted base plate of the model. The accelerometer was fastened to an L-bracket and oriented in line with the shaking direction of the shake table (Figure 5.2b). This

accelerometer was used to measure the acceleration of the model with respect to the acceleration of the soil column. In addition to the accelerometer mounted to 
the base plate, in Phase 2 of testing, another accelerometer was mounted directly to the SDOF lumped mass to calculate peak spectral amplitudes.

On the exterior of the model basement, a vertical array of five tactile pressure sensors were mounted and aligned at the center the model wall. As described in Chapter 4, each pressure sensor is placed in a protective sleeve to prevent caustic material and moisture from damaging the sensor. The pressure sensors are mounted to ensure that $1 / 3,1 / 2$, and $2 / 3$ the wall height is represented with a pressure sensors. For a model wall height of approximately $30 \mathrm{~cm}$, pressure sensors were mounted $5 \mathrm{~cm}$ apart to measure the development of earth pressures along the wall. "Gorilla" tape was used to adhere the pressure sensors to the wall surface and help restrict the rubber tubing from interfering with the testing surface (Figure 5.9). 


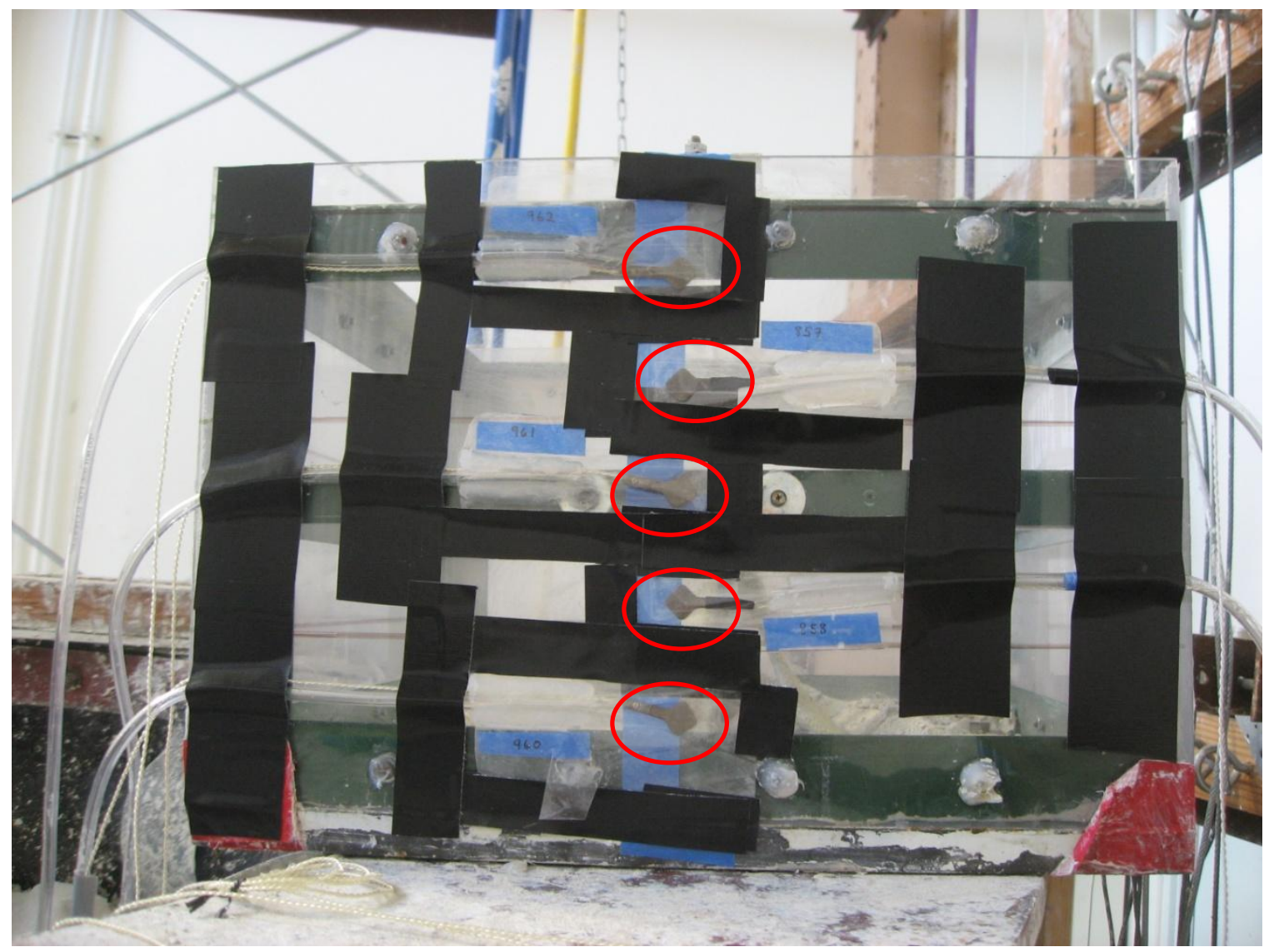

Figure 5.9: Snapshot of pressure sensor array as mounted on the scale model

\subsubsection{Model Basement Embedment Procedures}

Although the basement model was fully embedded, special attention was given to the clay wall to which the pressure sensor array would be adjoined. In order to ensure that the contact clay wall remain relatively undisturbed during embedment preparation, a thin metal sheet was inserted to protect the model-soil contact surface. A cavity was excavated at the center of the soil column of approximately the size of the model foundation footprint. Additional clay material was also excavated in order to provide space necessary to properly position the pressure sensor array with the contact clay surface. Once excavation was complete, the thin metal sheet was removed to prepare for model placement. 
A threaded eye-bolt was placed in the center hole of the model foundation and connected to the overhead crane with a "Kevlar" strap. Once the scale model was arranged into the correct orientation, the model was carefully wedged into the excavated cavity such that the pressure array was properly adjoined to the clay surface. Special attention was given to the plastic air tubes to ensure they were clear of any unwanted material. Voids around the scale model were backfilled with clay to prepare for shake table testing.

Following the first rounds of initial shake table testing, analysis of the pressure reading indicate that not all pressure sensors within the array made sufficient contact with the soil contact surface. A thin strip of clay was then placed at the pressure sensor-soil wall interface to ensure that soil pressures were detected during testing. The resulting pressures were corrected to an active earth pressure baseline. The dynamic increment is measured relative that correction. Dynamic earth pressure reading are presented and discussed in Chapter 6.

\subsection{Shake Table Instrumentation Configuration}

The figures and table below provide details of the instrumentation and configuration of the experimental set up. Figure 5.10 shows the instrumentation configuration in plan view, while Figure 5.11 shows the experimental set up in profile. A list the instrumentation and their abbreviations are presented in table

Table 5-2: List of instrumentation and nomenclature

\begin{tabular}{|l|l|}
\hline Instrumentation & Denoted \\
\hline 4 ACC's array near model wall face & $1 \mathrm{~F}, 2 \mathrm{~F}, 3 \mathrm{~F}, 4 \mathrm{~F}$ \\
\hline 2 ACC's below the model & $1 \mathrm{~S}, 2 \mathrm{~S}$ \\
\hline 5 pressure sensors on model wall face & $\mathrm{P} 1, \mathrm{P} 2, \mathrm{P3}, \mathrm{P} 4, \mathrm{P} 5$ \\
\hline 4 T-bars in NE, SE, SW, NW & $\mathrm{TNE}, \mathrm{TSE}, \mathrm{TSE}, \mathrm{TNW}$ \\
\hline
\end{tabular}




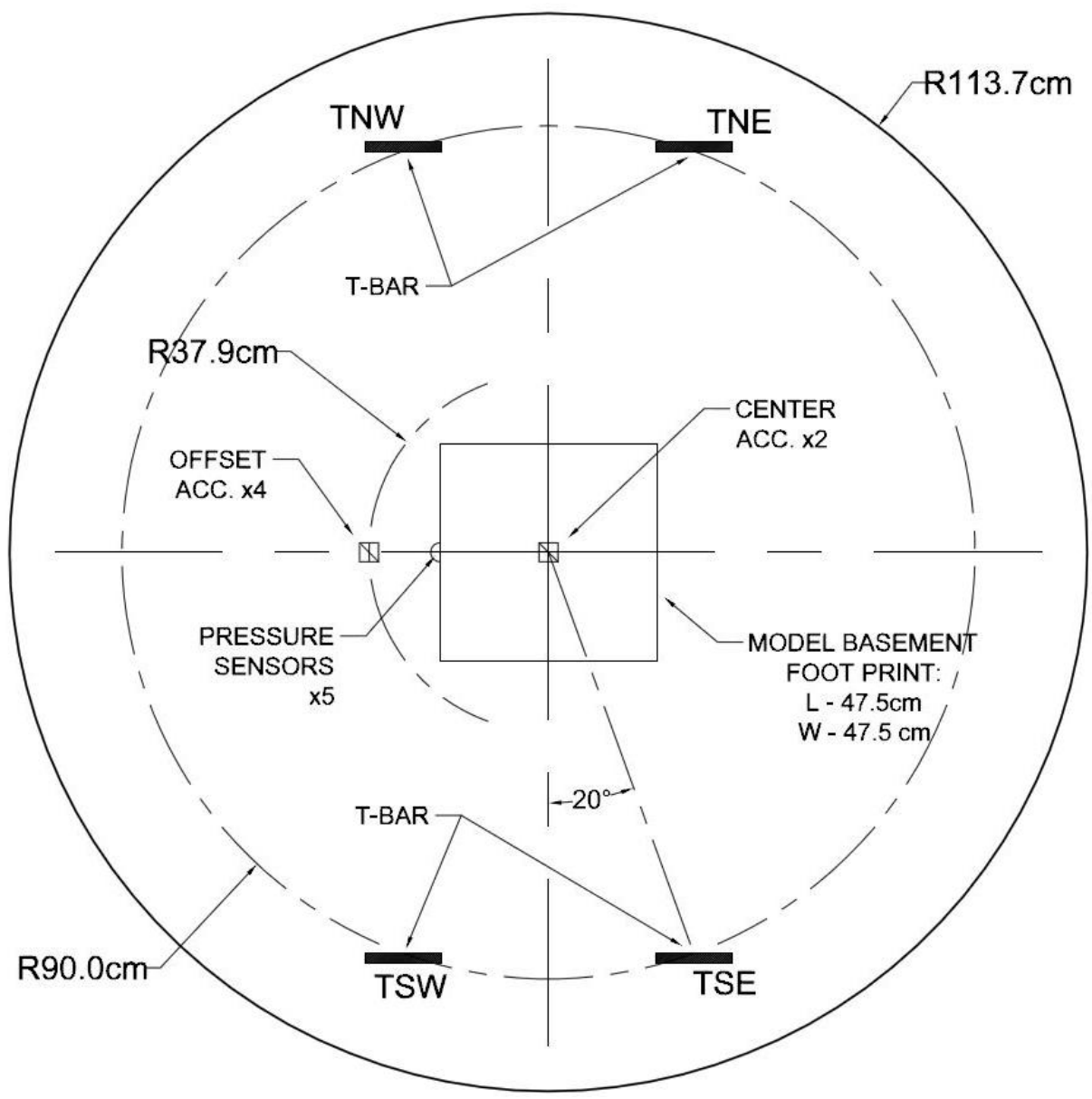

Figure 5.10: Plan view of soil column instrumentation configuration

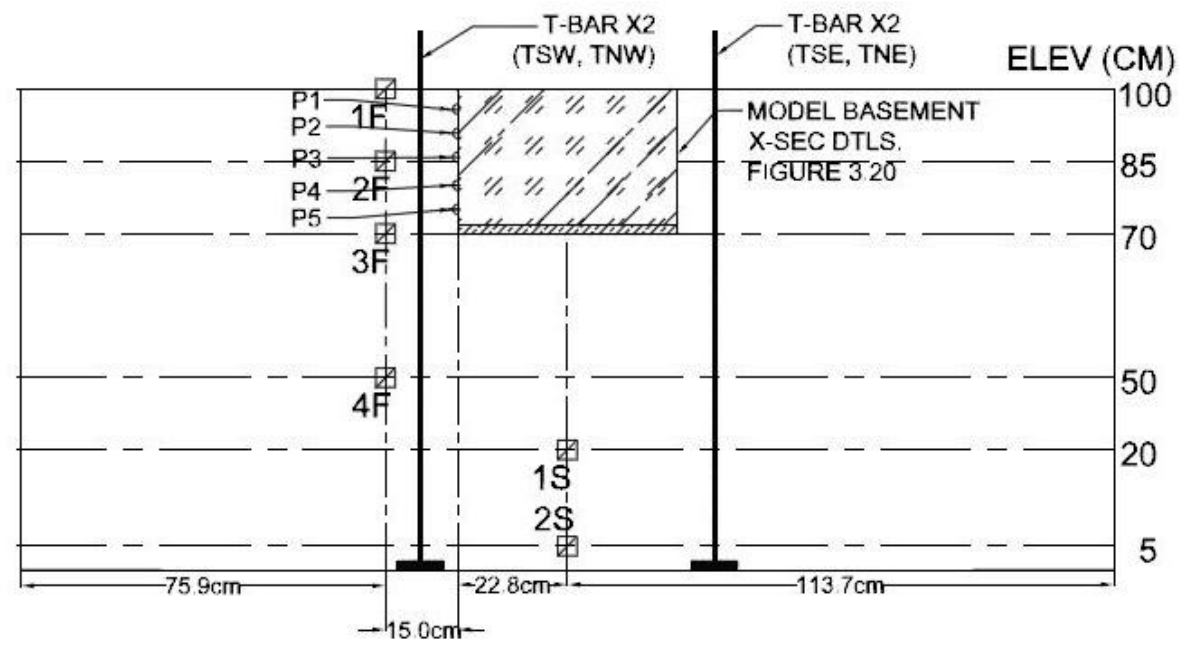

Figure 5.11: Profile view of soil column instrumentation configuration 
Chapter 6 - Experimental Test Results

\subsection{Introduction}

This chapter presents results of T-bar, hammer blow and shake table testing. Much of the shake table and testing container validation were previously presented in Crosariol (2010) and are summarized in this chapter. The earth pressure measurements are unique to this study and will be presented in detail in this chapter.

\subsection{T-Bar Pullout Testing}

T- Bar pullout tests were performed to estimate the undrained shear strength of the soil column. The T-bar results show the undrained shear strength in terms of elevation above the soil column base. Undrained shear strength results are calculated using Equation 5.1 with parameters discussed in Chapter 5. The underestimation of soil strength near the surface can be attributed to the effect of the T-bar breaking through the soil surface. The soil strength measured in the middle of the soil column is relatively consistent with the gradual trend of increasing strength closer to the base of the soil column. T-bar pullout testing results show soil strength spikes at the lower portion of the soil column. These spikes may be attributed to the initial acceleration of the overhead crane to a constant pullout velocity.

A total of four T-Bars were pulled over the course of the entire testing period which includes both phases of this study presented in Figure 6.1. The T- 
bar profiles show consistency with slight strength gain over time, leading to our conclusion of minimal consolidation over the testing period.

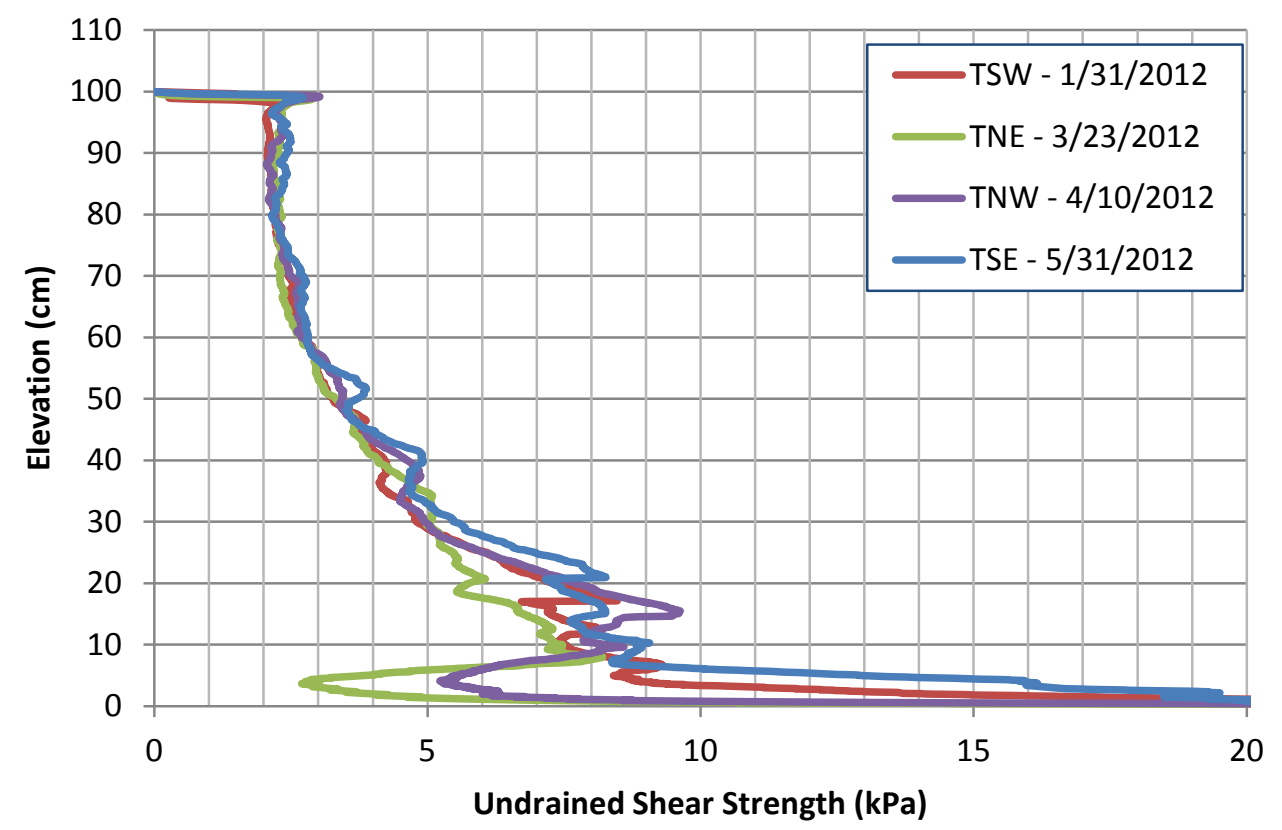

Figure 6.1: T-bar pull out test results

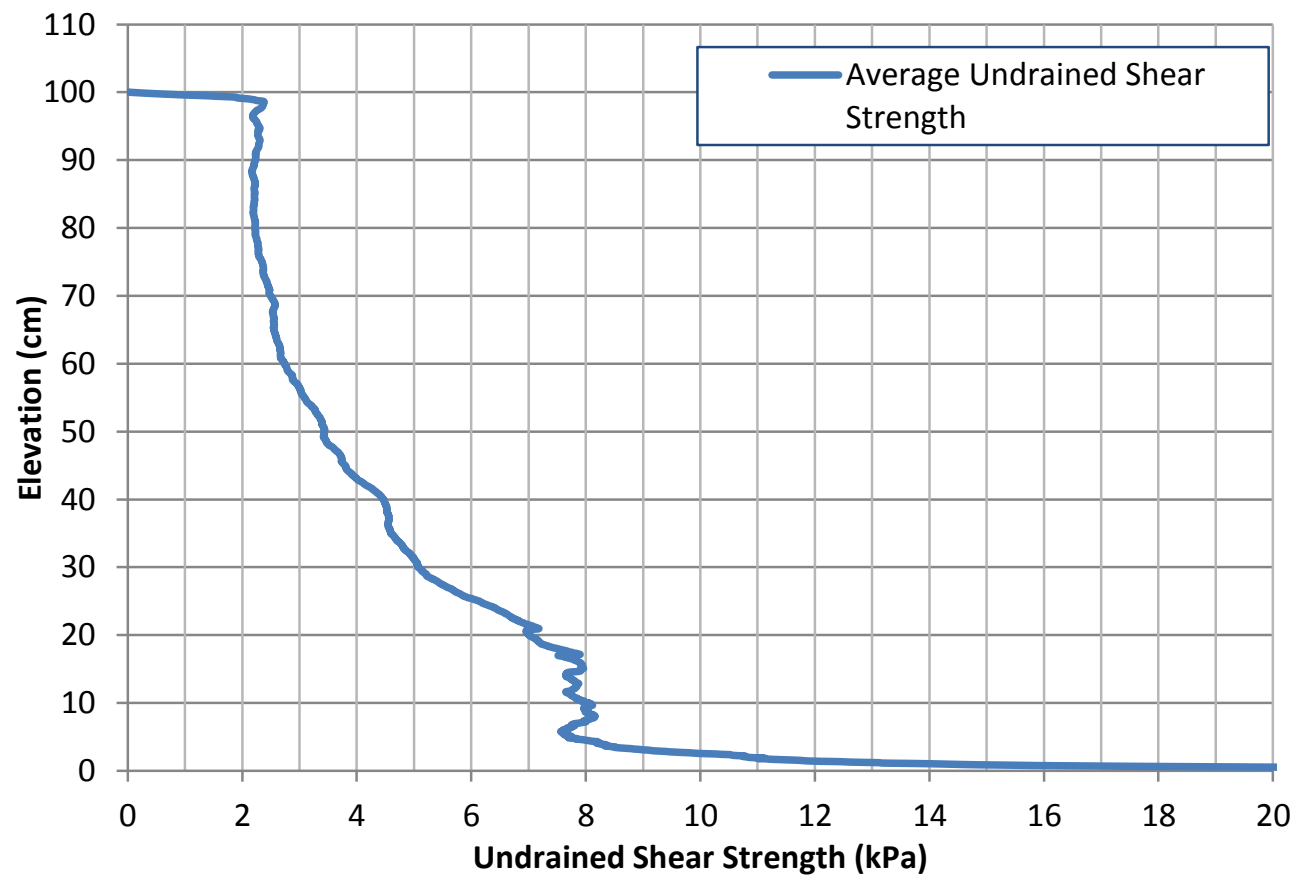

Figure 6.2: Average undrained shear strength of soil column using T-bar tests 


\subsection{Hammer blow Testing}

Hammer blow tests to measure shear wave velocity were performed prior to the initial embedment of the model structure using top-down procedures. The generated wave forms were primarily detected by accelerometers $2 F, 3 F$, and 4F placed within the clay backfill adjacent to pressure sensor array shown in Figure 5.11.

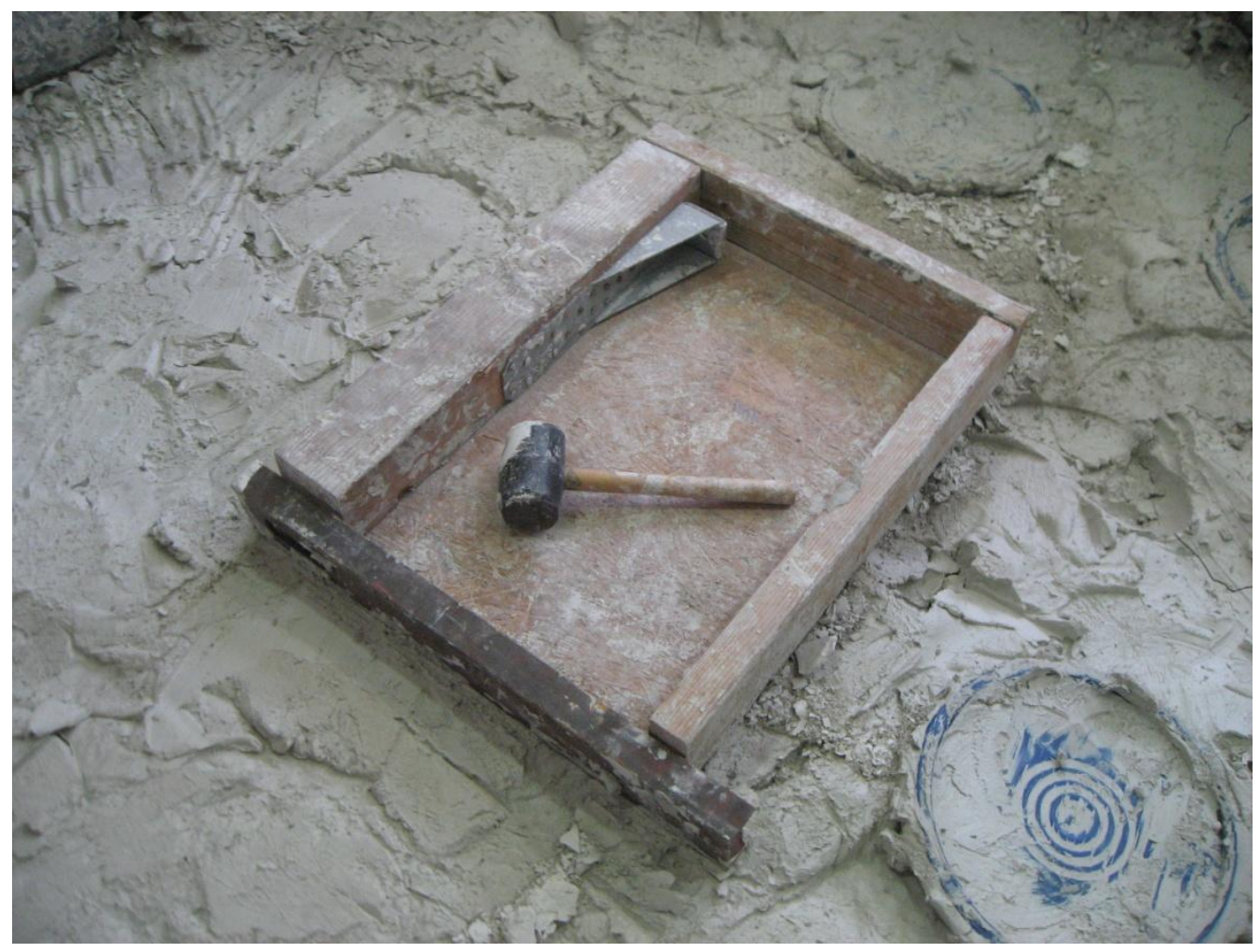

Figure 6.3: Hammer blow striking platform and rubber mallet

The striking platform consisted of a rectangular steel plate fastened to a wooden base as shown in Figure 6.3. The steel bar was coupled to the soil surface along the axis of the vertical accelerometer profile. A rubble mallet was used to strike the steel plate to generate shear waves. The magnitude of the shear waves were monitored using the data acquisition system. The hammer 
blow wave form was used to calculate the shear wave velocity of the soil column.

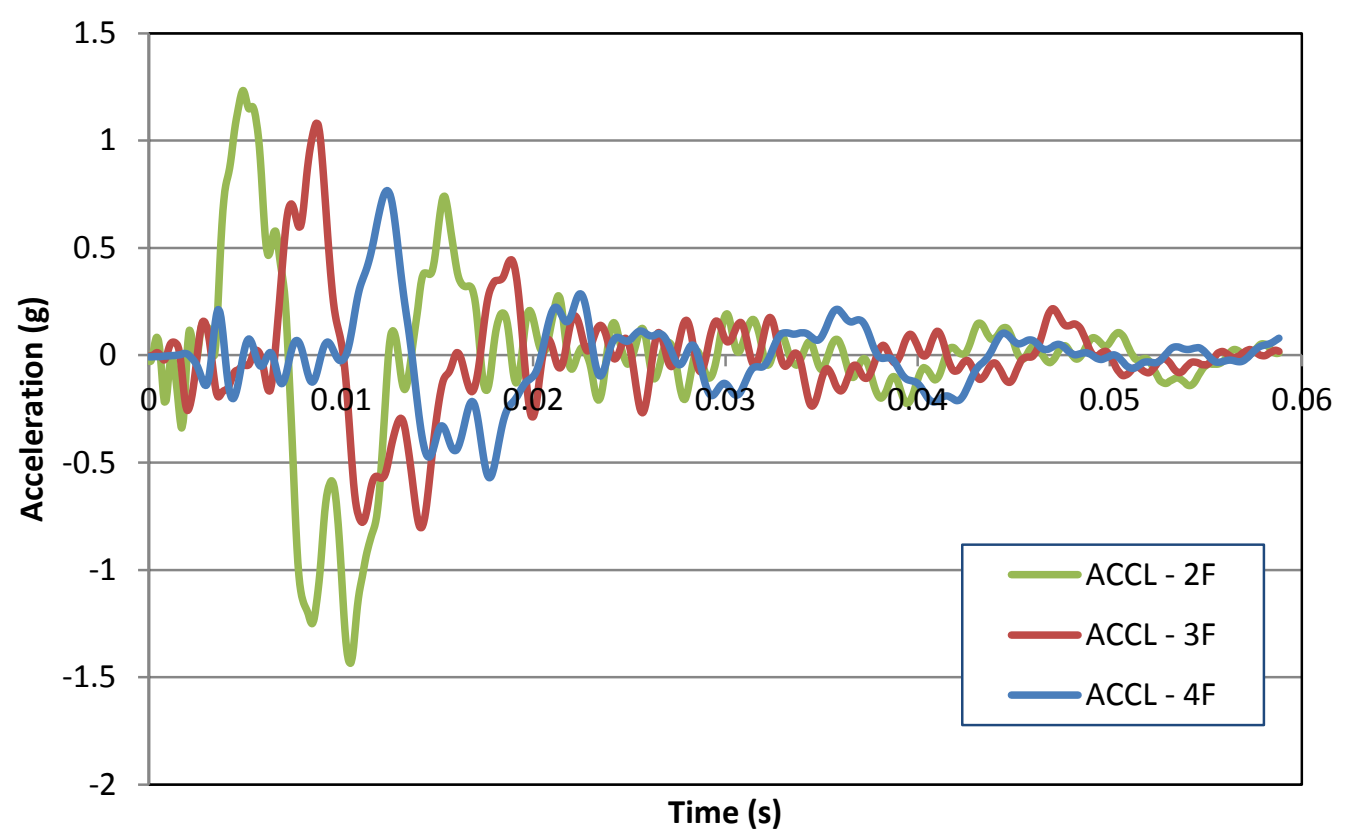

Figure 6.4 shows the typical hammer blow wave form. The wave forms that develop close to the top of the soil column are presented with a high amplitude which dampen over time. The arrows presented Figure 6.5 indicate the arrival times of the wave form at the depths of each accelerometer. Shear velocity, the quotient of the distance between each accelerometer and the arrivals time of the wave form measured at each accelerometer, is presented in Table 6-1. 


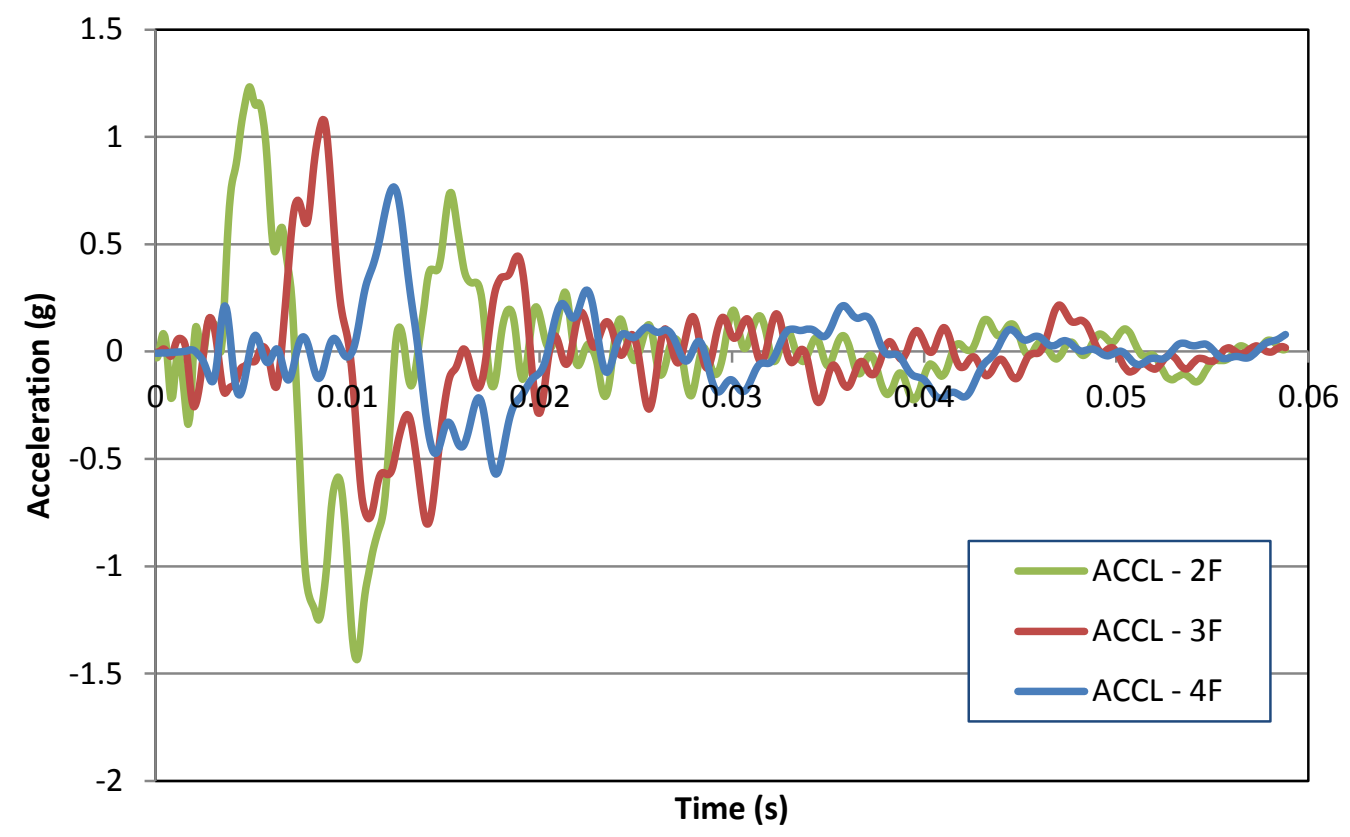

Figure 6.4: Typical wave form developed by top-down hammer blow tests

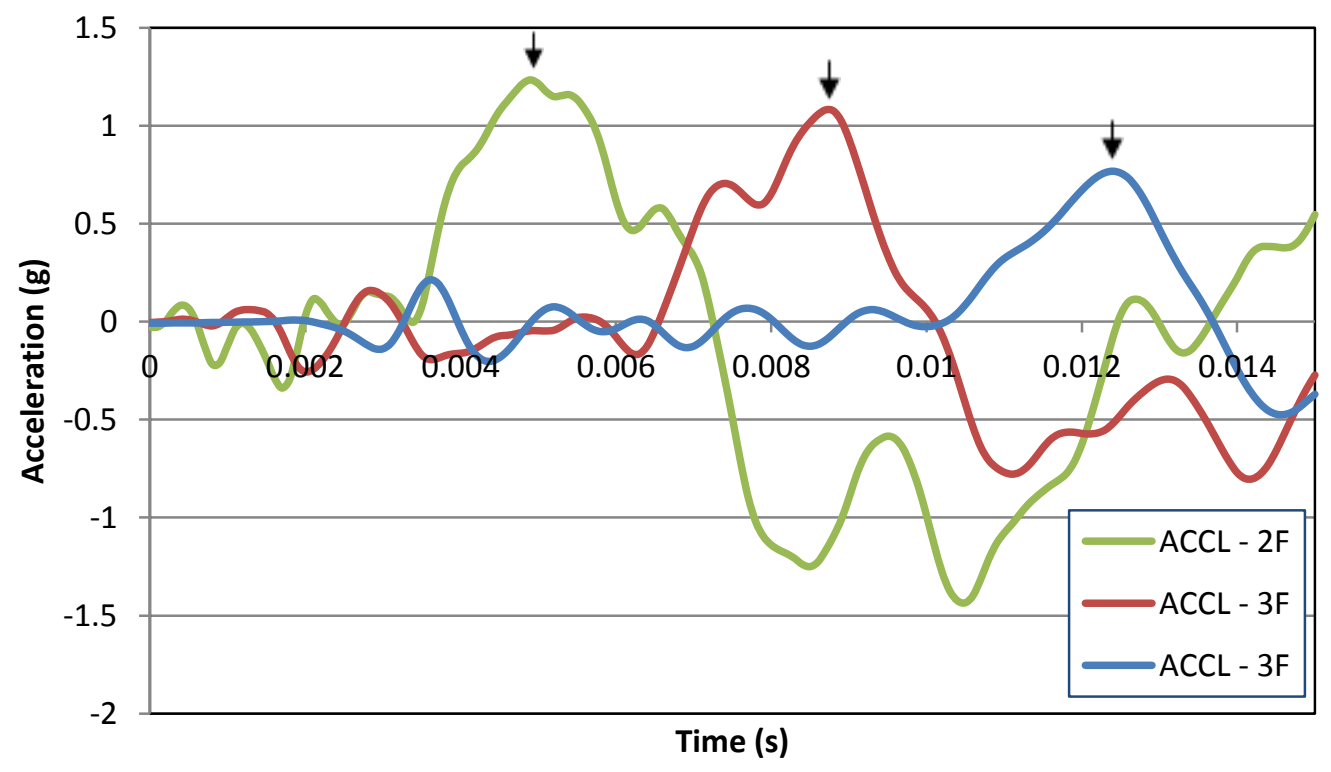

Figure 6.5: Arrival times of shear wave form for shear wave velocity calculation

Table 6-1 includes shear wave velocities determined from six hammer blow tests through the wave forms detected by the three accelerometer mentioned above. The results show that the soil between $2 \mathrm{~F}$ and $3 \mathrm{~F}$ as having a 
smaller shear wave velocity than the soil measured between $3 \mathrm{~F}$ and $4 \mathrm{~F}$. This is consistent with T-bar test results with larger undrained shear strength at elevations closer to the base of the soil column.

Table 6-1: Summary of top down hammer blow tests

\begin{tabular}{|c|r|r|r|}
\hline Accelerometer Range & \multicolumn{1}{l|}{$2 \mathrm{~F}-3 \mathrm{~F}$} & \multicolumn{1}{l|}{$3 \mathrm{~F}-4 \mathrm{~F}$} & \multicolumn{1}{l|}{$2 \mathrm{~F}-4 \mathrm{~F}$} \\
\hline Trial & Vs (m/s) & Vs (m/s) & Vs (m/s) \\
\hline 1 & 38.46 & 55.56 & 46.67 \\
\hline 2 & 40.54 & 54.05 & 47.30 \\
\hline 3 & 40.54 & 54.05 & 47.30 \\
\hline 4 & 40.54 & 55.56 & 47.95 \\
\hline 5 & 39.47 & 54.05 & 46.67 \\
\hline 6 & 39.47 & 54.05 & 46.67 \\
\hline Average & $\mathbf{3 9 . 8 4}$ & $\mathbf{5 4 . 5 5}$ & $\mathbf{4 7 . 0 9}$ \\
\hline
\end{tabular}

\subsection{Shake Table Performance}

The ability for the shake table to reproduce the input command signals was vetted by Crosariol (2010). The results of the comparative study between input signal and output table performance are summarized below.

- Shake Table scales command signals linearly.

- In general, output PGA is greater than the input signal.

- In terms of spectral response, variation is observed in high frequencies; however, for frequencies less than $10 \mathrm{~Hz}$ there is a reasonable spectral match.

These results can be directly applied to the current investigation as the experimental set up, testing platform, and scale modeling used in this study is built upon the experimental work presented in Crosariol (2010). 


\subsection{Testing Container Performance}

Extensive testing to analyze the performance of the testing container was conducted by Crosariol (2010) who stated, "For the 1D site response assumption to be valid, all points within any horizontal plane should be subjected to very similar ground motions." The following is a summary of the tests performed to verify the 1D site response of the testing container.

\subsubsection{Testing Container Boundary Effects}

A vertical array of accelerometers were placed within $15 \mathrm{~cm}$ of the rubber membrane to measure boundary effects. The spectral response of this vertical array was compared to the spectral response of the vertical array of accelerometers placed in the center of the testing container with the following results.

- Higher spectral acceleration at primary resonant periods was observed near the side wall than that observed in the center array. The soil container has an altering effect on the soil response and limits the effective diameter of the free-field soil column.

- No shift in the predominant period was observed.

- A qualitative comparison of acceleration time histories shows similar wave forms and wave amplitudes. Also, no distinct phase shift was reported between accelerations.

Crosariol (2010) reports that the observed boundary effect are minor, but suggests that placement of model structures or instrumentation within $0.3 \mathrm{~m}$ from the side wall of the testing container should be avoided. 


\subsubsection{Motion Spatial Consistency}

Crosariol (2010) placed a horizontal array of several accelerometers to test the subsurface 1D soil column response. A total of four accelerometer comprised the accelerometer array for this test at an elevation of $55 \mathrm{~cm}$ above the shake table. An accelerometer was placed in at the center and near the side wall of the testing container with the third in the middle of the two. The fourth accelerometer was placed at an offset position in order to measure acceleration

peaks at different points throughout the horizontal plane. At the resonant period, the accelerometers at the center and middle locations were reported to have a similar spectral response. As previously discussed the accelerometer by the side wall was observed to have a an increased amplitude while the accelerometer placed at the offset position was observed to have a decreased amplitude. The decreased amplitude for the acceleration at the offset position is attributed twodimensional effects of the testing container, but more probably caused by a misaligned accelerometer.

Crosariol (2010) reports that the motion consistency as shown by the overall the shape and magnitude of the spectral response is sufficient for the study.

\subsection{Problems and Limitations}

During the testing period a number of issues arose with some of the instrumentation. This section addresses these problems and the adjustments made in this investigation. 


\subsubsection{Experimental Drift in Earth Pressure Investigations}

Experimental drift was observed in the pressure sensors at various phases of the current investigation. This drift is the initial pressure and the ending pressure offset over the course of an input motion. In the initial Phase 1 shaking investigation (shake table tests with scale model without the attached SDOF oscillator), significant drift and data clipping was primarily in input motions with large PGA. Large drift and data clipping in the initial Phase 1 investigation distort the acquisition of peak pressures. Due to these issues, Phase 1 shake table tests were performed again following Phase 2 investigations and will be henceforth denoted as Phase 1'. In this paper, Phase 1' denotes shake table tests with for the retaining wall configuration taking place after the Phase 2 investigations. The initial Phase 1 investigations are omitted from the analysis.

Although experimental drift in earth pressures readings were most prominent in the initial Phase 1 investigations, some drift was observed in both Phase 1' and Phase 2 investigations. For most input ground motions, drift is observed to be within a $2 \%$ deviation from the starting pressures. However significant drift was observed for the Los Gatos and Cape Mendocino input motions, with one sensor recording a $23 \%$ deviation from starting pressures. Due to the significant drift observed, the data recorded for the Los Gatos and Cape Mendocino are also omitted from analysis.

\subsubsection{Pressure Sensor Failures}

Prior to any shake table testing, the pressure sensor located at a depth of $5 \mathrm{~cm}$ failed and no earth pressures were measured at that location. The 
remaining pressure sensors were located at depths of $10 \mathrm{~cm}, 15 \mathrm{~cm}, 20 \mathrm{~cm}$ and $25 \mathrm{~cm}$ along a total wall height of $30 \mathrm{~cm}$. Following Phase 2, the pressure sensor at location $25 \mathrm{~cm}$ failed. Phase 1' investigations were then conducted with a pressure sensor at locations of $10 \mathrm{~cm}(1 / 3 \mathrm{H}), 15 \mathrm{~cm}(1 / 2 \mathrm{H})$ and $25 \mathrm{~cm}(2 / 3 \mathrm{H})$ where $\mathrm{H}$ is the height of the wall.

\subsection{Site Amplification}

Surface soil deposits have been understood to amplify seismic motion relative to bedrock motions. Observations made in the 1989 Loma Prieta earthquake have shown amplification in soft soil sites up to four times the accelerations observed in nearby rock (Idriss 1990). In this investigation, site amplification is measured through the vertical accelerometer arrays embedded in the soil column. Site amplification is easily observed by comparing the acceleration response spectra for each accelerometer in the vertical array. Figure 6.6 and Figure 6.7 show the $5 \%$ damped acceleration response spectrum for the TCU 075 W (Chi Chi West) motion for Phase1' and Phase 2 respectively. 


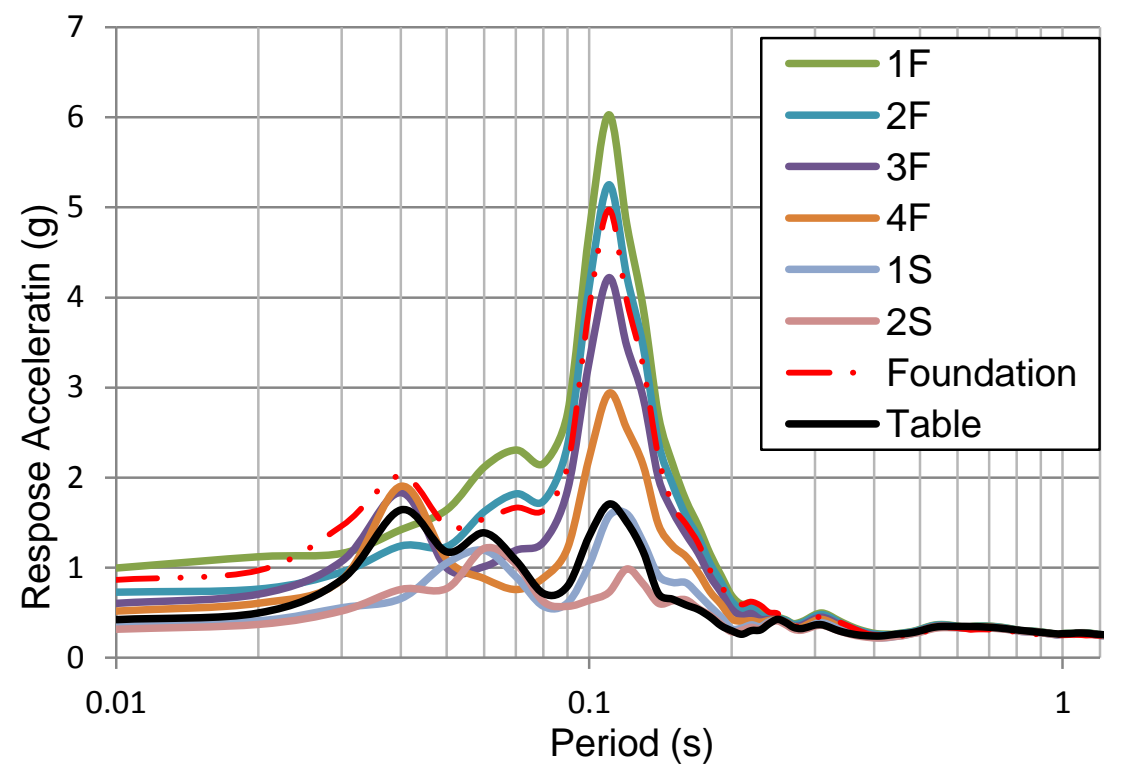

Figure 6.6: 5\% damped spectra response acceleration for TCU $075 \mathrm{~W}$ (Phase 1') where $1 S$ and $2 S$ are the accelerometers directly below the model

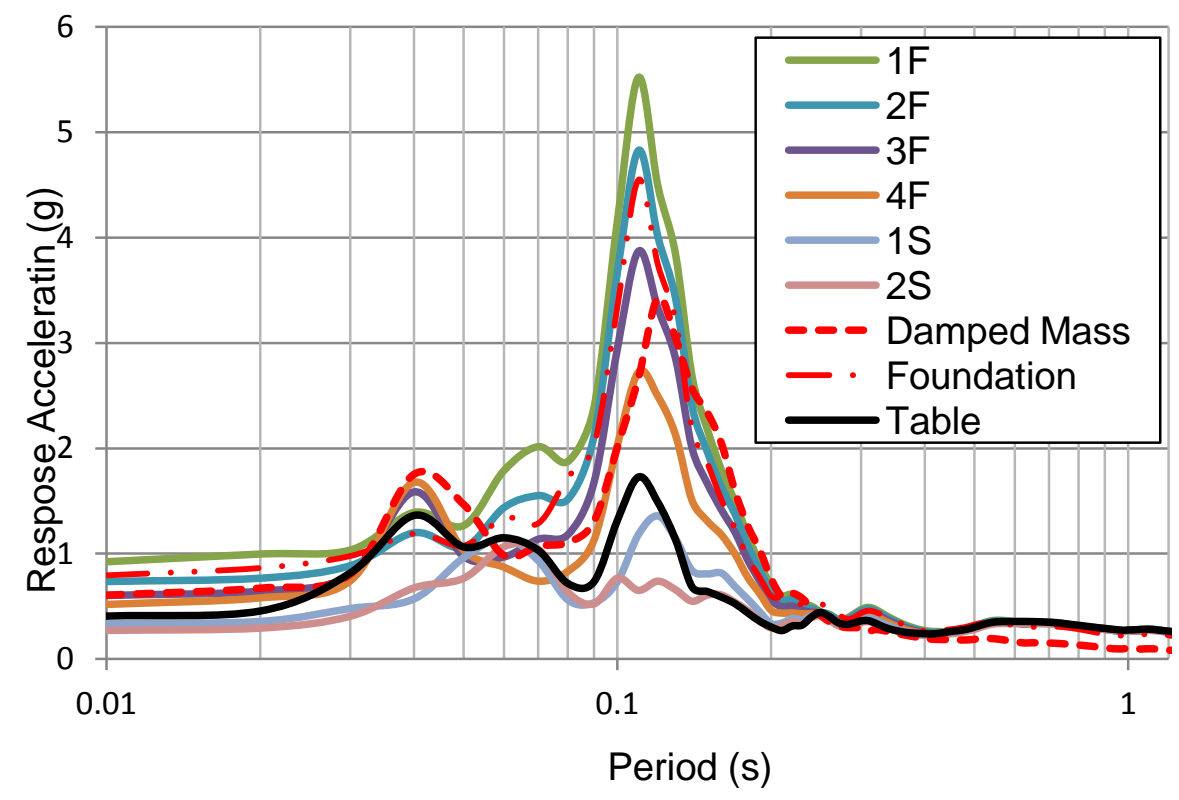

Figure 6.7: $5 \%$ damped spectra response acceleration for TCU $075 \mathrm{~W}$ (Phase 2) where $1 \mathrm{~S}$ and $2 \mathrm{~S}$ are the accelerometers directly below the model

A comparison of the site amplification presented in Figure 6.6 and 6.7, the peak response in Phase 2 test is less than the peak response acceleration in 
Phase1'. A 5\% spectral acceleration response plot was created to compare the spectral response of the soil over time. Figure 6.8 shows gradual increase in response acceleration over the testing period. This behavior can be attributed to soil stiffening due to the curing of fly ash over the course of the testing period.

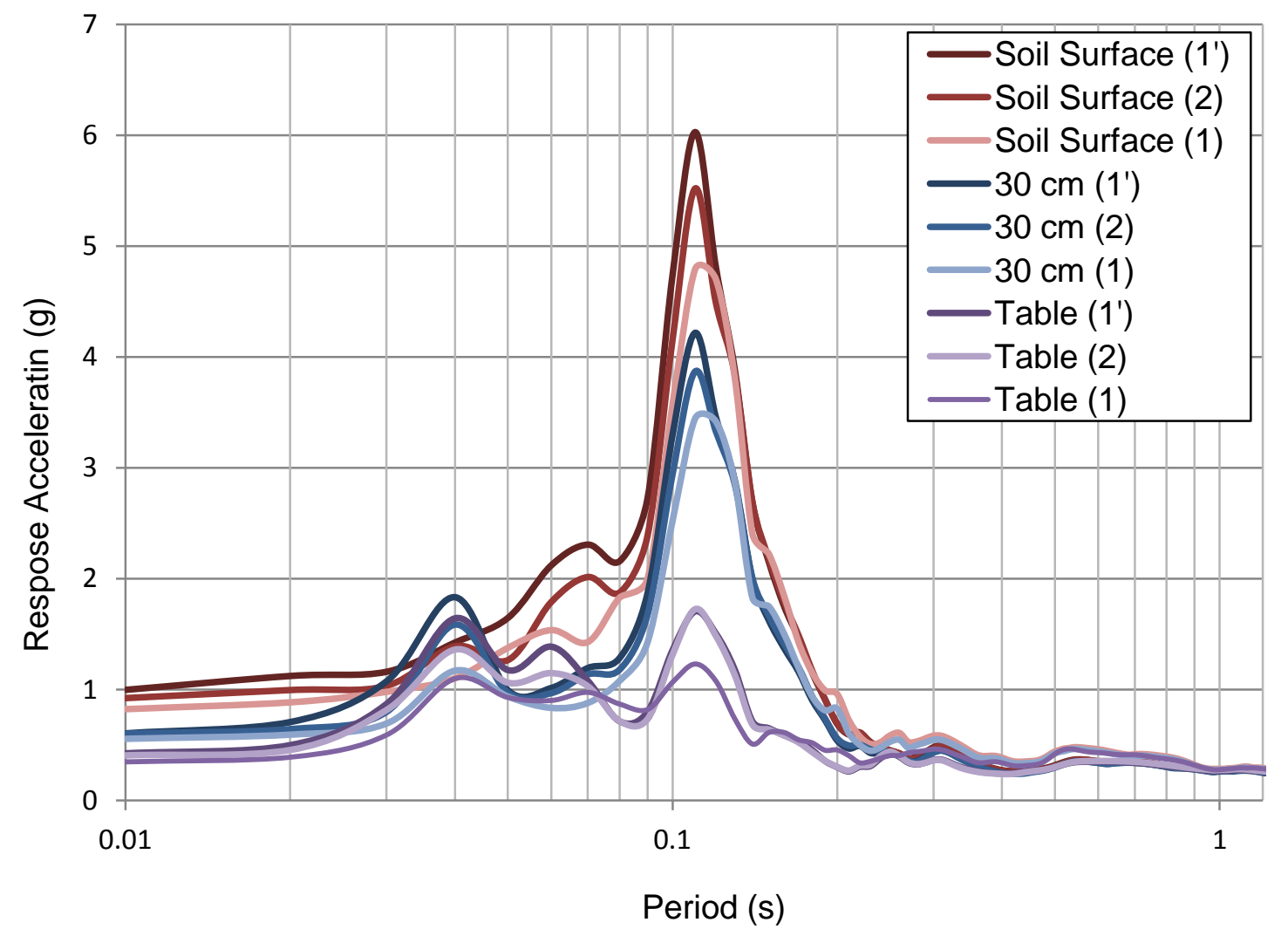

Figure 6.8: Comparison of $5 \%$ damped spectra response acceleration for TCU $075 \mathrm{~W}$ at the soil surface, $30 \mathrm{~cm}$ depth (3F), and table accelerometer locations from phases 1,2 and 1'.

\subsection{Ground Motion Parameters and Acceleration Response}

Ground motion parameters for each shaking event in Phase 1' and Phase 2 of this study are presented in Table 6-2 and Table 6-3 respectively. The ground motion parameters include the maximum recorded acceleration, the Arias Intensity $\left(\mathrm{I}_{\mathrm{a}}\right)$, the cumulative absolute velocity $(\mathrm{CAV})$, and the predominate period 
$\left(T_{p}\right)$. Arias intensity is a ground motion parameter that reflects the amplitude, frequency content, and duration of a ground motion estimated by applying the equation 6.1 (Kramer 1996).

$$
I_{a}=\int_{0}^{\infty}[a(t)]^{2} d t
$$

Similarly, cumulative absolute velocity is a ground motion parameter estimated by applying equation 6.2 (Kramer 1996).

$$
C A V=\int_{0}^{T_{d}}|a(t)| d t
$$

The predominate period $\left(T_{p}\right)$ is the period at which the maximum spectral acceleration response occurs in a response spectrum with $5 \%$ damping. The ground motion parameters are calculated based on the accelerations recorded at the soil surface to coincide with the parameters most commonly used in engineering design.

Table 6-2: Ground motion parameters for different shaking event during Phase 1'

\begin{tabular}{|l|r|r|r|r|}
\hline \multicolumn{7}{|c|}{ Phase 1' - Soil Surface } \\
\hline Shaking Event & Max Accel $(\mathrm{g})$ & $\mathrm{I}_{\mathrm{a}}(\mathrm{m} / \mathrm{s})$ & CAV $(\mathrm{m} / \mathrm{s})$ & $\mathrm{T}_{\mathrm{p}}(\mathrm{s})$ \\
\hline TCU075 N & 0.67 & 8.12 & 22.24 & 0.12 \\
\hline TCU075 W & 0.98 & 14.66 & 30.07 & 0.12 \\
\hline ELC180 & 0.96 & 15.05 & 35.29 & 0.10 \\
\hline ELC270 & 0.71 & 9.33 & 24.12 & 0.10 \\
\hline HSUP045 & 0.50 & 0.99 & 4.40 & 0.04 \\
\hline HSUP135 & 0.80 & 4.75 & 8.47 & 0.04 \\
\hline JOS000 & 0.78 & 4.68 & 18.54 & 0.12 \\
\hline JOS090 & 0.91 & 8.08 & 23.67 & 0.12 \\
\hline LO9000 & 0.50 & 0.99 & 4.40 & 0.06 \\
\hline LO9009 & 0.35 & 0.27 & 3.05 & 0.06 \\
\hline
\end{tabular}


Table 6-3: Ground motion parameters for different shaking event during Phase 2

\begin{tabular}{|l|r|r|r|r|}
\hline \multicolumn{7}{|c|}{ Phase 2 - Soil Surface } \\
\hline Shaking Event & Max Accel $(\mathrm{g})$ & $\mathrm{I}_{\mathrm{a}}(\mathrm{m} / \mathrm{s})$ & CAV $(\mathrm{m} / \mathrm{s})$ & $\mathrm{T}_{\mathrm{p}}(\mathrm{s})$ \\
\hline TCU075 N & 0.60 & 6.41 & 19.89 & 0.12 \\
\hline TCU075 W & 0.90 & 12.21 & 27.64 & 0.12 \\
\hline ELC180 & 0.90 & 11.24 & 30.90 & 0.10 \\
\hline ELC270 & 0.64 & 7.25 & 21.51 & 0.10 \\
\hline HSUP045 & 0.42 & 0.79 & 4.02 & 0.04 \\
\hline HSUP135 & 0.79 & 3.55 & 7.49 & 0.04 \\
\hline JOS000 & 0.64 & 4.10 & 17.73 & 0.12 \\
\hline JOS090 & 0.83 & 6.79 & 21.94 & 0.12 \\
\hline LO9000 & 0.29 & 0.32 & 3.53 & 0.06 \\
\hline LO9009 & 0.32 & 0.23 & 2.72 & 0.06 \\
\hline
\end{tabular}

\subsection{Acceleration Reduction/Dynamic Acceleration}

Acceleration time histories were collected for both Phase 1' and Phase 2 shake table investigations at accelerometers locations shown in Figure 5.11 and Figure 5.12 respectively. The acceleration time history data was baseline corrected and filtered using the Seismosignal software (Seismosoft 2012) to reduce noise and minimize the long period drift after integration to velocity and displacement time histories. The acceleration time history data was filtered using a fourth-order bandpass filter allowing frequencies between $0.1 \mathrm{~Hz}$ and $25 \mathrm{~Hz}$ to pass through.

The filtered and base line corrected acceleration time histories were observed having been phase shifted from the raw acceleration reading as an 
artifact of the applied changes. This phase shift is shown in Figure 6.9 for a small time window to better explemplify the changes. In order that the corrected acceleration time histories would accurately coincide with the wave form of the raw acceleration time histories, all corrected acceleration time histories were phase shifted by $0.15 \mathrm{sec}$. This adjustment serves to ensure that the corrected and raw accelerations are in phase with each other, in order to accurately observe the pressure response due to these accelerations. The adjusted in phase acceleration time histories is presented in Figure 6.10.

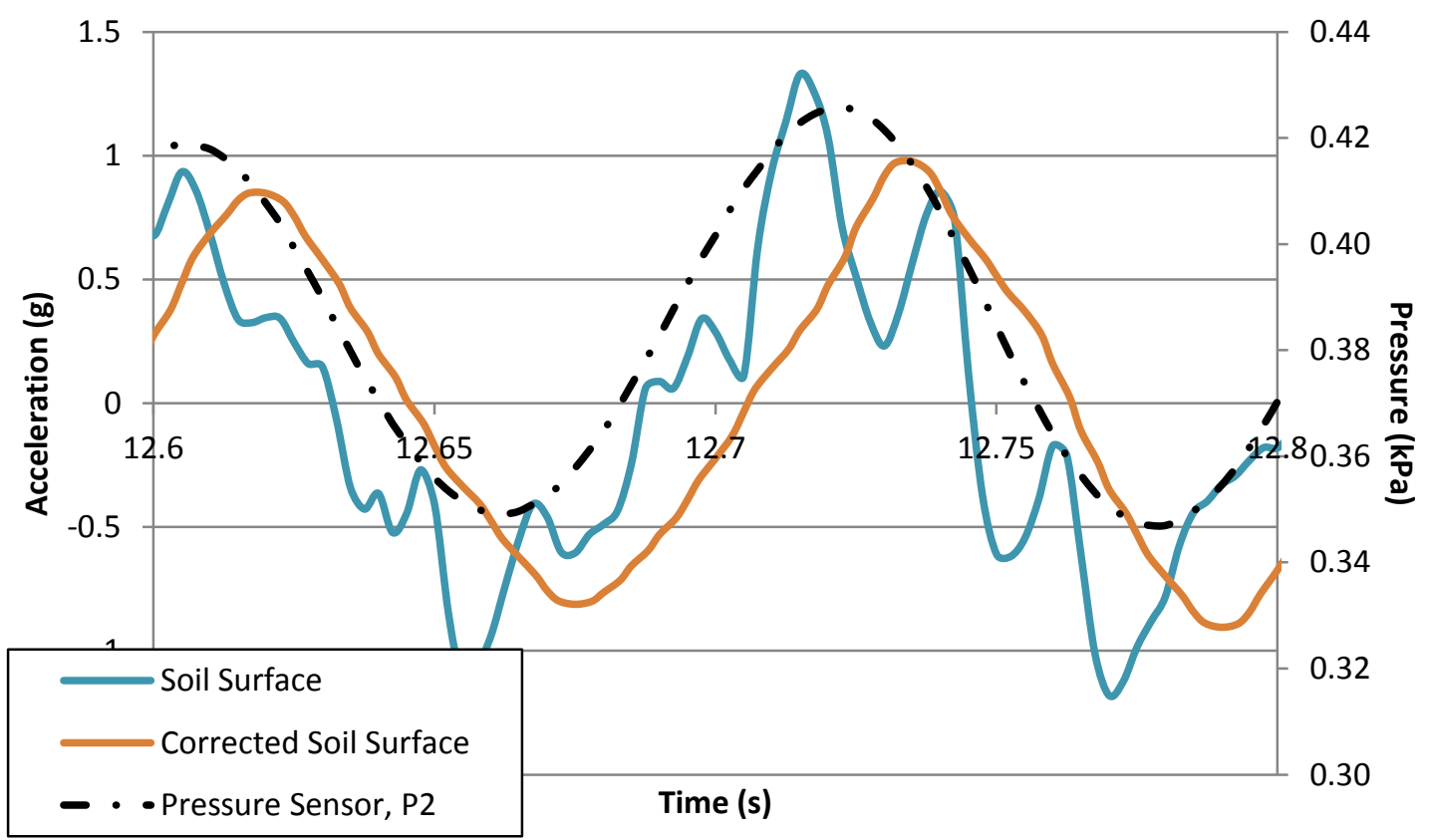

Figure 6.9: Out of phase relationship between raw acceleration data and corrected acceleration data for TCU $075 \mathrm{~W}$ motion (Phase 1') 


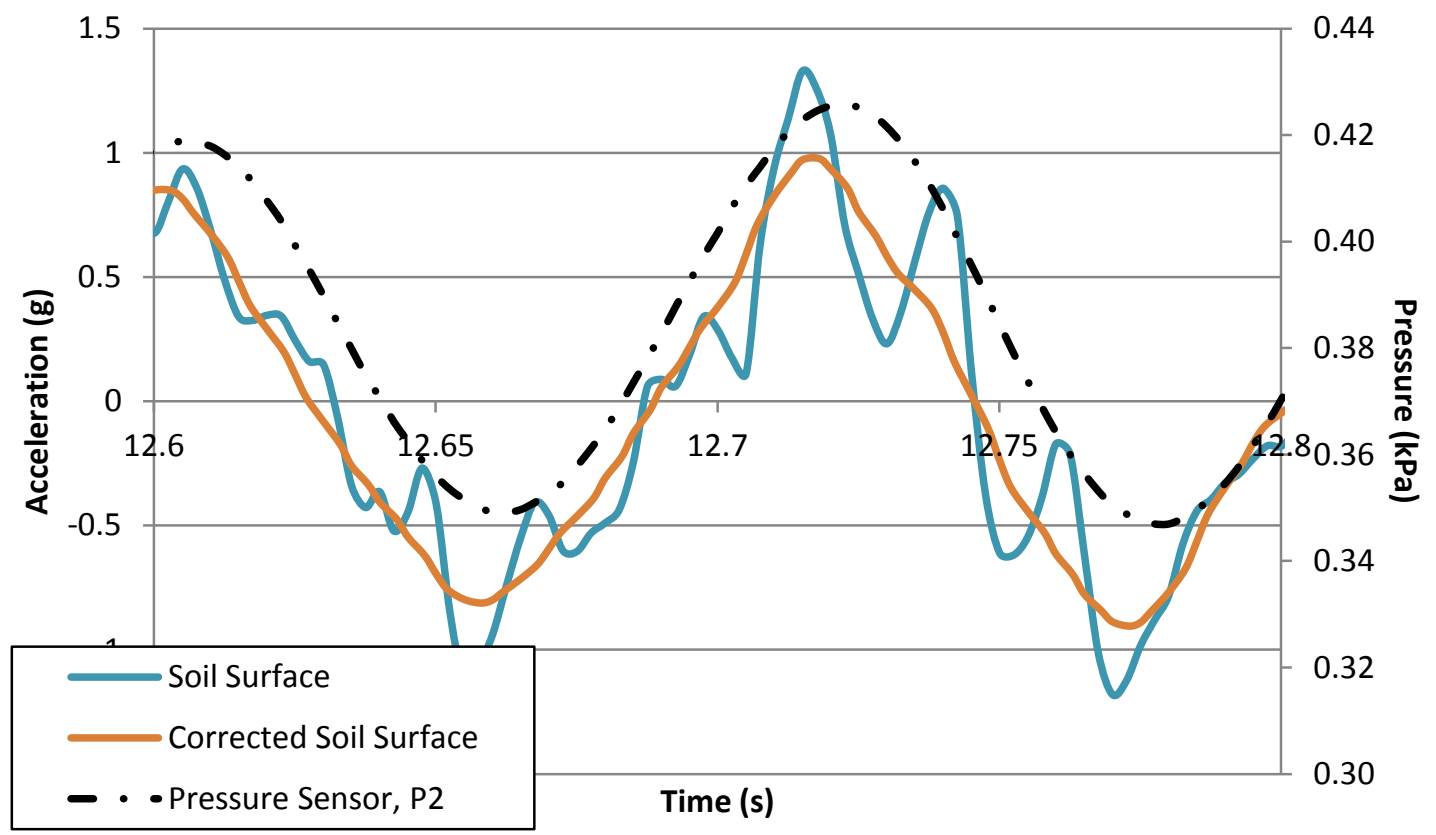

Figure 6.10: In phase relationship between raw acceleration data and corrected acceleration data after $0.15 \mathrm{sec}$ shift for TCU $075 \mathrm{~W}$ motion

Figure 6.11 shows a few cycles of acceleration as recorded at the soil surface, shake table, model foundation, soil depth of $30 \mathrm{~cm}$ (wall height), and the shake table for the TCU075W input motion. Looking at the acceleration wave forms of the shake table in comparison to the accelerations recorded a near the top of the soil column, there is a phase difference. Although there is some uniformity between the accelerations at the model foundation and in the soil at that level, a slight phase difference is also observed between the accelerations recorded in the soil and at the soil surface. These phase differences are thought to indicate that inertial forces, and by extension dynamic earth pressures, do not occur simultaneously over the face of the wall. 


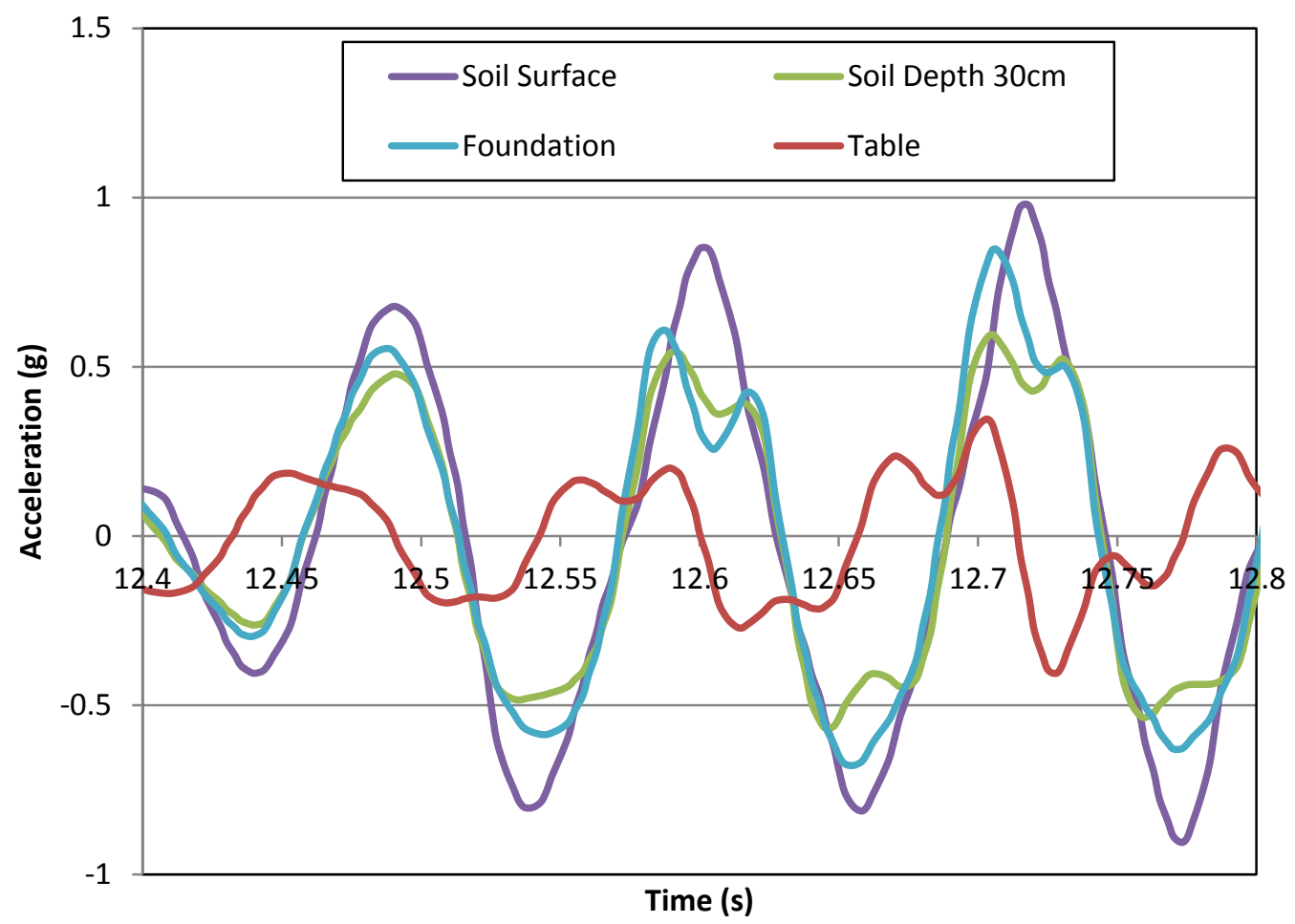

Figure 6.11: Acceleration cycles recorded at soil surface, shake table, model foundation and a soil depth of $30 \mathrm{~cm}$ for the TCU075W input motion

\subsection{Total Lateral Earth Pressures}

Total earth pressures here are the summation of the initial static pressures due to the soil and the additional dynamic pressures developed during shaking. This section presents pressure sensor calibrations, findings of earth pressure time histories in relation to soil accelerations, and analysis of the dynamic component of the total earth pressures along the face of the model wall.

\subsubsection{Pressure Sensor Calibration and Reduction}

Total earth pressures were measured directly by pressure sensors on the model wall face to explore the development of seismic earth pressures shaking. These pressure were collected for Phase 1' and Phase 2 shake table 
investigations at locations shown in Figure 5.10. The recorded pressure time histories for each shaking event were calibrated and reduced for analysis. Similar to pressure sensor limitations reported by Al Atik (2008), the pressure sensors used in this investigation were susceptible to errors in linearity, repeatability, and drift. The original calibration factors provided by the manufacturer did not accurately represent the pressures applied to the sensor. New calibration correction factors were developed in order to correspond the pressures being applied. The recorded pressure time histories were first calibrated to match the response from water submergence testing as described in Chapter 3 to account for the effects of the protective sleeve on the response of the pressure sensors.

The prototype San Francisco Bay Mud is found to have an average friction angle of $34^{\circ}$ (Bonaparte and Mitchell 1979). The use of this friction angle as an approximation to the friction angle of the model soil is verified with the measured undrained shear strength. The results of the T-bar pull out tests estimate the undrained shear strength (Su) as $2.23 \mathrm{kPa}$ for top $30 \mathrm{~cm}$ of the soil column. Using the relationship for undrained soil that $\mathrm{T}=\mathrm{Su}$. where $\mathrm{T}$ is the shear strength of the soil, in combination with the relationship that $T=\sigma^{\prime} \tan \left(\varphi^{\prime}\right)$, where $\sigma^{\prime}$ and $\varphi^{\prime}$ are the effective stress and friction angle respectively, a relationship can be derived between the undrained strength of the soil and the friction angle. A $34^{\circ}$ friction angle approximates an undrained shear strength of around $2.2 \mathrm{kPa}$ between model soil depths of $20 \mathrm{~cm}$ and $25 \mathrm{~cm}$ which shows agreement with the T-bar test results. The average friction angle of $34^{\circ}$ is adopted as a reasonable 
approximation of the drained friction angle to approximate the theoretical active earth pressure along the wall face of the model.

\subsubsection{Pressure Time History}

In Figure 6.12 the pressure time history in Phase 1 ' is shown to be in phase with the acceleration wave forms developed by the input ground motion. Although not presented, the pressure wave form appears to be in phase with the ground acceleration for pressure sensor depths of $10 \mathrm{~cm}, 15 \mathrm{~cm}$ and $20 \mathrm{~cm}$. The integrated velocity time history on the other hand, shows a significant delay between peak velocities and peak pressures presented in Figure 6.13.

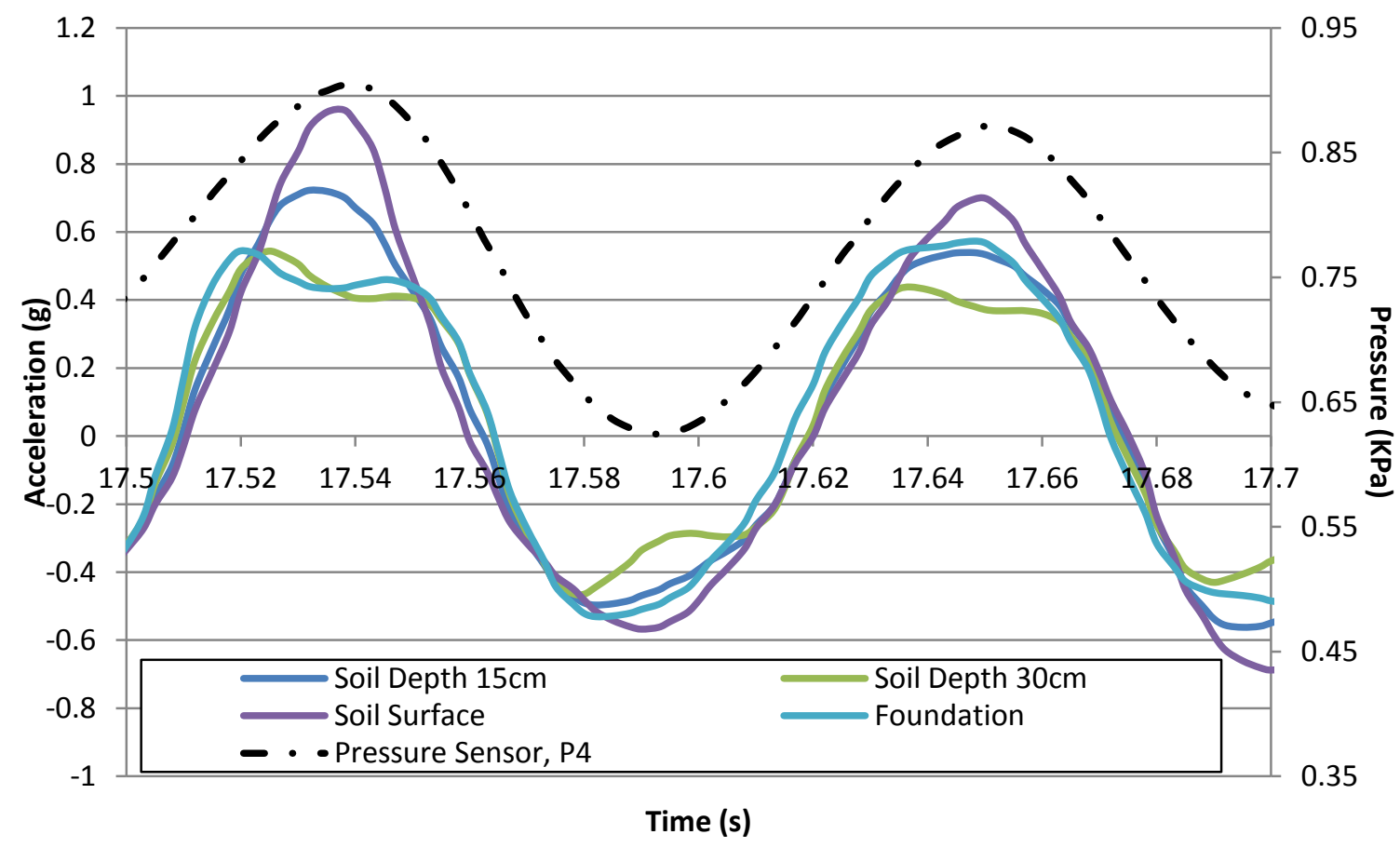

Figure 6.12: Pressure time history superimposed on acceleration time histories for the El Centro 180 motion (Phase 1') 


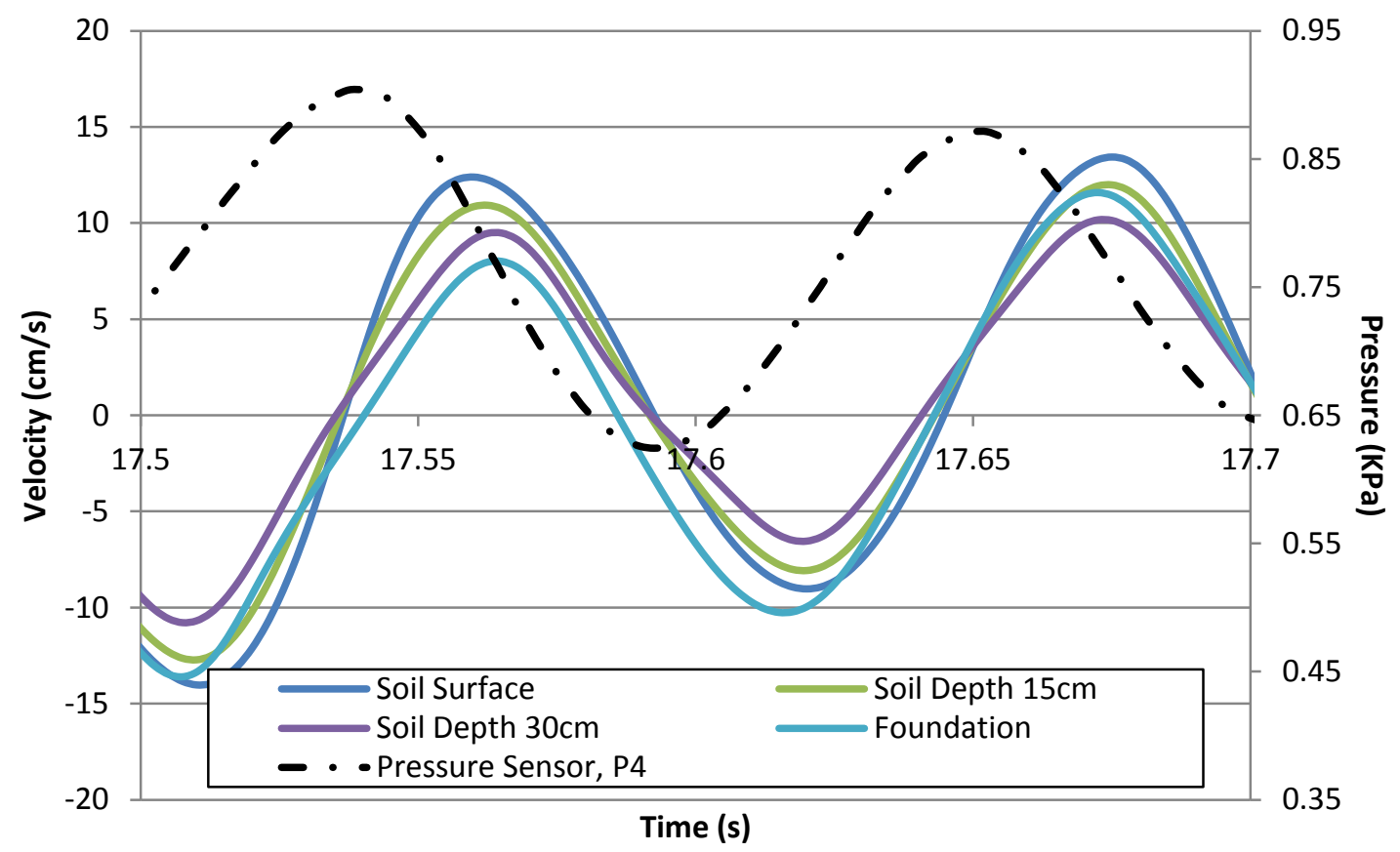

Figure 6.13: Pressure time history superimposed on velocity time histories for the El Centro 180 motion (Phase 1')

For Phase 2, Figure 6.14 presents the relationship between pressures and acceleration at depths of $10 \mathrm{~cm}, 15 \mathrm{~cm}, 20 \mathrm{~cm}$ and $25 \mathrm{~cm}$ for a model basement wall with height of $30 \mathrm{~cm}$. Observing the pressure development on the basement wall at a specific point in time, at depths of $10 \mathrm{~cm}$ and $15 \mathrm{~cm}$ the pressure time history is in phase with the acceleration time history, suggesting that the top half of the wall moves in line with input motion. Further down the wall, the pressure time history is gradually shifted out of phase with the acceleration time history. At a depth of $20 \mathrm{~cm}$, the pressure time history lags the acceleration time history about 0.2 wavelengths, where the wavelength is about .12 seconds. At a depth of $25 \mathrm{~cm}$, the pressure time history lags the acceleration time history about 0.66 wavelengths. This behavior can be attributed to the interaction of the soil with the scale model inclusion of a SDOF oscillator to the model in Phase 2. 

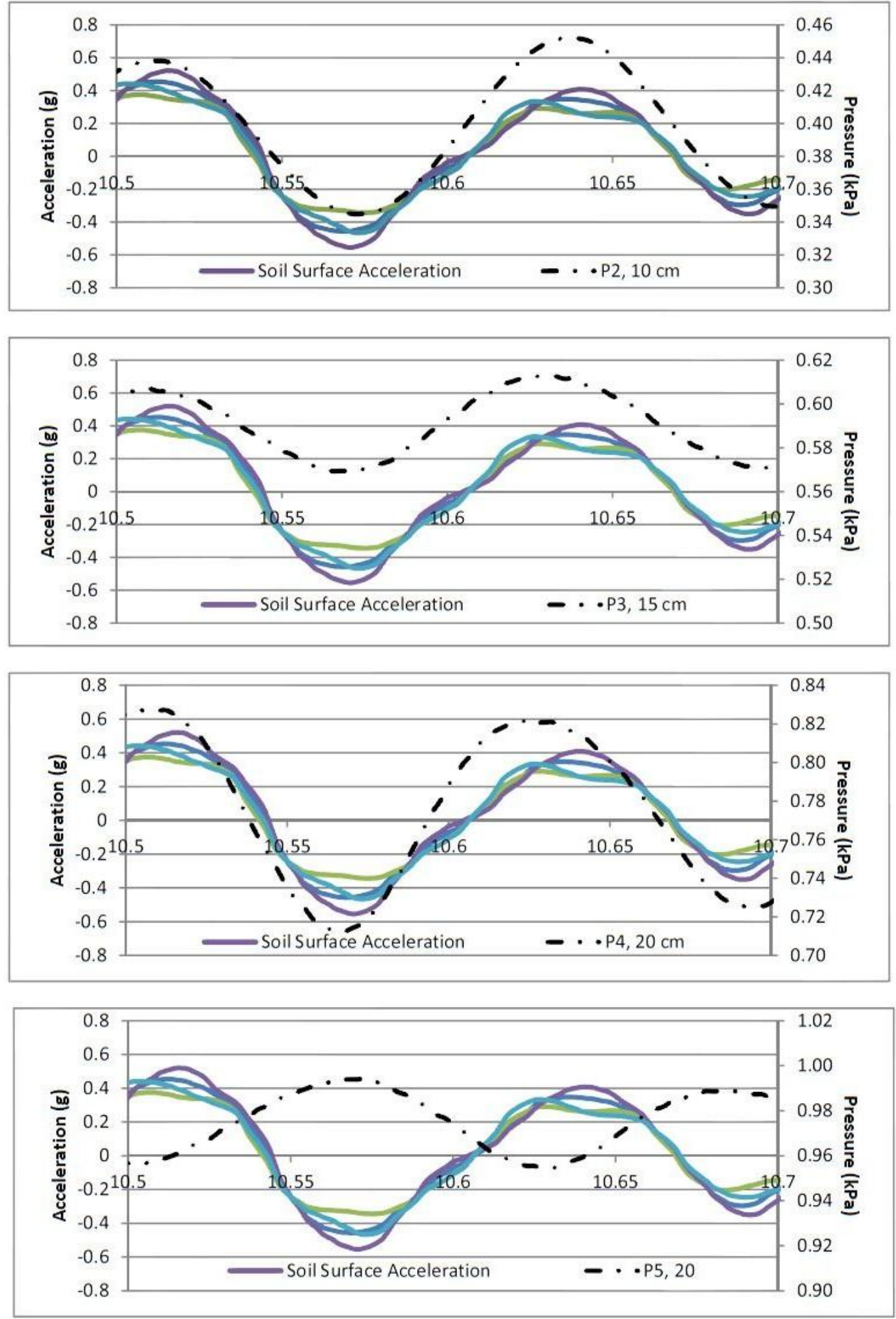

Figure 6.14: Pressure time history for each pressure sensor superimposed on acceleration time history for the TCU075N motion (Phase 2) 


\subsubsection{Dynamic Increment}

The dynamic pressure increment is the component of the total lateral earth pressure induced by horizontal ground motion above the initial static pressures. Figure 6.15 and Figure 6.16 show the development of the seismic increment profile in terms of a percent increase above static pressures for Phases 1' and 2. Figures representing the seismic increment profile for each of the ground motion used in the current investigation are presented in Appendix C.

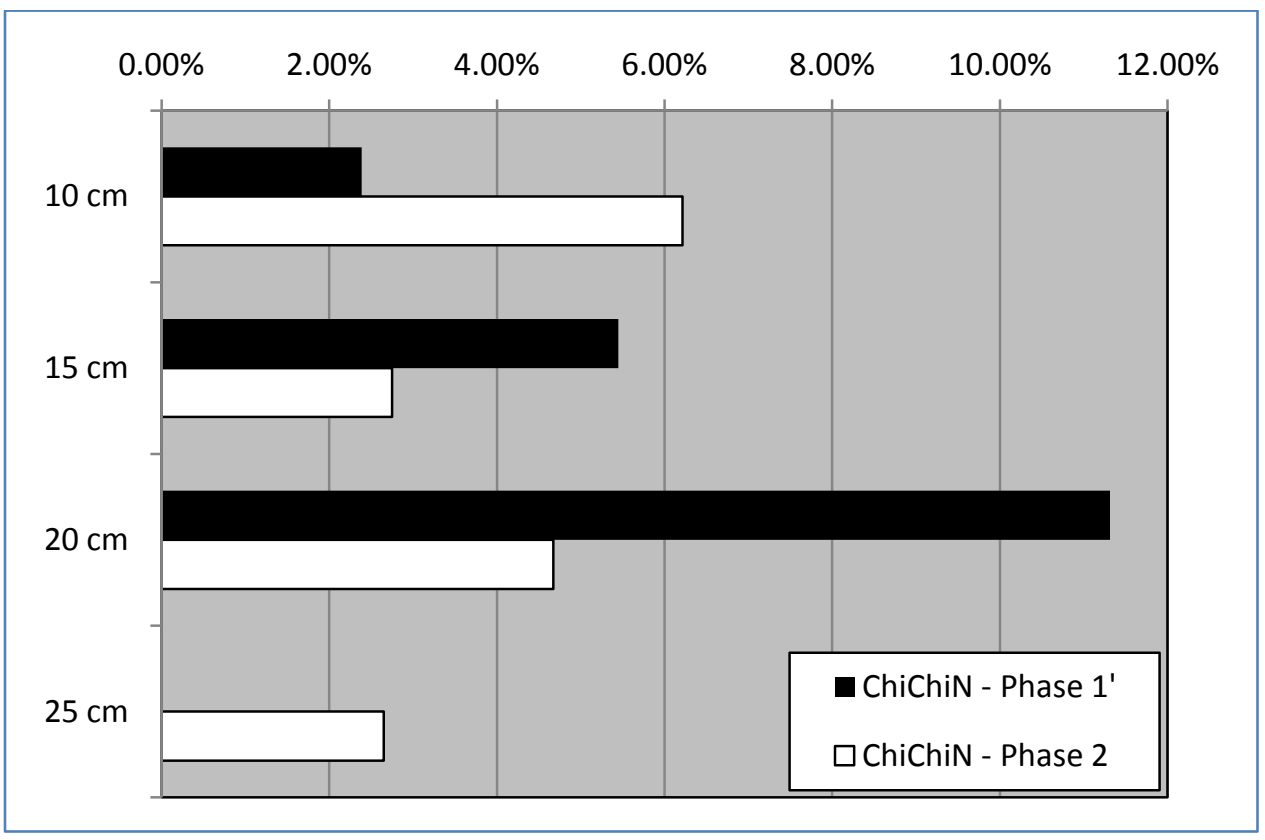

Figure 6.15: Peak dynamic increment profile in terms of percent increase above static pressures for TCU $075 \mathrm{~N}$ motion 


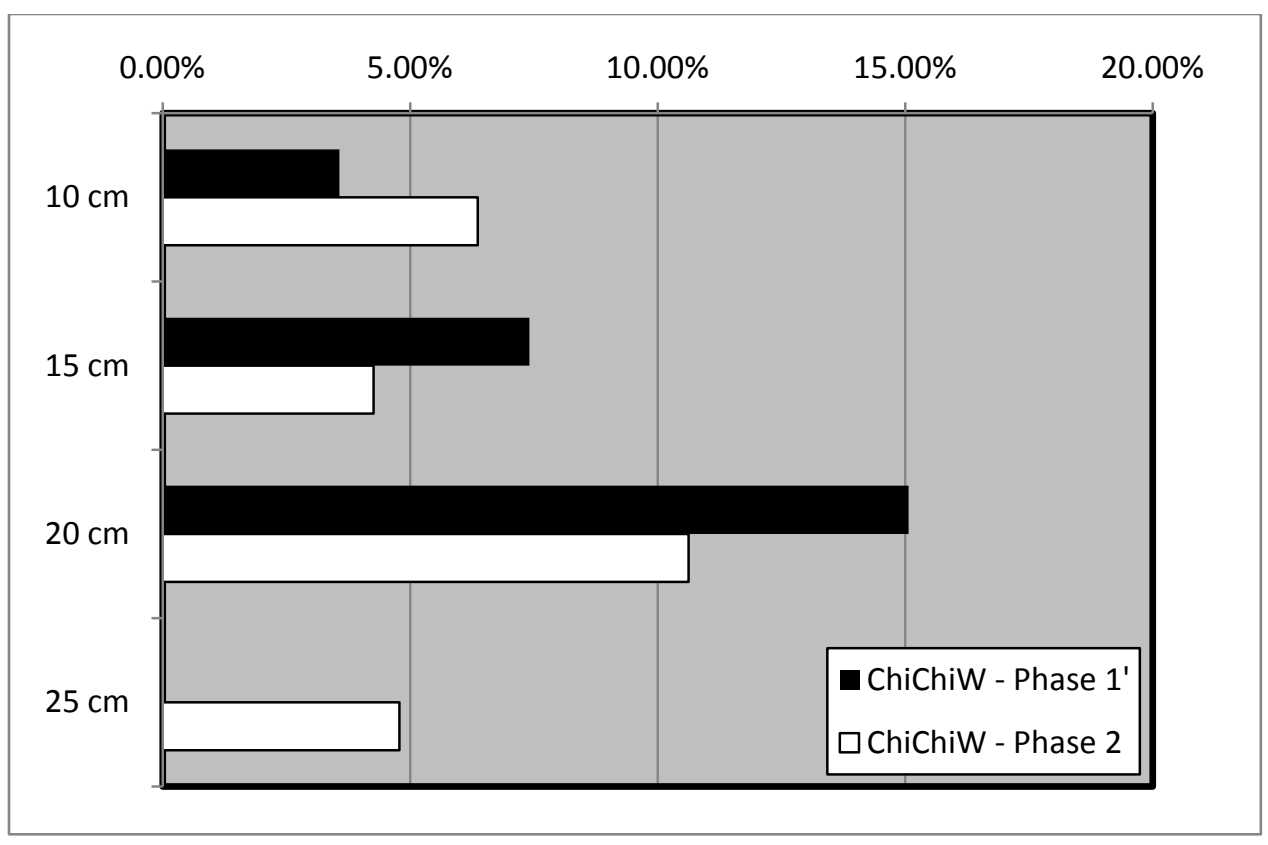

Figure 6.16: Dynamic increment profile in terms of percent increase above static pressures for TCU $075 \mathrm{~W}$ motion

Average dynamic increment profile is presented in Figure 6.17. At the depth of a given pressure sensor, the dynamic increment measured for each input motion was averaged together and plotted with depth. For the Phase 1' configuration, the average dynamic increment profile forms a triangular distribution. However, the Phase 2 model configuration varies with the depth of the pressure sensor. The average dynamic increment profile is used to characterize the pressure distribution for both configurations of the model. 


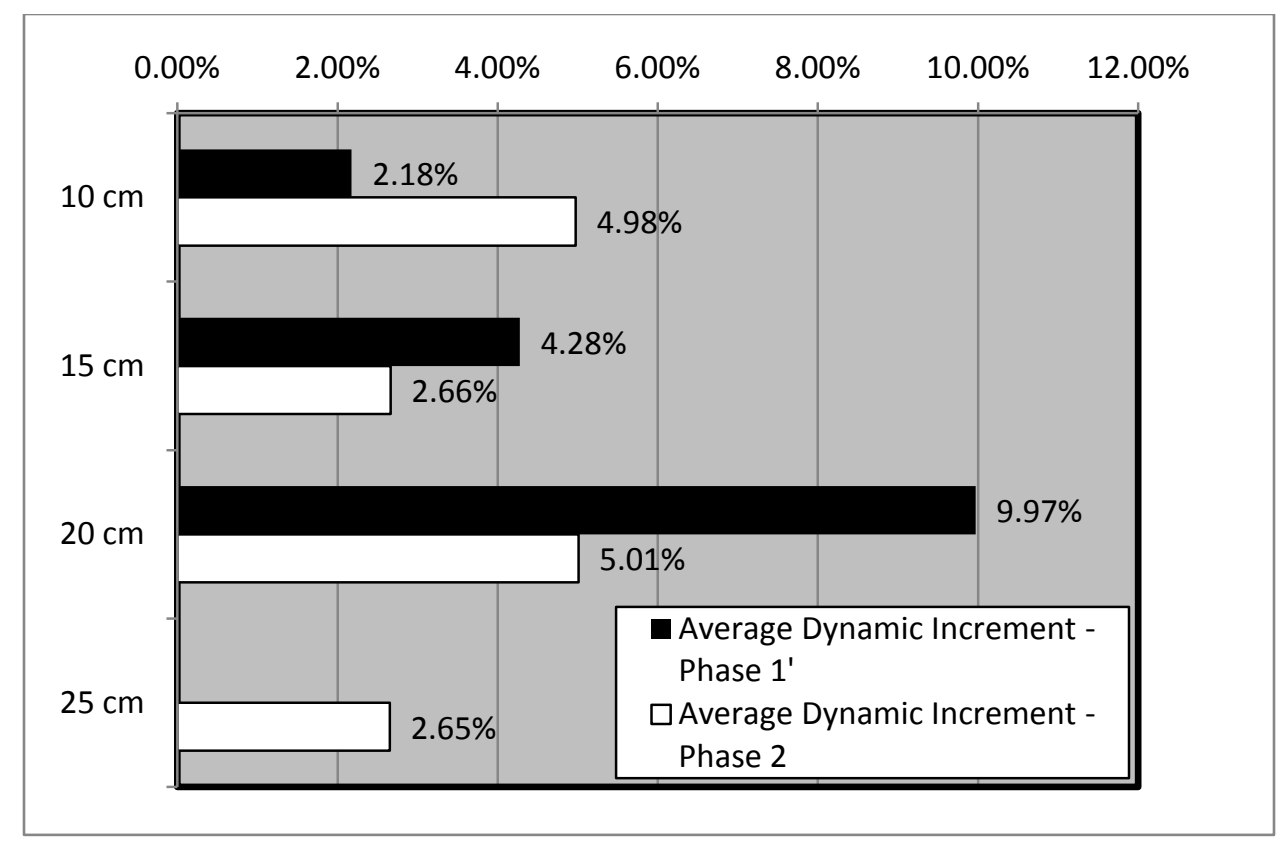

Figure 6.17: Average dynamic increment profile in terms of percent increase above static pressures

The dynamic increment is also presented as a function of arias intensity and cumulative absolute velocity. For each input motion, the measured peak dynamic increment from each pressure sensor was averaged together. As a result, one average dynamic increment is taken as representative of the pressure developed during a shaking event. Figure 6.18 and Figure 6.19 show the average peak dynamic increment from Phase 1' as a function of arias intensity and cumulative absolute velocity respectively. Bar and whiskers indicate the maximum and minimum increment observed for that event. As shown in Figure 6.18, the average dynamic increment correlates linearly with arias intensity. A similar relationship is presented in Figure 6.19 for cumulative absolute velocity ground motion parameter. 


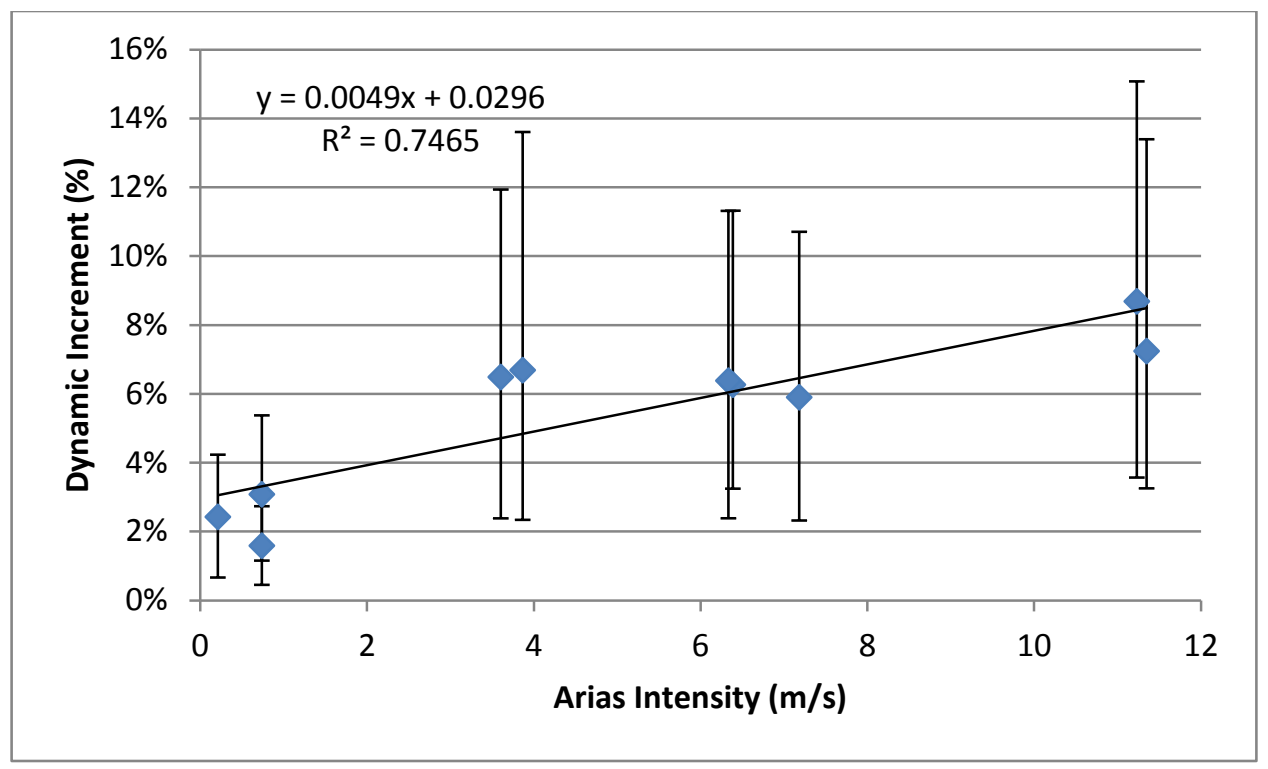

Figure 6.18: Average peak dynamic increment as a function of Arias Intensity (Phase 1')

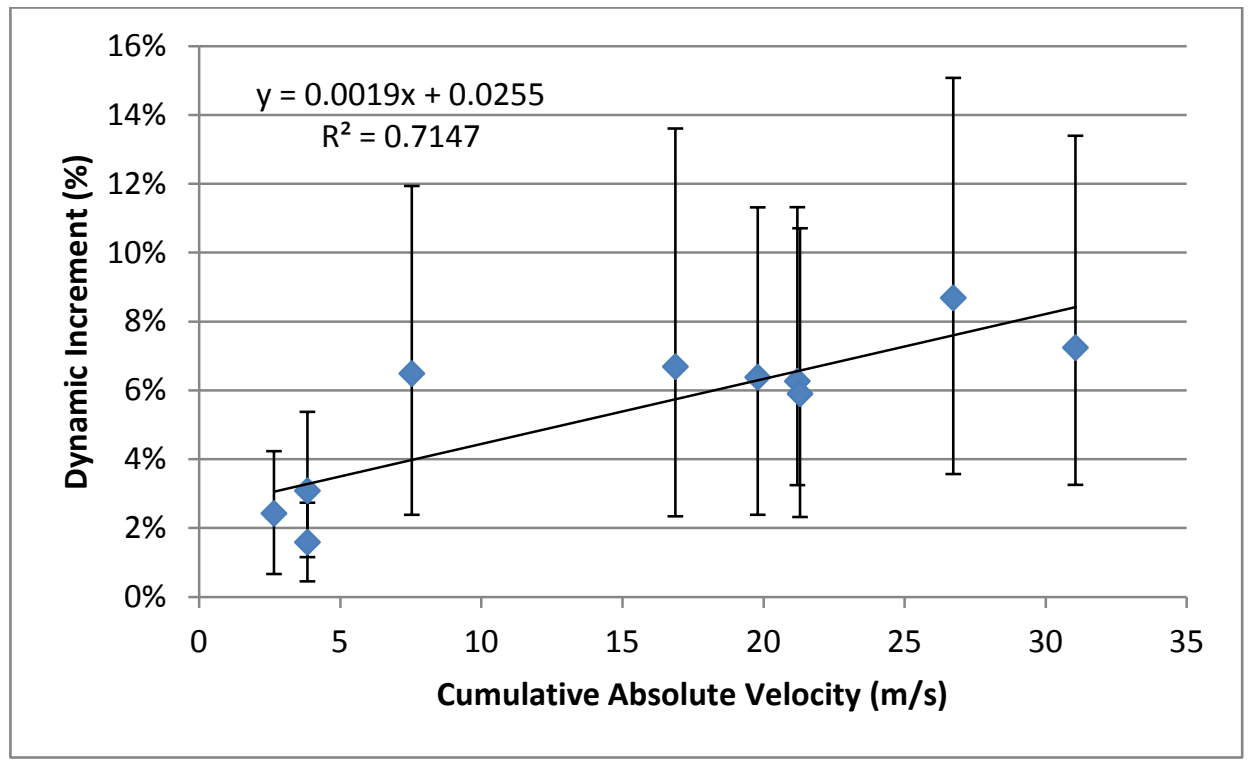

Figure 6.19: Average peak dynamic increment as a function of Cumulative Absolute Velocity (Phase 1')

Figure 6.20 presents the average dynamic increment from Phase 2 as a function arias intensity. Phase 2 shows a steady increase of the average dynamic increment over and the arias intensity increases. Similar correlations are 
made with results from the phase 1 ' configuration. Indicators to variations in the dynamic increment due to wall type is not prominent. A similar relationship is presented in Figure 6.21 for the cumulative absolute velocity ground motion parameter.

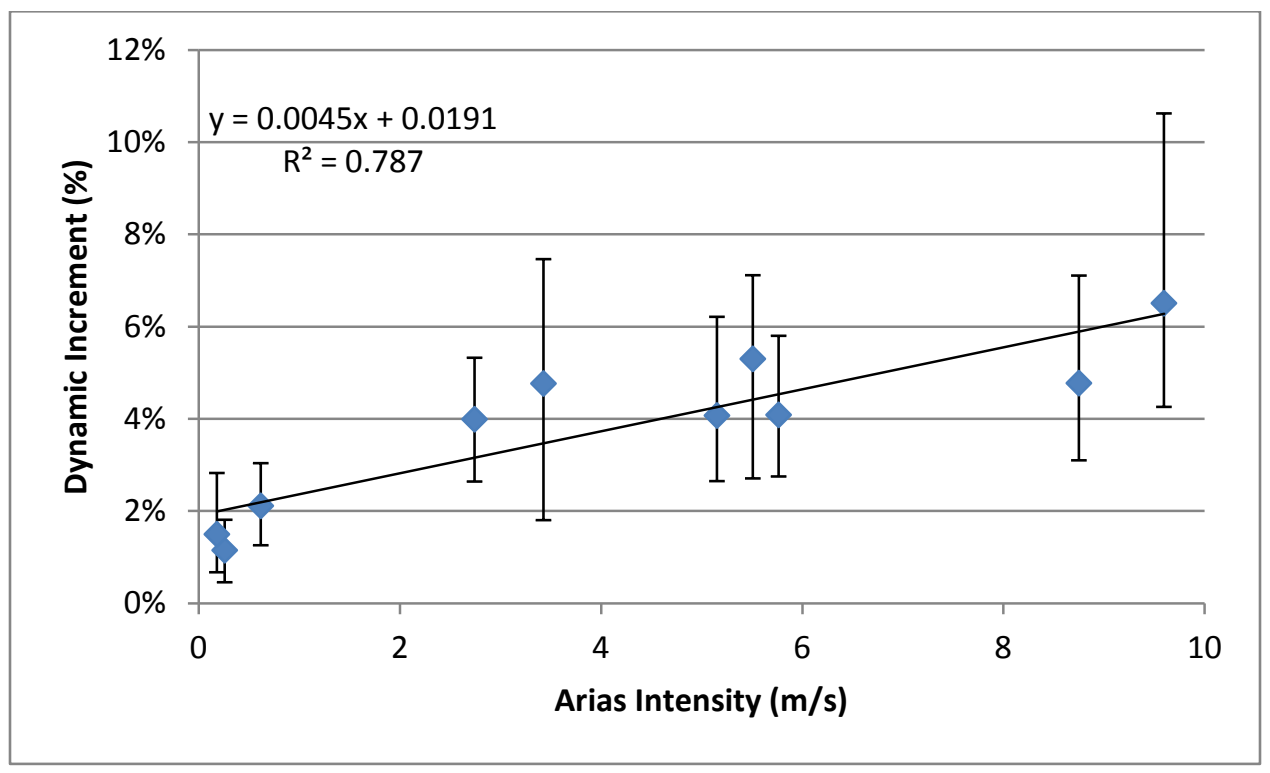

Figure 6.20: Average peak dynamic increment as a function of Arias Intensity (Phase 2) 


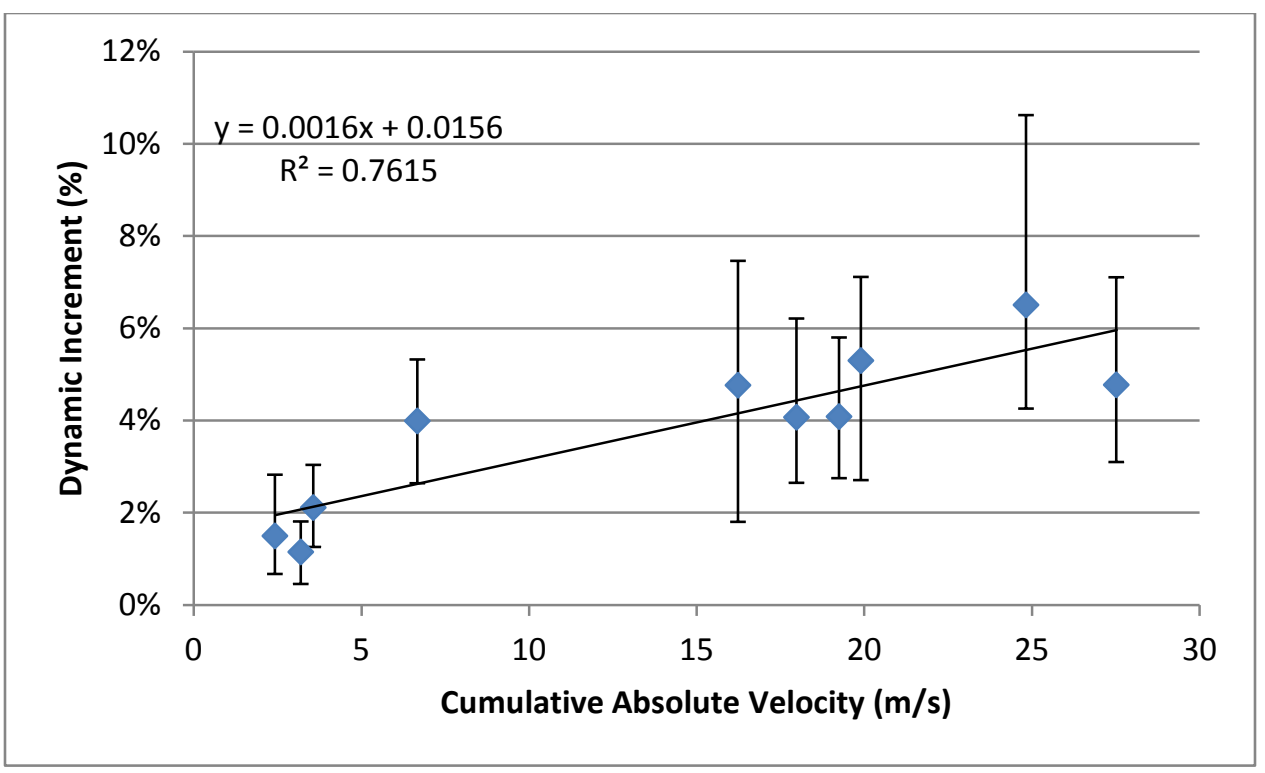

Figure 6.21: Average peak dynamic increment as a function of Cumulative Absolute Velocity (Phase 2)

\subsection{Evaluation of Seed and Whitman (1970)}

As previously discussed in Chapter 2, the current standard of practice for evaluating seismic earth pressures is the simplified Mononobe-Oakabe (M-O) method presented in Seed and Whitman (1970). The method is developed based on a number of assumptions which include a backfill consisting of dry cohesionless materials. Lew et al (2010) reports the M-O method as "extremely conservative" in the prediction of seismic earth pressures.

The conservative nature of the $\mathrm{M}-\mathrm{O}$ method may be related to confusion regarding the specification of the horizontal ground acceleration, otherwise referred to as the seismic coefficient $\left(k_{h}\right)$. Although, Whitman (1991) and NEHRP documents recommend that the seismic coefficient be taken as the peak ground acceleration (PGA) in most cases, in practice, the seismic coefficient for basement and retraining walls is often taken as less than the design PGA. 
The justification for the reduced seismic coefficient is based on a few considerations as reported in Lew et al (2010). One reason is that the M-O method is a pseudo-static procedure that uses pseudo-static coefficients to represent dynamic lateral loading. Another reason suggests that the PGA may not accurately represent the effective ground acceleration over the duration of shaking. Additionally, since vertical shear wave propagation through backfill soil is potentially out of phase, a seismic coefficient reduction may average lateral loads over the height of the wall. Furthermore, the Federal Highway Administration (FHWA) design guide suggests that "for retaining walls wherein limited amounts of seismic deformation is acceptable..., use of a seismic coefficient of between one-half and two-thirds of the peak horizontal acceleration divided by gravity would appear to provide a wall design that will limit deformations in the design earthquake to small values." (Kavazanjian, Matasović, Hadj-Hamou, and Sabatini, 1997)

Due to the reasons mentioned above, horizontal ground acceleration $\left(k_{h}\right)$ may be taken as a fraction of the PGA for cohesionless backfill or retained earth materials depending on the site's predicted peak ground acceleration as presented in Table 6-4.

Table 6-4: Horizontal Ground Acceleration for Cohesionless Backfill or Retained Earth Materials (from Lew et al (2010))

\begin{tabular}{|c|c|}
\hline $\begin{array}{l}\text { Peak Ground } \\
\text { Acceleration (g) }\end{array}$ & $\begin{array}{c}\text { Recommended } \\
\text { Kh }\end{array}$ \\
\hline$<0.4$ & 0 \\
\hline 0.4 & 0.25 PGA \\
\hline 0.6 & 0.5 PGA \\
\hline 1.0 & 0.67 PGA \\
\hline
\end{tabular}


Although the M-O method was developed with the assumption of a dry cohesionless backfill, it is common for retained earth to have some cohesion. Retained earth with some cohesion in the backfill can reduce static lateral earth pressures due to the electrostatic attraction between clay particles, and by extension the inclusion of cohesion is expected to reduce lateral seismic earth pressures. The following sections evaluate the $\mathrm{M}-\mathrm{O}$ method with data collected from the current shake table investigations.

\subsubsection{Seismic Coefficient}

In the application of the M-O method for cohesionless soils , a seismic coefficient $\left(k_{h}\right)$ of between $1 / 2$ and $2 / 3$ of the PGA divided by gravity would, according to FHWA standards, result in a design with small acceptable deformations. The inclusion of cohesion in retained earth may further reduce the aforementioned wall deformations and require an even greater reduction of the PGA as the seismic coefficient. In the current investigation, the seismic coefficient is back calculated from measured total lateral earth pressures (due to the sum of static and dynamic earth pressures) on the model wall face.

For the back calculation of the seismic coefficient, the corrected measured total earth pressures are separated into components consisting of the initial static pressure and the dynamic pressure induced by ground motion. The static pressure component was extrapolated as a triangular distribution over the height of the wall with a base static pressure of $\mathrm{K}_{\mathrm{a}} \mathrm{H}$, where $\mathrm{K}_{\mathrm{a}}$ is the coefficient of active earth pressure, $\nu$ is the unit weight of the soil, and $\mathrm{H}$ is height of the wall. The resultant of the static pressure distribution is $\mathrm{P}_{\mathrm{A}}$. The dynamic pressure 
component is the maximum pressure throughout the time history at each sensor location on the wall face above the initial static pressures. For the back calculation, the dynamic pressure distribution is approximated as a triangular distribution based on the dynamic pressure components measured at the pressure sensor locations on the wall face. The dynamic pressure triangular distribution fits a linear regression through the data with an intercept at the top of the wall. This approximation removes some variation in the dynamic increment $\left(\Delta \mathrm{K}_{\mathrm{AE}}\right)$ with depth presented in Section 6.10.3, but is consistent with the application of the method. The resultant of the dynamic pressure distribution is $\Delta \mathrm{P}_{\mathrm{AE}}$. The $\Delta \mathrm{P}_{\mathrm{AE}}$ equation is manipulated as

$$
\Delta K_{A E}=\frac{\Delta P_{A E}}{\frac{1}{2} \gamma H^{2}}
$$

to calculate the dynamic increment. Finally, using the Seed and Whitman (1970) simplification, the seismic coefficient is determined as

$$
K_{h}=\frac{4}{3} \Delta K_{A E}
$$

The back calculated seismic coefficients for cohesive retained earth range from about $2 \%$ to less than $8 \%$ of the peak acceleration measured at the soil surface. The results for both Phase1 and Phase 2 are presented in Table 6-5. 
Table 6-5: Back calculated seismic coefficient and percent of soil surface acceleration for Phase 1 and Phase 2

\begin{tabular}{|c|c|c|}
\hline Phase 1' & $\mathbf{K}_{\mathbf{h}}$ & \% ACCL Soil Surface \\
\hline Josh 000 & 0.048 & $7.23 \%$ \\
\hline Josh 090 & 0.043 & $4.71 \%$ \\
\hline HSUP 045 & 0.021 & $4.22 \%$ \\
\hline HSUP 135 & 0.045 & $5.65 \%$ \\
\hline Elcen 180 & 0.050 & $5.23 \%$ \\
\hline Elcen 270 & 0.041 & $5.76 \%$ \\
\hline LO9 000 & 0.011 & $2.19 \%$ \\
\hline LO9 090 & 0.017 & $6.01 \%$ \\
\hline Chichi N & 0.044 & $6.56 \%$ \\
\hline Chichi W & 0.060 & $6.12 \%$ \\
\hline
\end{tabular}

\begin{tabular}{|c|c|c|}
\hline Phase 2 & $\mathbf{K}_{\mathbf{h}}$ & \% ACCL Soil Surface \\
\hline Josh 000 & 0.022 & $3.59 \%$ \\
\hline Josh 090 & 0.025 & $2.96 \%$ \\
\hline HSUP 045 & 0.010 & $2.37 \%$ \\
\hline HSUP 135 & 0.019 & $2.43 \%$ \\
\hline Elcen 180 & 0.023 & $2.54 \%$ \\
\hline Elcen 270 & 0.019 & $3.04 \%$ \\
\hline LO9 000 & 0.006 & $1.97 \%$ \\
\hline LO9 090 & 0.007 & $3.45 \%$ \\
\hline Chichi N & 0.019 & $3.14 \%$ \\
\hline Chichi W & 0.033 & $3.63 \%$ \\
\hline
\end{tabular}

\subsubsection{Total Lateral Earth Pressures}

The earth pressures measured in this investigation are used to evaluate the validity of the M-O method applicability to predict the development of total lateral earth pressures on a wall retaining earth with some cohesion. For the analysis, the seismic coefficient is taken as both $2 \%$ and $8 \%$ of peak soil surface acceleration. These seismic coefficients are selected as upper and lower limits based on the back calculation presented in Section 6.11.1. From the resultant 
static and dynamic pressure components, a total earth pressure distribution is developed based on the approximated triangular distribution about the height of the wall. The total pressure distribution allows for measured pressures to be compared to predicted pressures as a result of $\mathrm{M}-\mathrm{O}$ method as shown in Figure Figure 6.22 and Figure 6.23.

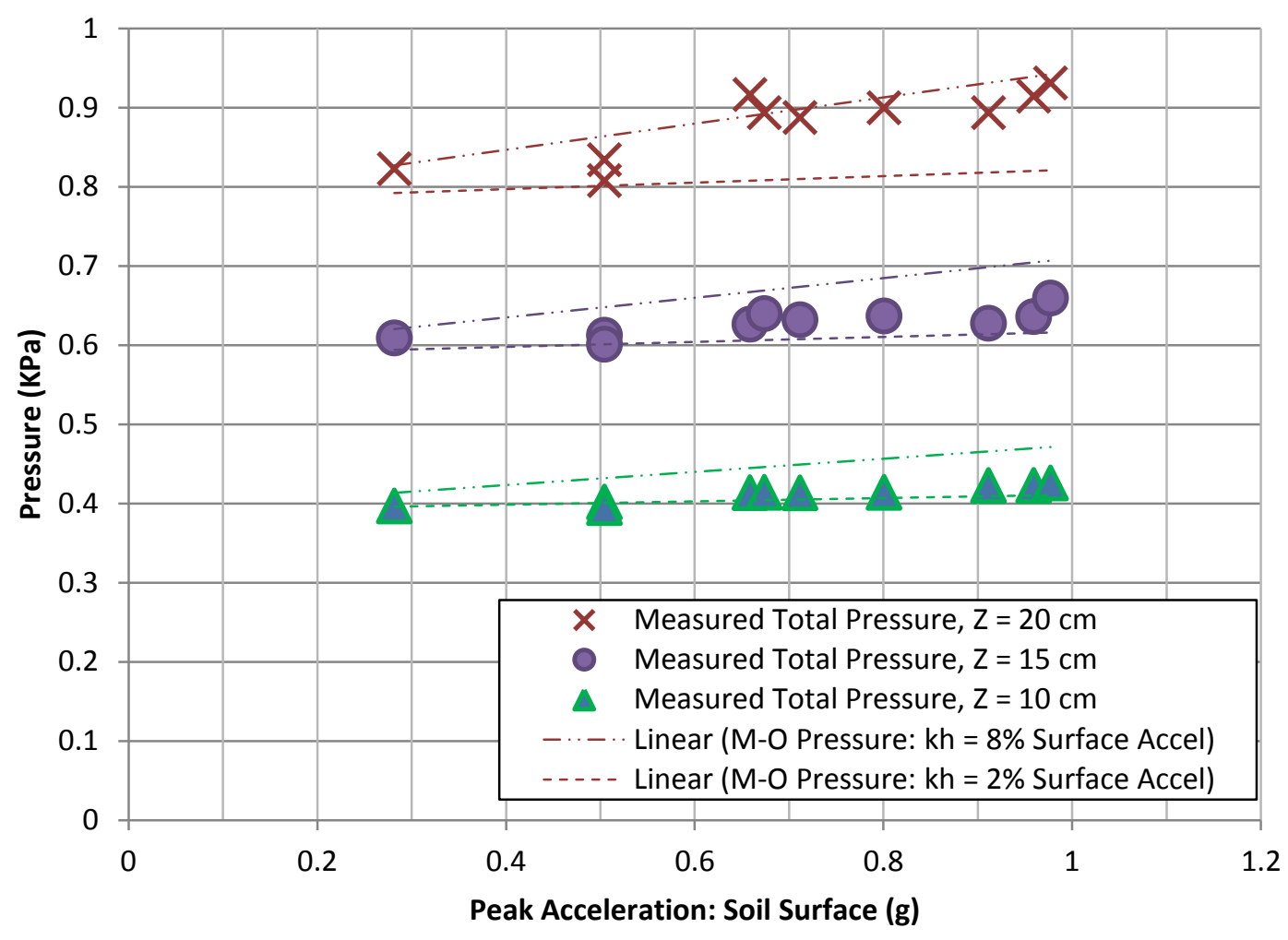

Figure 6.22: Recorded earth pressures in comparison to $\mathrm{M}-\mathrm{O}$ analysis using a seismic coefficient of $2 \%$ and $8 \%$ of peak accelerations at the soil surface (Phase 1') 


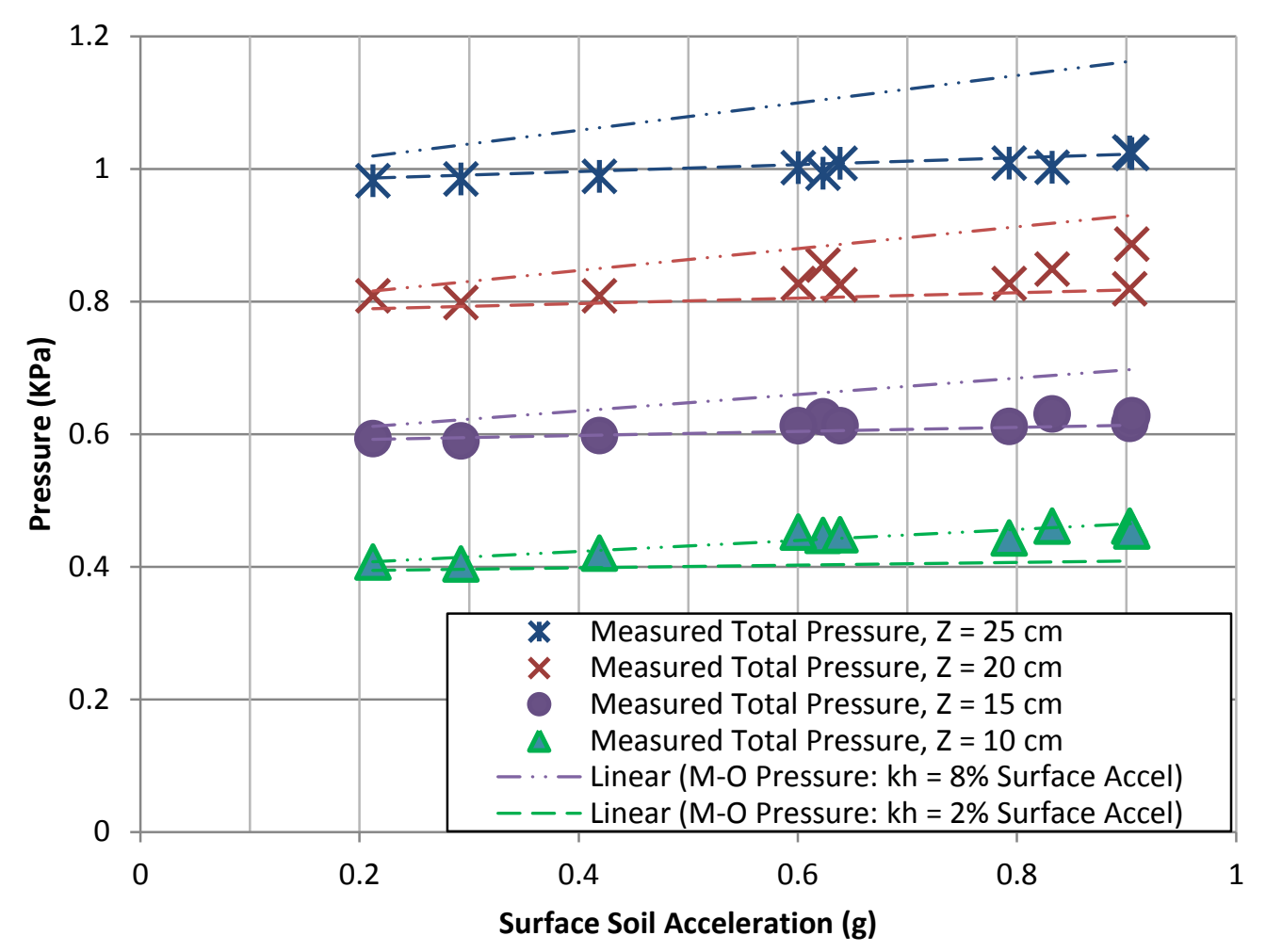

Figure 6.23: Recorded earth pressures in comparison to $\mathrm{M}-\mathrm{O}$ analysis using a seismic coefficient of $2 \%$ and $8 \%$ of peak accelerations at the soil surface (Phase 2)

\subsection{Discussion of Experimental Results}

The experimental investigation in both Phase 1 ' model retaining wall and Phase 2 model basement with damped mass is ground work to provide understanding of the development of seismic earth pressures with cohesion in backfill/ retained earth.

The development of the acceleration wave form in the soil column provides insight to the development of dynamic earth pressures in clay soils. The acceleration wave form at different elevations is observed to be phase shifted with the input table acceleration and, to some extent, with each other. The resulting pressures due to this these phase shifted accelerations do not develop 
simultaneously about the face for the wall. This supported with the variation found in the dynamic increment profiles. Furthermore, the inclusion of a SDOF oscillator to the model structure further demonstrates the out of phase relationship between the development of total pressures on the wall face in response to input table acceleration.

The dynamic increment profile is presented as percent pressure increase above the initial static pressures with wall depth for a input motion. The dynamic increment profile for retaining wall configuration (Phase 1') is observed to have a triangular distribution. A resultant of 3.8 times the static pressures acting at $1 / 3 \mathrm{H}$ above the base is calculated based on the triangular distribution presented in the average dynamic increment profile (Figure 6.17).

For the basement wall configuration (Phase 2), the dynamic increment profile develops a little differently. The dynamic increment shows variation at each sensor position but no clear distributions are observed. The addition of the SDOF oscillator to the model shows an increase to the dynamic increment in the upper third of the wall face. For a model basement retaining cohesive soils, the dynamic increment varies with depth, and input motion.

Arias intensity and cumulative absolute velocity are explored as indicators of seismic earth pressure. Average peak dynamic increment is observed to correlate linearly with both ground motion parameters. Although the dynamic increment is shown to develop differently for each model configuration, the differences with respect to arias intensity and cumulative absolute velocity are not pronounced. 
Back calculating the proposed seismic coefficient from recorded total earth pressures also provides some insight to the development of seismic earth pressures. The back calculated seismic coefficient, $k_{h}$ is found to be between 2 $8 \%$ of the peak acceleration recorded at the soil surface. For the application of the $\mathrm{M}-\mathrm{O}$ method, the standard of practice recommends the use of a seismic coefficient of $1 / 2$ to $2 / 3$ of the design PGA due to a number of considerations presented in Section 6.11. Although the Mononobe- Okabe (M-O) method may be inappropriate for cohesive soils, the experimental results suggest for retained soil with significant cohesion a seismic coefficient of about 1/10 the PGA.

The M-O method can be used with a seismic coefficient of $1 / 10$ th the peak acceleration at the soil surface to predict the development of seismic earth pressures. Besides the reduced seismic coefficient, no other consideration was applied to the method to account for cohesion in the soil. As shown in Figures 6.20 and 6.21 , the M-O method with the applied reduction closely predicts the seismic earth pressures recorded in this investigation. 
Chapter 7 - Summary and Conclusions

\subsection{Project Scope Summary}

Predominate methods for evaluating seismic earth pressures are typically developed from empirical data collected from retaining structures with cohesionless backfill. Although there are a few methods that account for cohesion in seismic retaining wall design, empirical research investigating the development of seismic earth pressures amidst cohesive soils is limited.

Testing platform used to explore the development of seismic earth pressures in cohesive soil consists of a flexible walled testing container mounted to shake table. The input motions consisted of seven shaking events and their azimuths for a total of fourteen input motions. These motions are selected to provide a variety of amplitudes and frequencies to the investigation. A model retaining structure was constructed for the investigation with two configurations. For the first configuration (denoted Phase 1), the model retaining structure was fully embedded mimicking a flexible retaining wall. The second configuration (denoted Phase 2), a single degree of freedom oscillator was attached to the foundation of the fully embedded model to mimic a rigid basement structure. For each configuration, pressure sensors were mounted to the wall face of the structure to measure total earth pressures.

This chapter summarizes shake table testing results and recommends possibilities for future research. 


\subsection{Findings from Experimental Research}

The total earth pressure time history for this investigation was superimposed with the acceleration time history for each input shaking motion. From the superposition of the total earth pressure time history and the acceleration time history, phase relationships can be observed for each model configuration. For the retaining wall configuration (Phase 1), the total earth pressure time history is observed in phase with the acceleration time history suggesting that the embedded model moves in line with the applied ground motion.

One the other hand, the phase relationship between the total earth pressure time history and the acceleration time history for the basement wall configuration (Phase 2) is observed to vary with depth of pressure sensor. For each motion, total earth pressures recorded at depths of $10 \mathrm{~cm}$ and $15 \mathrm{~cm}$ are observed to be in phase with the acceleration time history. However, total earth pressures recorded at depths of $20 \mathrm{~cm}$ and $25 \mathrm{~cm}$ are observed to lag the acceleration time history an average of 0.3 and 0.7 wavelengths respectively,

where one wave length is about 0.12 seconds. These phase differences indicate that inertial forces, and by extension dynamic earth pressures do not occur simultaneously over the face of the wall. .

The dynamic increment is defined as the percent increase of earth pressures above static conditions. At the depth of each pressure sensor, the dynamic increment recorded for all input motions are averaged together. The average dynamic increment profile is used to characterize the pressure 
distribution for both model configurations. The dynamic increment profile for the retaining wall configuration has a triangular distribution. Based on an average dynamic increment profile, the resultant of the triangular distribution is about 3.8 times the static pressures applied $1 / 3 \mathrm{H}$ above the base of the model.

For the basement wall configuration, the pressure distribution varies with the depth. Interestingly, at the depths of about $10 \mathrm{~cm}$ and $20 \mathrm{~cm}(1 / 3 \mathrm{H}$ and $2 / 3 \mathrm{H}$ respectively) the average dynamic increment is about $5 \%$, while the average dynamic increment at depths of $15 \mathrm{~cm}$ and $25 \mathrm{~cm}(1 / 2 \mathrm{H}$ and $5 / 6 \mathrm{H}$ respectively) is about $2.6 \%$. From the investigation, shape of distribution of the dynamic earth pressure component is unclear, however, soil-structure interaction appears to bias larger in dynamic earth pressure readings in the upper 2/3s of the wall height. In general, the dynamic increment for the basement wall configuration varies with position on the wall face, where localized peaks in pressure observed at depths of $1 / 3 \mathrm{H}$ and $2 / 3 \mathrm{H}$

There is a correlation between the average dynamic increment, arias intensity, and cumulative absolute velocity. For both ground motion parameters the average dynamic increment for each input motion is observed to increase linearly with arias intensity. Although the dynamic increment is shown to develop differently for each model configuration, the differences with respect to arias intensity and cumulative absolute velocity are not pronounced.

Although originally developed for cohesionless soils, the simplified mononobe-okabe (M-O) method was used as in conjunction with the experimental results. The seismic coefficient was back calculated from measured 
earth pressures during the shake table investigations. For the analysis, a triangular dynamic pressure distribution was assumed as prescribed by the method. Although the method prescribes the use of $1 / 2$ to $2 / 3$ of the design PGA for the seismic coefficient, for the parameters of this investigation, a seismic coefficient of about $1 / 10$ the PGA correlates well with experimental findings.

\subsection{Opportunities for Future Investigations}

This section lists opportunities for future investigations in order to build upon the finding of the present research.

- Perform physical test to evaluate seismic earth pressures

o with the inclusion more pressure sensors to clearly define the shape dynamic earth pressure distributions

- with varying structural period of the model basement

- for a $12 \mathrm{ft}$ prototype wall as is the criterion presented in some building codes

o with parameters satisfying the usage of $\mathrm{M}-\mathrm{O}$ method using charts presented in the NCHRP 611 to correct for cohesion. 


\section{References}

Al Atik, L. and Sitar, N. (2007). Development of Improved Procedures for Seismic Design of Buried and Partially Buried Structures. Pacific Earthquake Engineering Research Center, PEER 2007/06, Berkeley, Calif.

Al Atik, L. and Sitar, N. (2010), "Seismic Earth Pressures on Cantilever Retaining Structures," Journal of Geotechnical and Geoenvironmental Engineering, October, (136) 10, pp. 1324-1333.

Anderson, D.G., Martin, G.R., Lam, I., and Wang, J.N. (2008). Seismic Analysis and Design of Retaining Walls, Buried Structures, Slopes and Embankments. National Cooperative Highway Research Program Report 611, Transportation Research Board, Washington, DC.

Bonaparte R., Mitchell J.K. 1979. The properties of San Francisco Bay Mud at Hamilton Air Force Base, California. Dept. of Civil Engineering, University of California, Berkeley, USA.

Building Seismic Safety Council. (2004a). NEHRP Recommended Provisions for Seismic Regulations for New Buildings and Other Structures (FEMA 450), 2003 Edition, Part 1 - Provisions. BSSC, Washington, DC.

Building Seismic Safety Council. (2004b). NEHRP Recommended Provisions for Seismic Regulations for New Buildings and Other Structures (FEMA 450), 2003 Edition, Part 2 - Commentary. BSSC, Washington, DC.

Coulomb, C. A. 1776. Essai sur une application des regles des maximis et minimis a quelques problemes de statique relatifs a l'architecture. Memoires de l'Academie Royale pres Divers Savants 7.

Crosariol, V. (2010) "Scaled 1g Testing of Soil-Structure-Interaction Models" Master's Thesis, Cal Poly San Luis Obispo.

Franklin, A. G., and Chang, F. K. (1977). "Earthquake Resistance of Earth and RockFill Dams; Report 5: Permanent Displacement of Earth Embankments by

Kavazanjian, E., Matasović, N., Hadj-Hamou, T., and Sabatini, P.J. (1997). Geotechnical Engineering Circular \#3 - Design Guidance: Geotechnical Earthquake Engineering for Highways, Volume 1-Design Principles. Federal Highway Administration Report No. FHWA-SA-97-076.

Newmark's Sliding Block Analysis," Misc. Paper S-71-17, Soils and Pavement Lab., U.S. Army Engineers Waterways Experiment Station, Vicksburg, Miss. 
Gruber, A. (1996). "Stress-Strain Testing of a Model Soil for Earthquake Simulation,"Rpt. to the Dept. of Civil Eng., Univ. of California, Berkeley, August

lai, S. (1989). "Similitude for Shaking Table Tests on Soil-Structure-Fluid Model in $1 \mathrm{~g}$ Gravitational Field," Soils and Foundations, JSSMFE, 29(1), 105118.

Lew, M., Sitar, N., Al Atik, L., Pourzanjani, M., and Hudson, M. (2010). "Seismic Earth Pressures on Deep Building Basements." SEAOC 2010 Convention Proceedings, Los Angeles, CA.

Kline, S. (1965). Similitude and Approximation Theory, McGraw-Hill, New York

Kuo, S. (2012) "Scale Model Shake Table Testing of Shallow Embedded Foundations in Soft Clay" Masters Thesis, Cal Poly San Luis Obispo.

Langhaar, H. (1951). Dimensional Analysis and Theory of Models, John Wiley and Sons, New York

Meymand, P. J. (1998). "Shaking table scale model tests of nonlinear soilpilesuperstructure interaction in soft clay." Ph.D. Dissertation, Univ. of California, Berkeley.

Microchip. 2009. MCP6001/1R/1U/2/4 http://ww1.microchip.com/downloads/en/DeviceDoc/21733j.pdf

Moncarz, P. and Krawinkler, H. (1981). "Theory and Application of Experimental ModelAnalysis in Earthquake Engineering," Rpt. No. 50, John Blume Earthquake Eng. Ctr.,Stanford Univ.

Mononobe, N., and Matsuo M. 1929. On the determination of earth pressures during earthquakes. Proceedings, World Engineering Congress 9: 179187.

Nakamura, S. (2006). "Reexamination of Mononobe-Okabe Theory of Gravity Retaining Walls Using Centrifuge Model Tests." Soils and Foundations, (46) 2, 135-146.

Newmark, N.M. (1965). "Effects of Earthquakes on Dams and Embankments," Fifth Rankine Lecture, Geotechniqniue, (15) 2, 139-160.

Okabe S. 1926. General theory of earth pressure," Journal of the Japanese Society of Civil Engineers, Tokyo, Japan 12(1). 
Ortiz, L.A., Scott, R.F., and Lee, J. (1983). "Dynamic Centrifuge Testing of a Cantilever Retaining Wall." Earthquake Engineering and Structural Dynamics, (11), 251-268.

Palmer, M. C., O'Rourke, T. D., Olson, N. A., Abdoun, T., Ha, D., and O'Rourke, M. J. [2009] "Tactile pressure sensors for soil-structure interaction assessment," Journal of Geotechnical and Geoenvironmental Engineering, ASCE 135(11), 1638-1645.

Randolph, M. F., and Houlsby, G. T. (1984). "Limiting pressure on a circular pile loaded laterally in cohesive soil." Geotechnique, 34(4), 613-623.

Rankine, W. 1857. On the stability of loose earth. Philosophical Transactions of the Royal Society of London 147.

Richards, R, and Elms, D.G. (1979). "Seismic Behavior of Gravity Retaining Walls," Journal of the Geotechnical Engineering Division, ASCE, (105) GT4: 449-64.

Richards R. and X. Shi (1994). "Seismic Lateral Pressures in Soils with Cohesion." Journal of Geotechnical Engineering, ASCE, Vol. 120, No. 7 , pp 1230-1251.

Rocha, M. (1957). "The Possibility of Solving Soil Mechanics Problems by Use of Models," Proc. 4th Intl. Conf. Soil Mech. Fdn. Eng., London, Vol. 1, 183188.

Sitar N, Mikola RG, Candia G. 2012. Seismically induced lateral earth pressures on retaining structures and basement walls.Proceedings, Geo-Congress 2012. Geo-Institute of ASCE: Oakland, CA

Seed, H. and Clough, R. (1963). "Earthquake Resistance of Sloping Core Dams," J. Soil Mechanics and Foundation Div., ASCE, 89(1), 209-242

Seed, H. B., and Whitman, R. V. (1970). "Design of earth retaining structures for dynamic loads." Lateral Stresses in the Ground and Design of Earth Retaining Structures, 103-147.

Stewart, D. P., and Randolph, M. F. (1991). "A new site investigation tool for the centrifuge." Centrifuge 91 (eds. Ko and McLean), Balkema, Rotterdam, 531-538.

Tekscan Flexiforce User Manual —Rev H (2010) 
Wartman, J. (1996). "A Laboratory Study of the Effects of Fly Ash on the GeotechnicalProperties of Soft Clay,” M.E. Thesis, Univ. of California, Berkeley

Wood, J.H. (1973) "Earthquake induced soil pressures on structures," PhD Thesis, California Institute of Technology, Pasadena, CA.

Wong, C. P. (1982), "Seismic Analysis and Improved Seismic Design Procedure for Gravity Retaining Walls," thesis presented to the Department of Civil Engineering, at Massachusetts Institute of Technology, in Cambridge, Mass., in 1982, in partial fulfillment of the requirements for the degree of Master of Science.

Whitman, R.V. (1991). "Seismic Design of Earth Retaining Structures," Proceedings, Second International Conference on Recent Advances in Geotechnical Earthquake Engineering and Soil Dynamics, ASCE, St. Louis, MO., 1767-1778. 
Appendix A

PRESSURE SENSOR CALIBRATION AND CORRECTIONS 

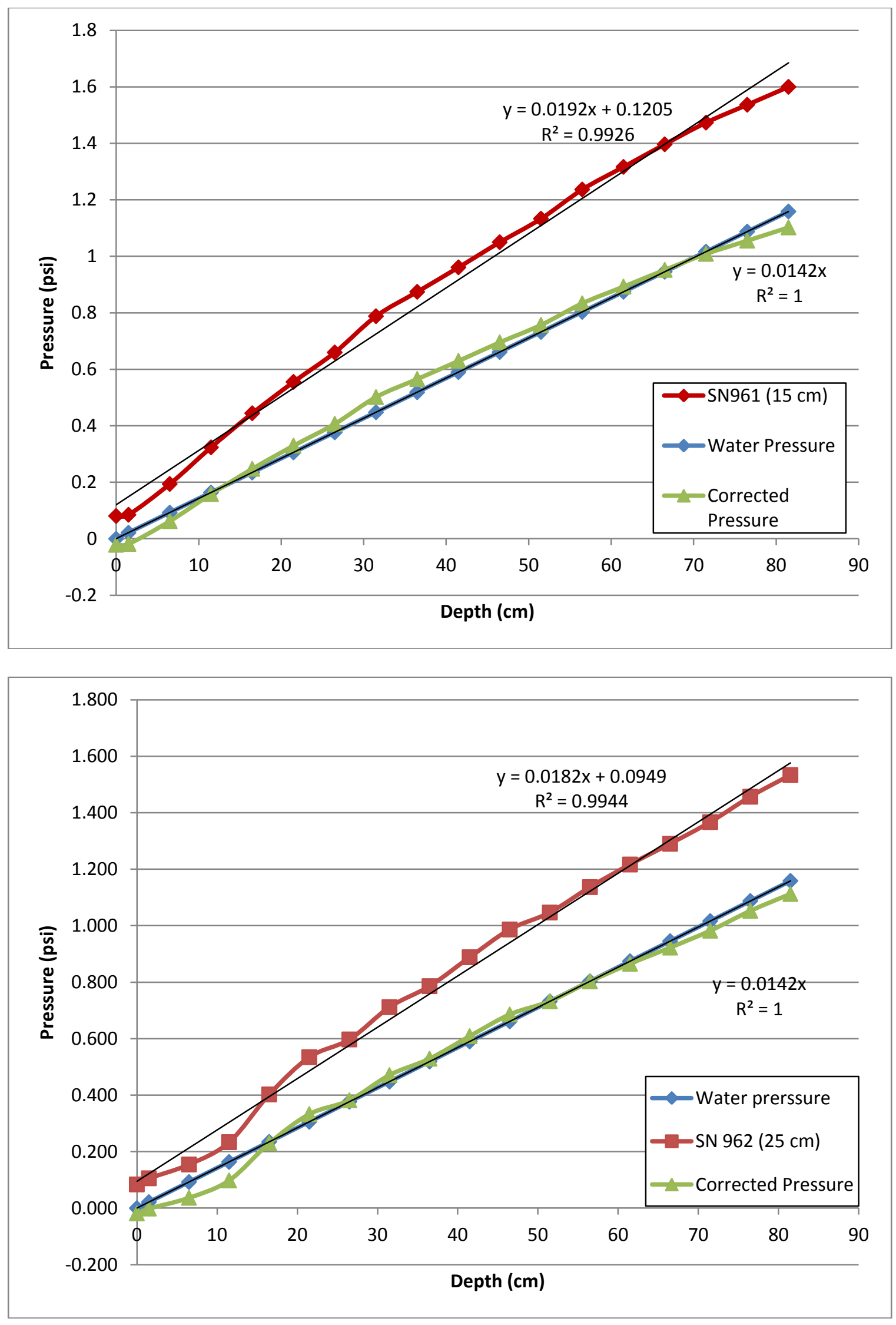

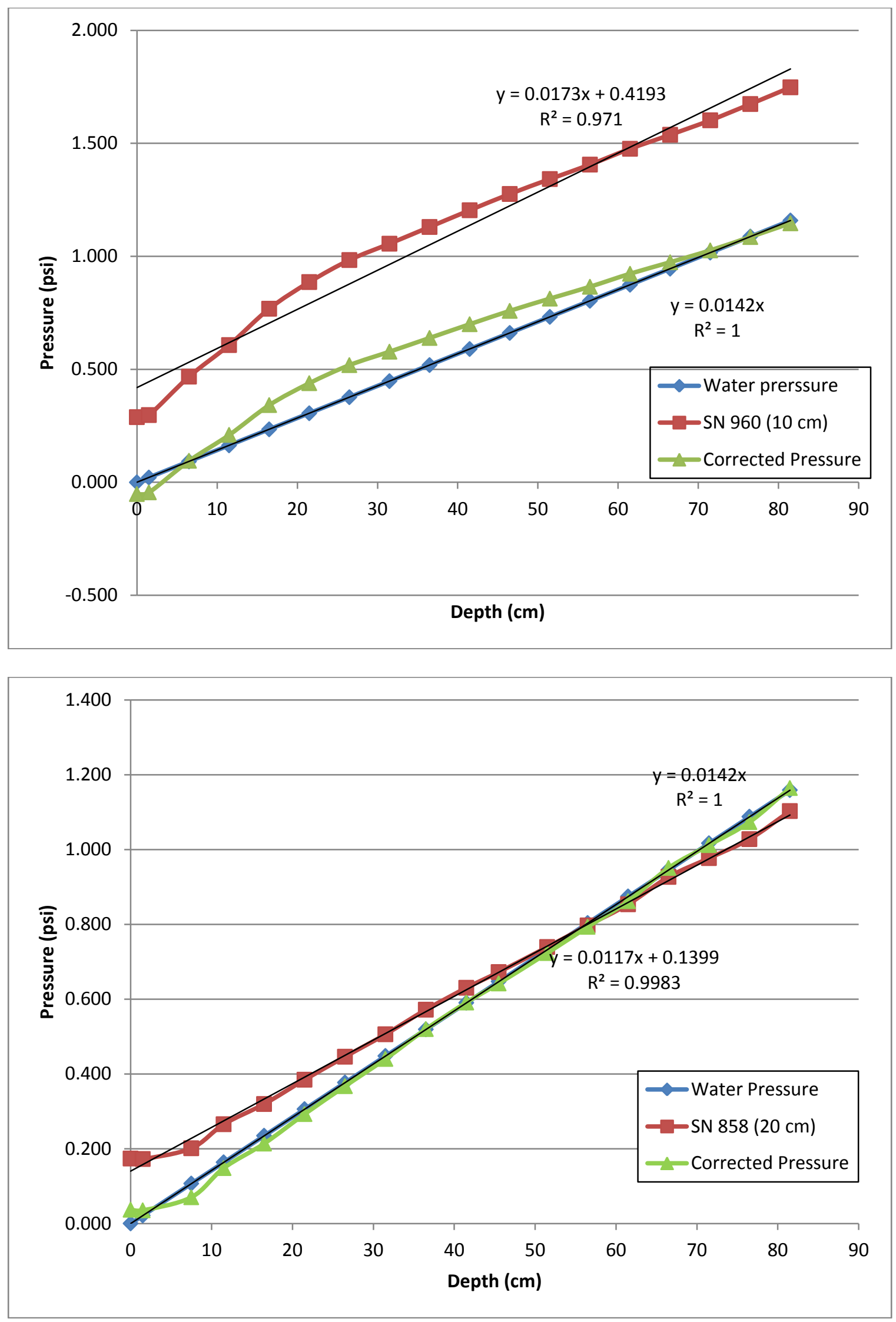
Appendix B

SUPERPOSITION OF PRESSURE AND ACCELERATIONS 

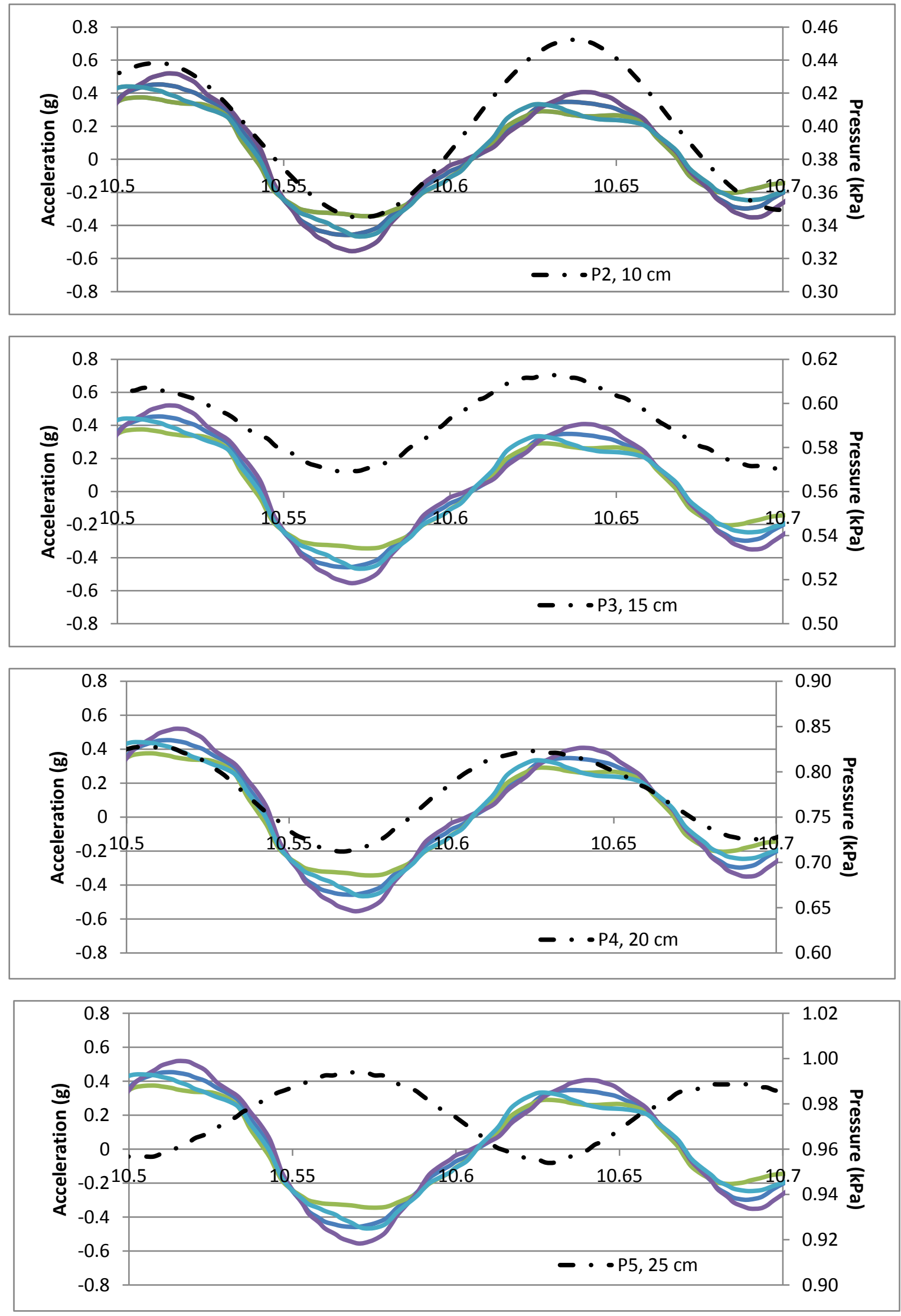

Soil Acceleration, Depth: 1/2 Model Wall Height Soil Acceleration, Depth: Model Foundation 

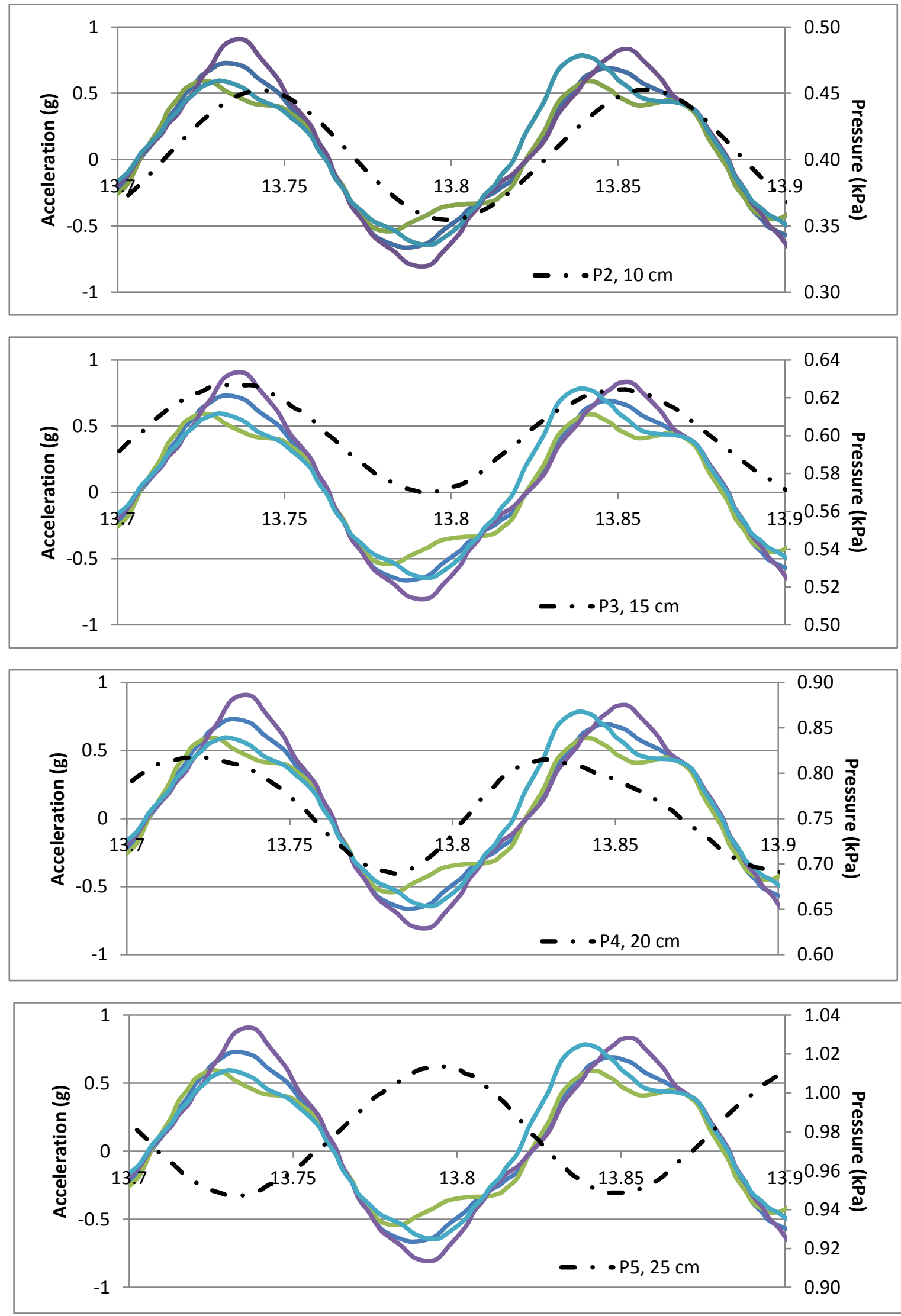

Soil Acceleration, Depth: 1/2 Model Wall Height Soil Acceleration, Depth: Model Foundation 
Superposition of Pressure and Accelerations for Josh 000 (Phase 2)
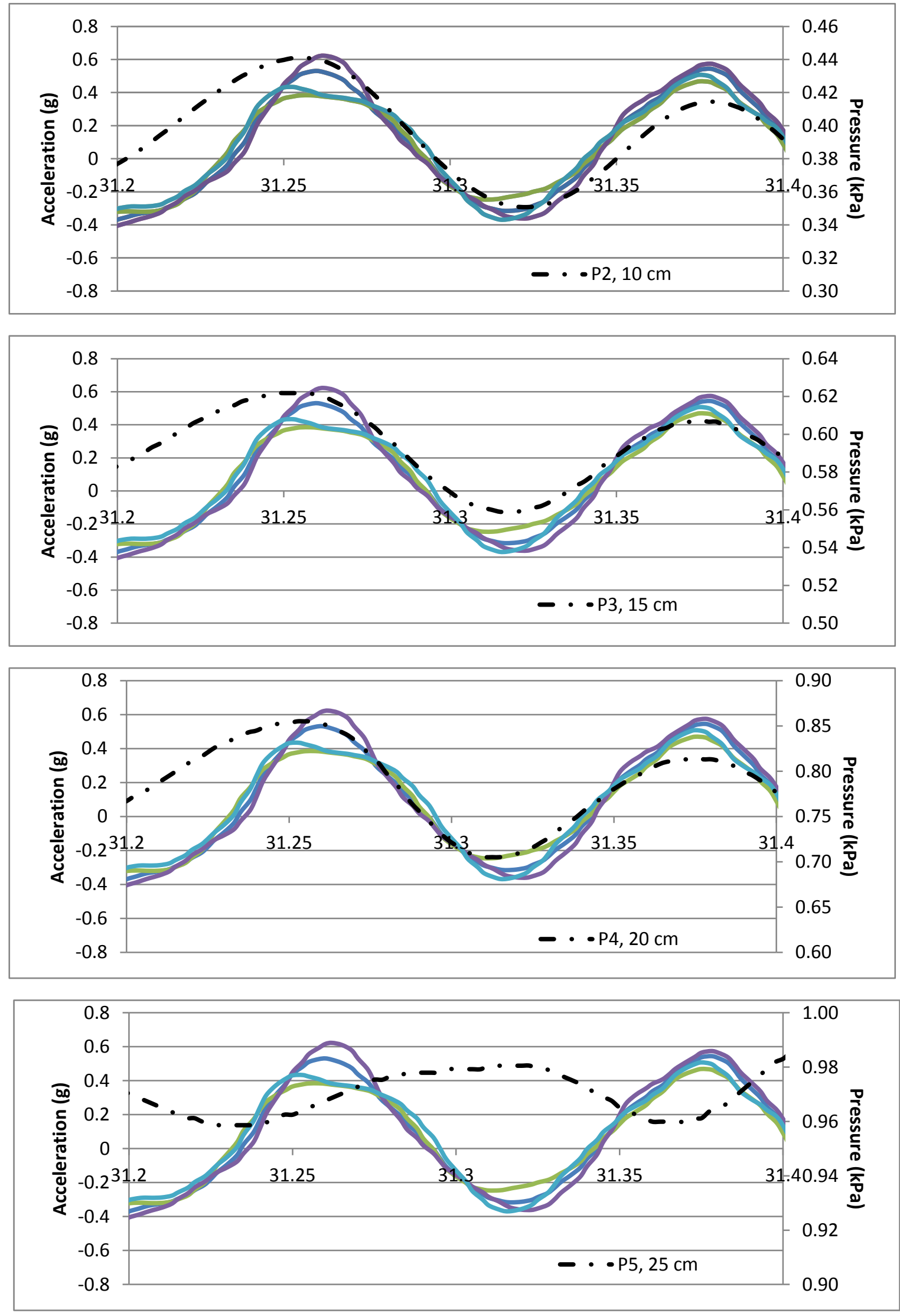

Soil Acceleration, Depth: 1/2 Model Wall Height 
Superposition of Pressure and Accelerations for Josh 090 (Phase 2)
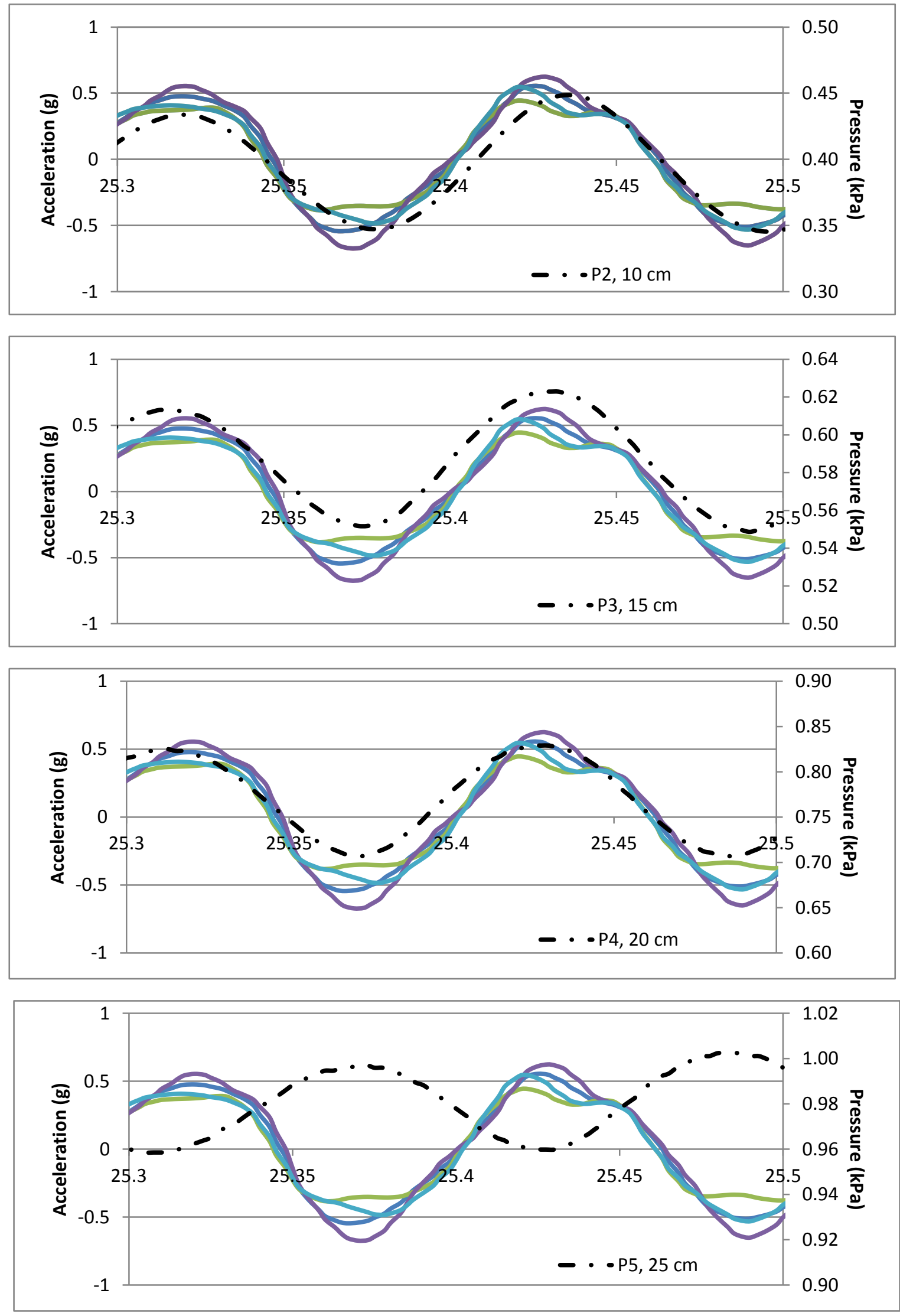

Soil Acceleration, Depth: 1/2 Model Wall Height Soil Acceleration, Depth: Model Foundation 
Superposition of Pressure and Accelerations for El Centro 180 (Phase 2)
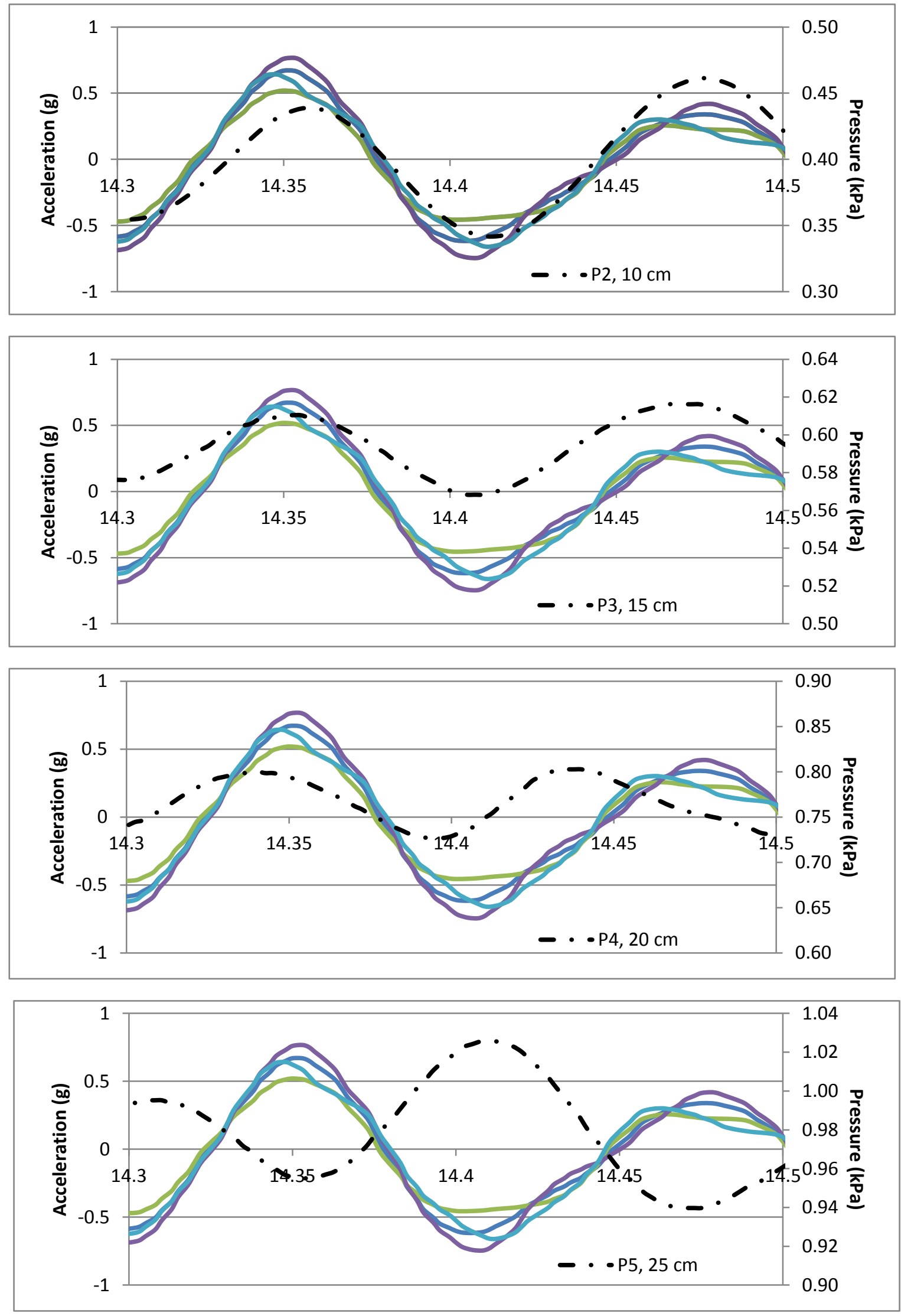

Soil Acceleration, Depth: 1/2 Model Wall Height $\longrightarrow$ Soil Acceleration, Depth: Model Foundation 
Superposition of Pressure and Accelerations for El Centro 270 (Phase 2)
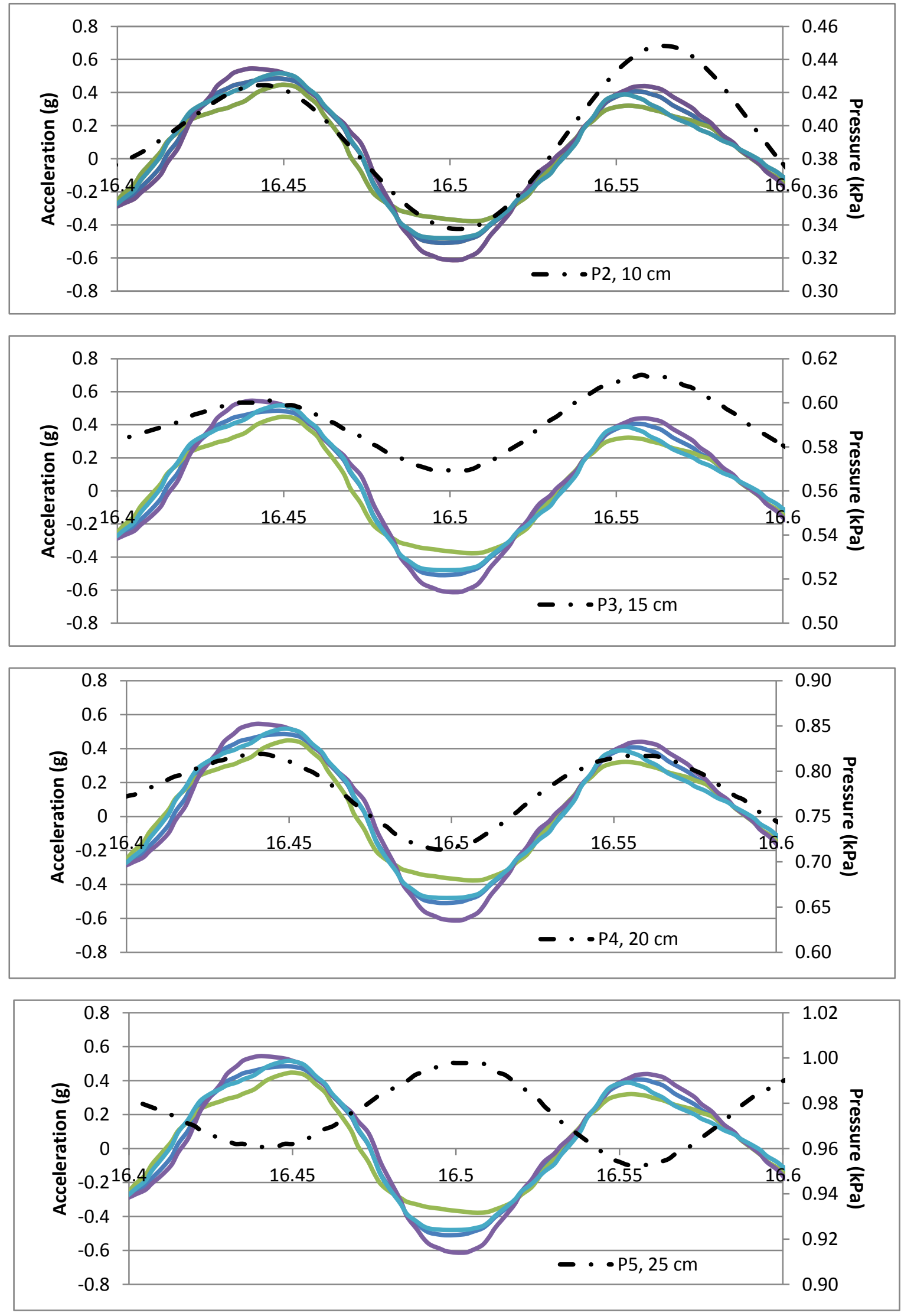

Soil Acceleration, Depth: 1/2 Model Wall Height Soil Acceleration, Depth: Model Foundation 

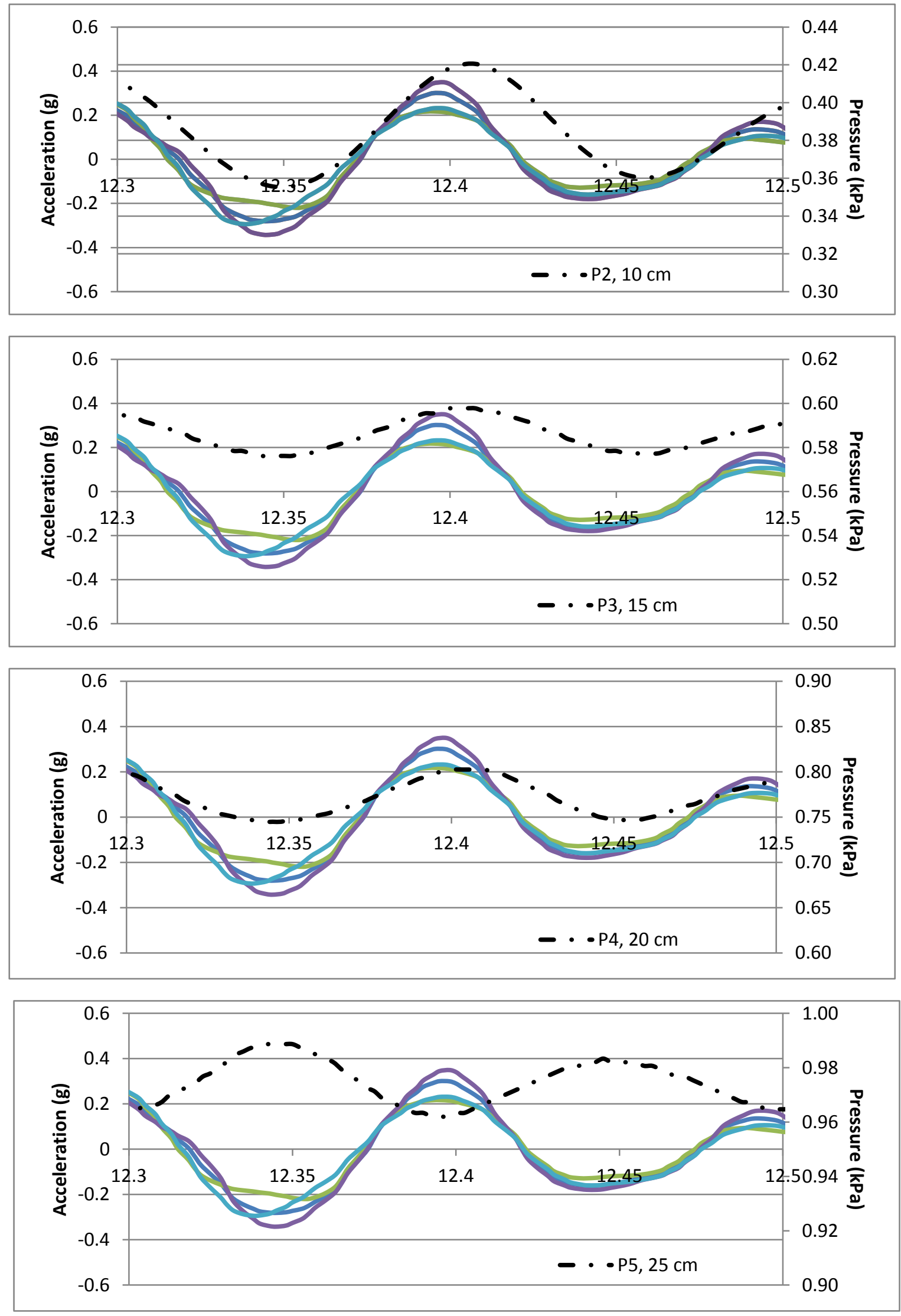

Soil Acceleration, Depth: 1/2 Model Wall Height Soil Acceleration, Depth: Model Foundation 

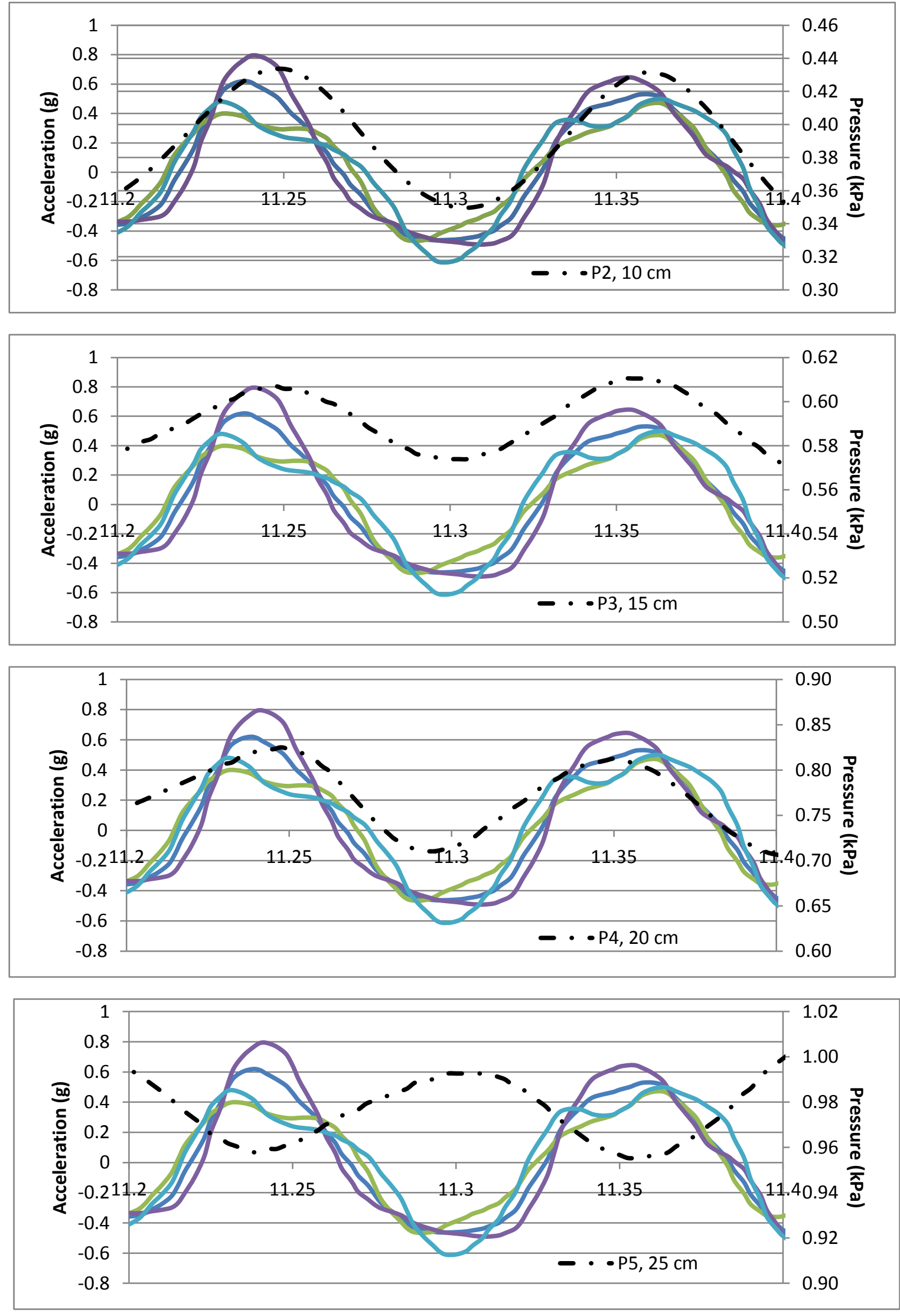

Soil Acceleration, Depth: 1/2 Model Wall Height $\longrightarrow$ Soil Acceleration, Depth: Model Foundation 
Superposition of Pressure and Accelerations for LO9 000 (Phase 2)
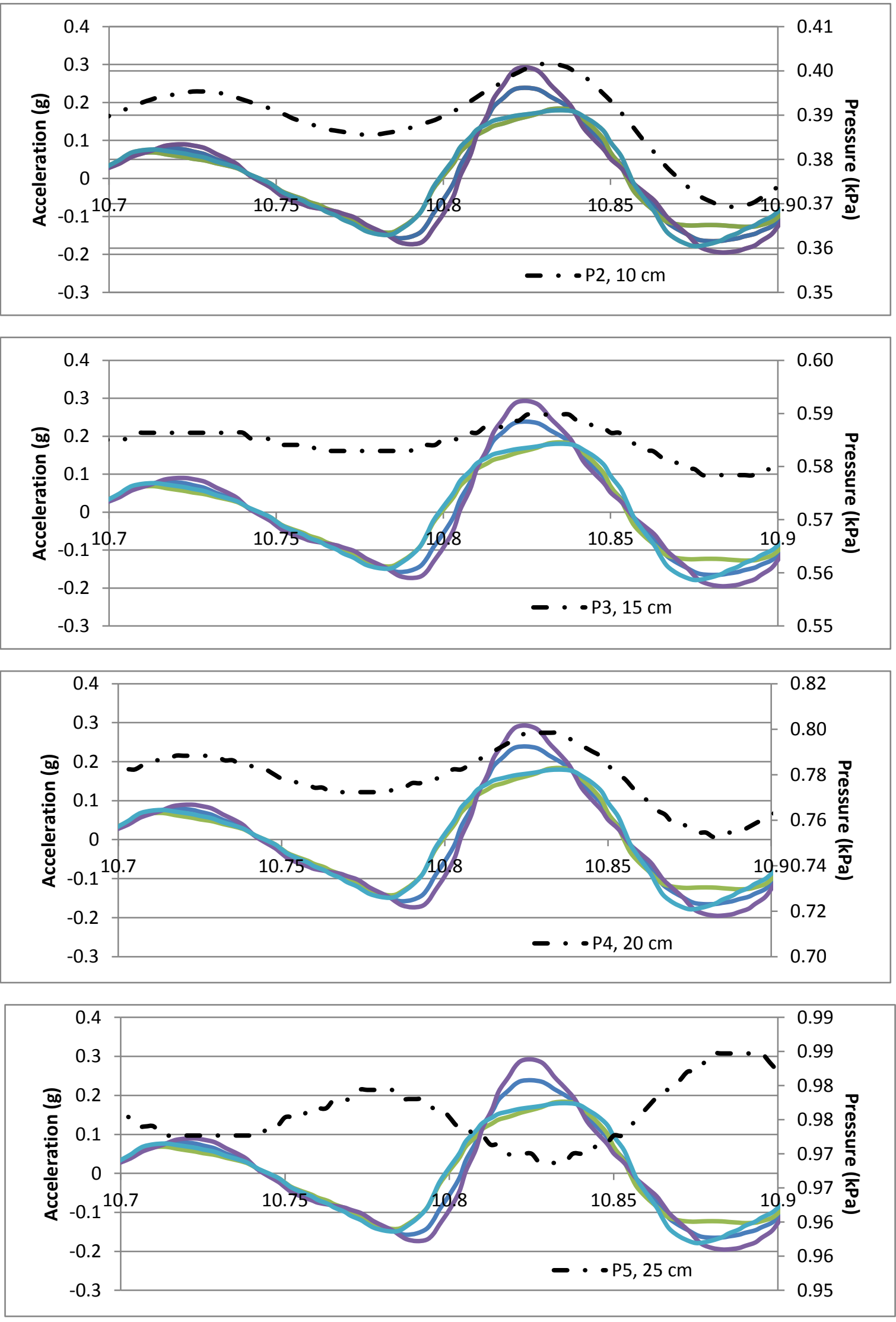

Soil Acceleration, Depth: 1/2 Model Wall Height Soil Acceleration, Depth: Model Foundation 
Superposition of Pressure and Accelerations for LO9 090 (Phase 2)
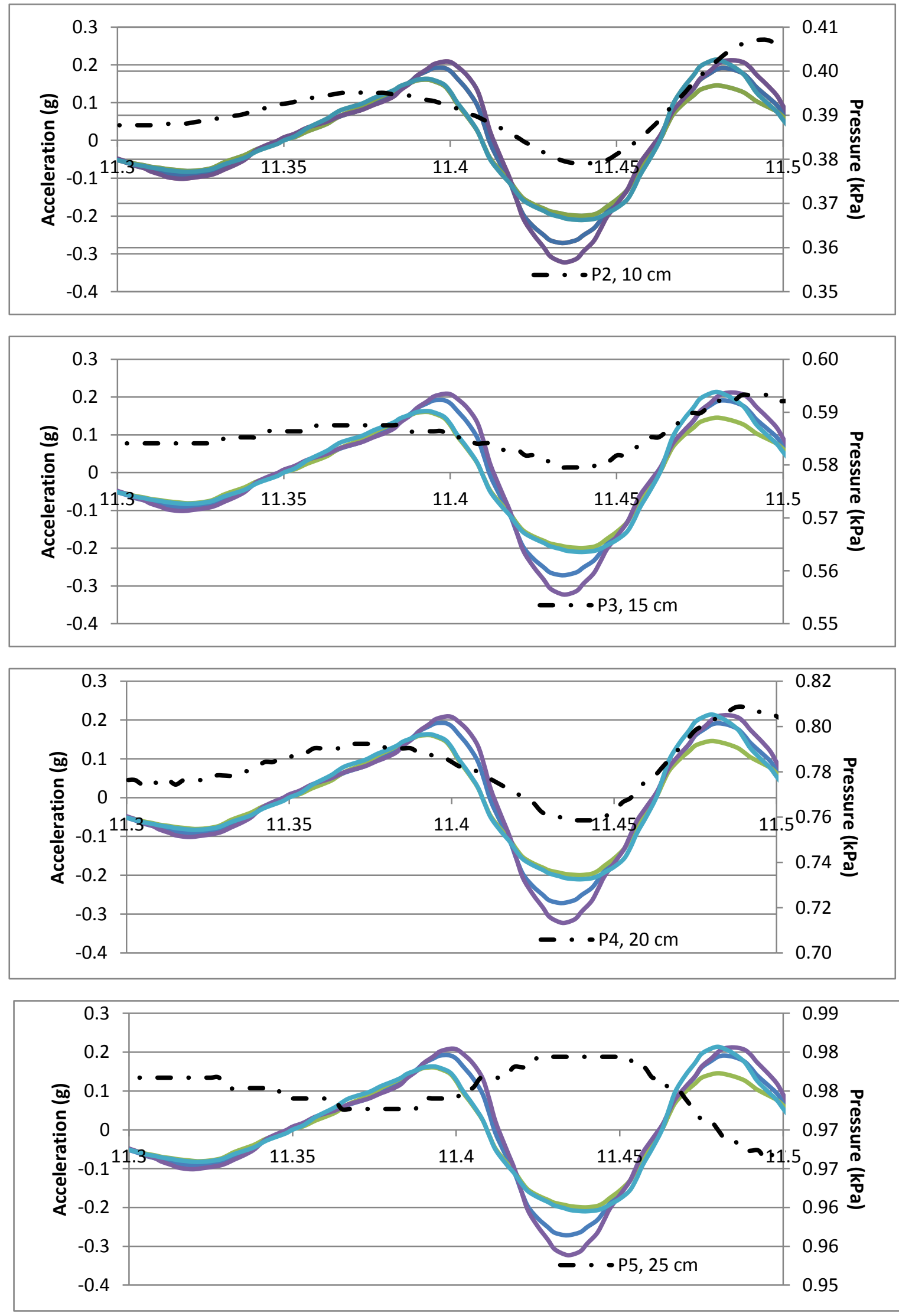

Soil Acceleration, Depth: 1/2 Model Wall Height Soil Acceleration, Depth: Model Foundation 
Appendix C

DYNAMIC INCREMENT PROFILE 

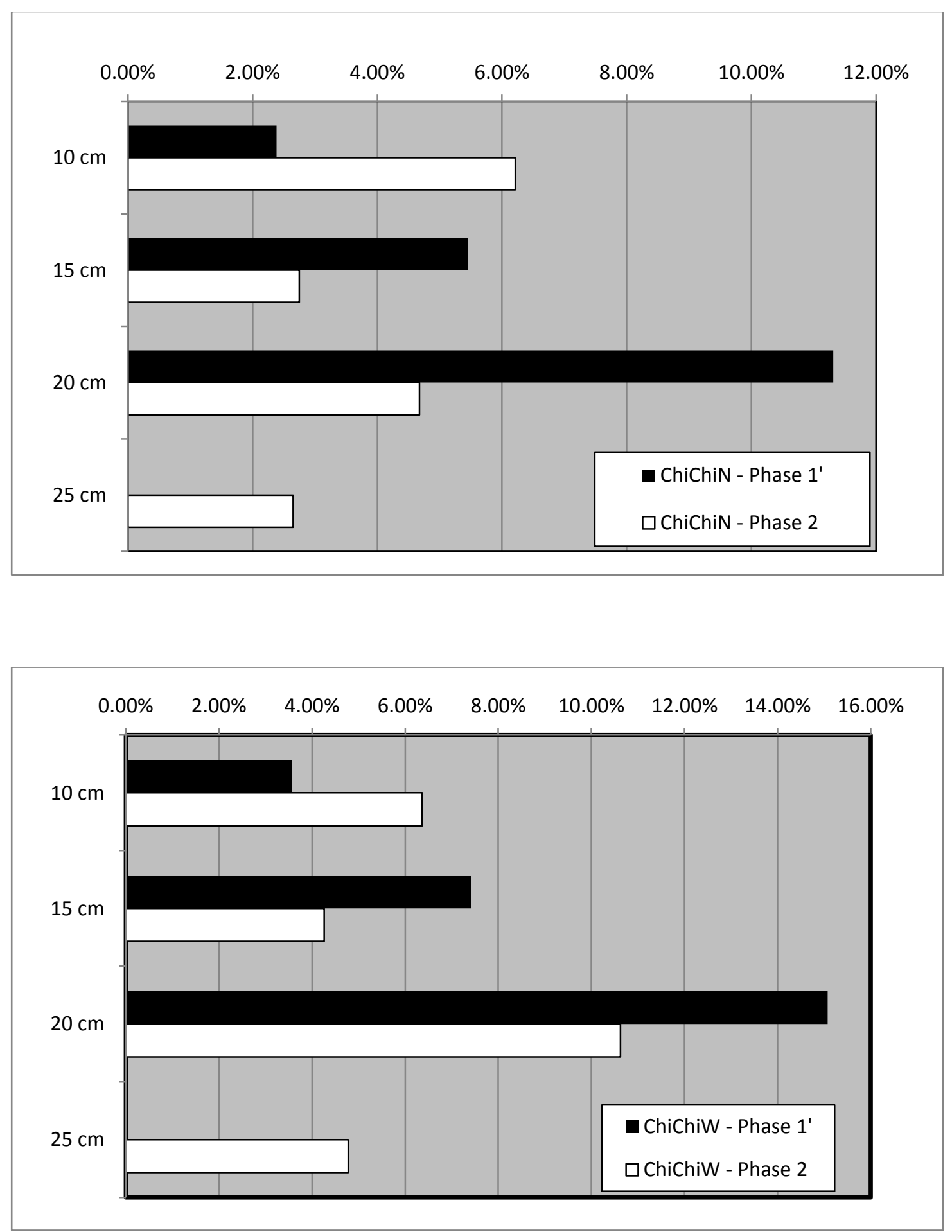

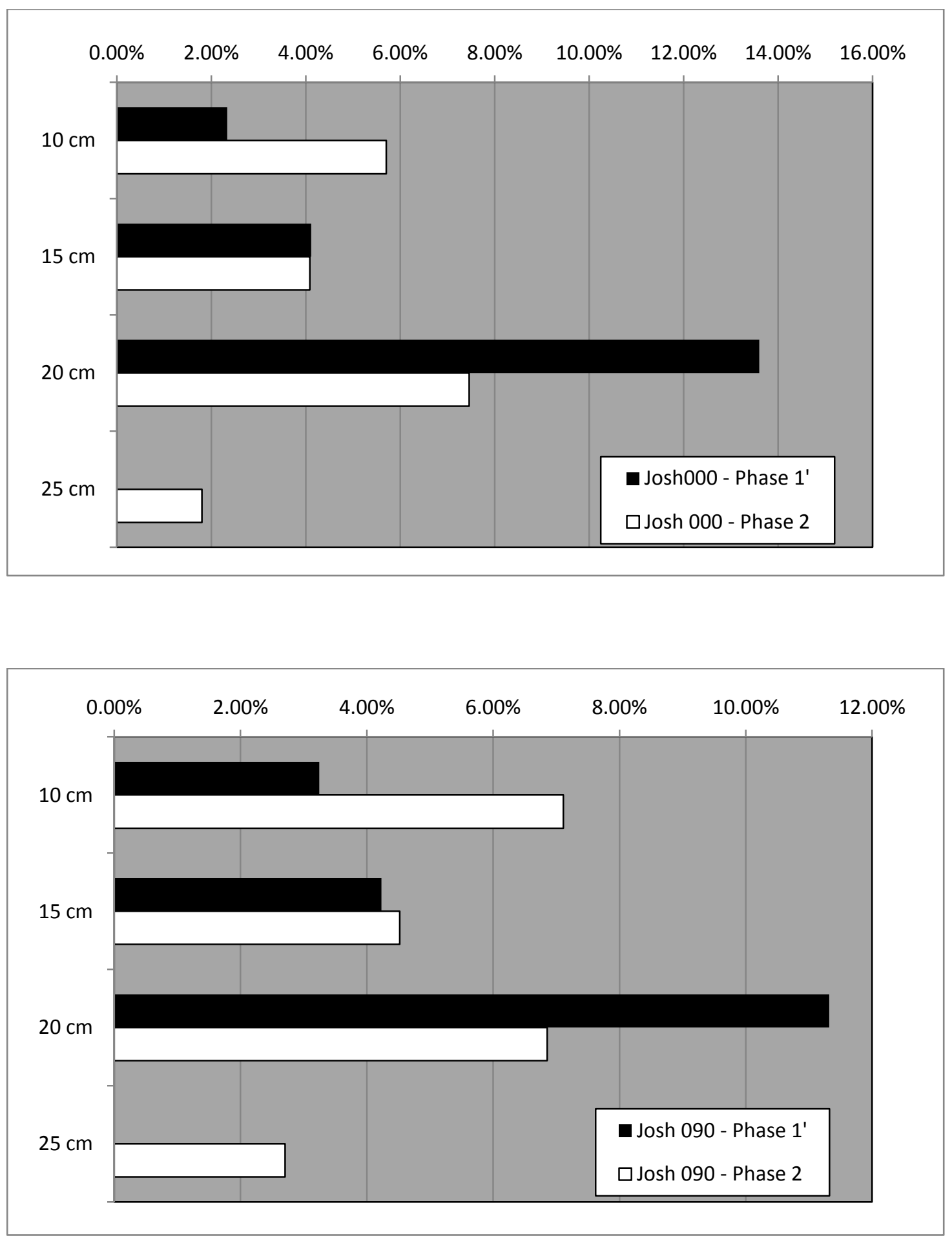

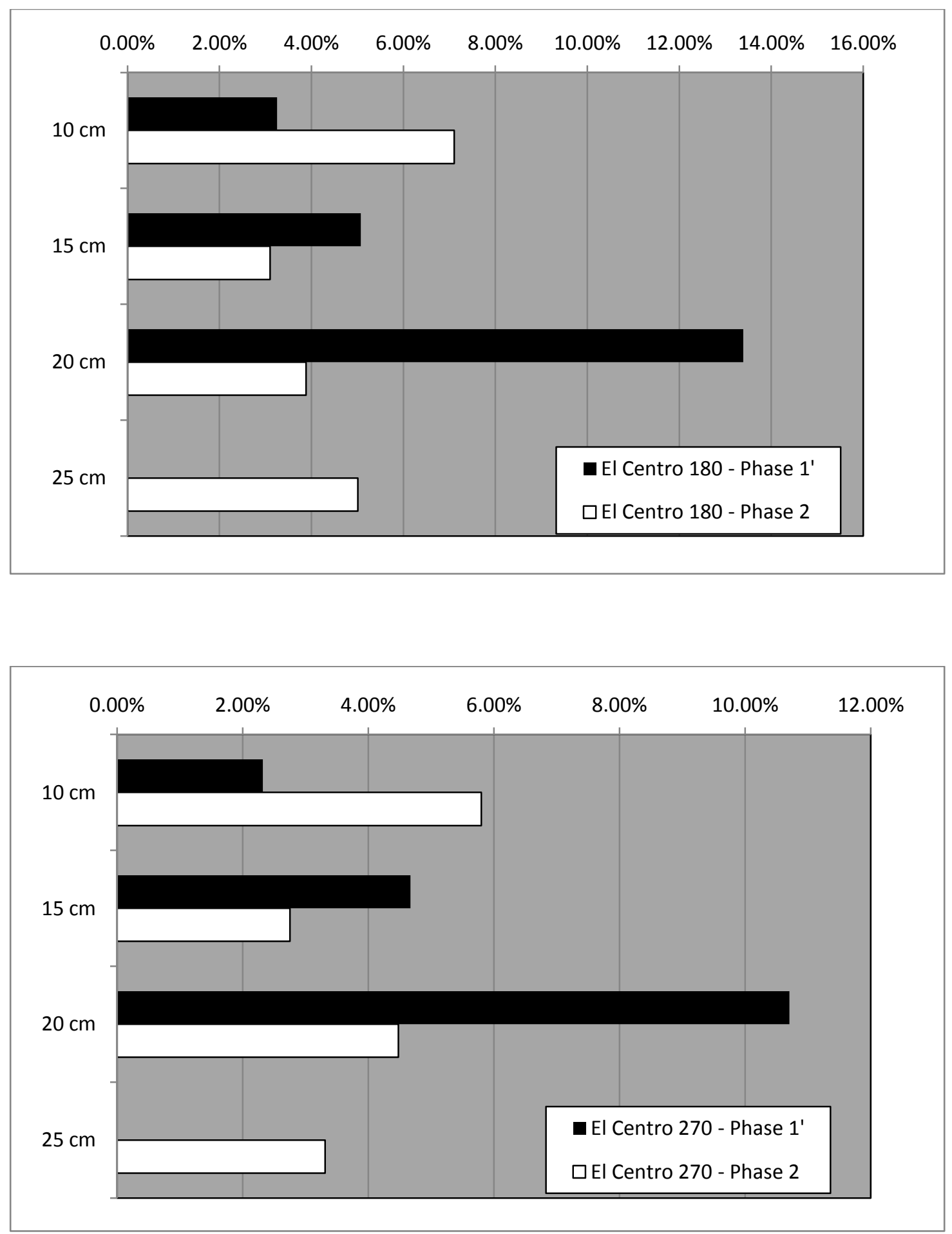


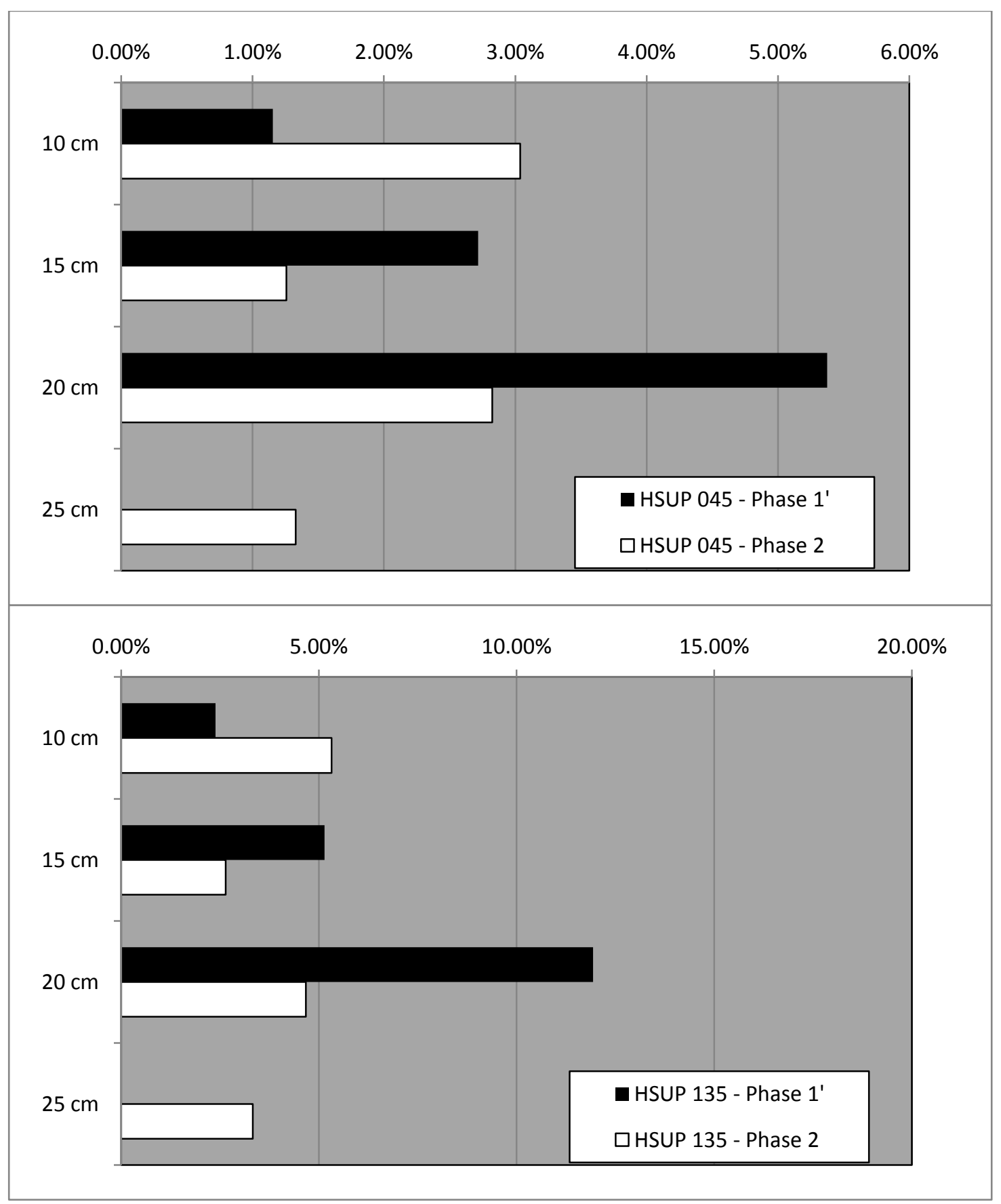



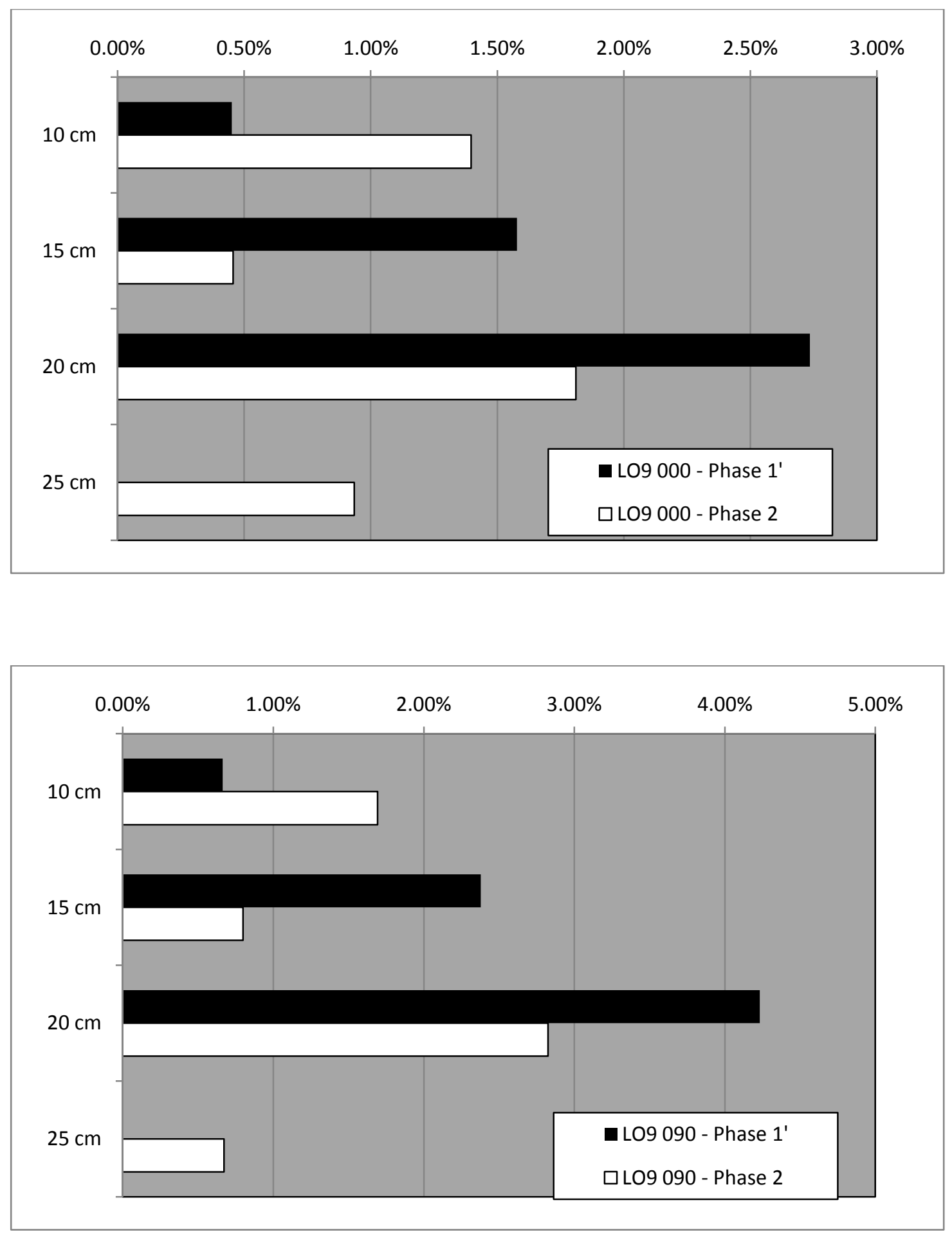